\title{
Development of Determing the Critical Micelle Concentration of Surfactants by Simple and Fast Titration Method
}

\author{
Shengen Wu, Feiqing Liang, Danna Hu, Hao Li, Weijie Yang and Qiuhua Zhu*
}

\section{Contents}

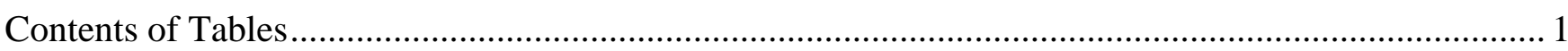

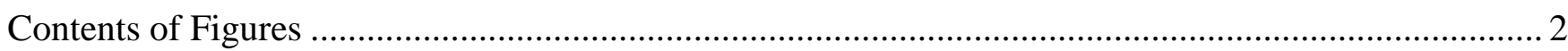

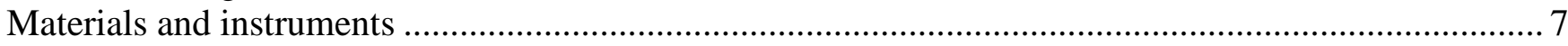

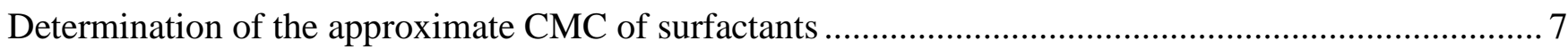

Preparation of samples for CMC determination by fluorometric method using THP-T1 as probe .......... 8

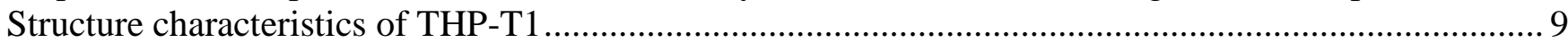

Influence of SDS concentration in initial titration solution on titrated CMC value ............................. 15

Factors influencing the $\Delta V_{\mathrm{H} 2 \mathrm{O}}$ value from near CMC to CMC ......................................................... 16

CMC determination of cationic CTAB by titration and fluorescence methods using THP-T1 as probe 17

CMC determination of zwitterionic surfactant BS-12 by titration and fluorescence methods using THP-

$\mathrm{T} 1$ as probe

CMC determination of nonionic surfactant Triton X-100 by titration and fluorescence methods using

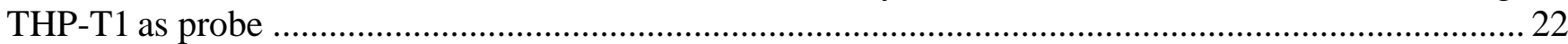

CMC determination of cationic surfactants with relative high CMC values (DDBAC and DTAC) by titration and fluorescence methods using THP-T1 as probe.........................................................2. 26

CMC determination of nonionic surfactant with very low CMC value (Tween-20) by fluorescence

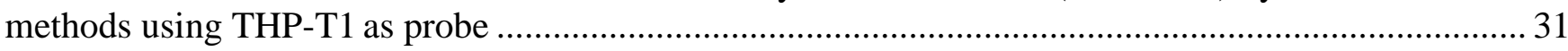

Suitable concentration range of THP-T1 for CMC titration of different kinds of surfactants and comparison of the CMC values determined by titration and other methods .......................................... 32 Determination of the approximate CMC values of new surfactants or surfactants from different supplie

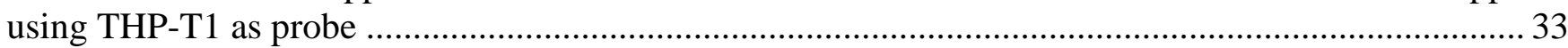

Determination of the CMC values of DDBAC and DTAC by conductivity method ........................... 38

Determination of the CMC values of surfactants in phosphate buffer saline (PBS) ............................ 39

Determination of the CMC values of other surfactants using general $c^{\prime}{ }_{\text {THP }}$ at titration end point ........... 43

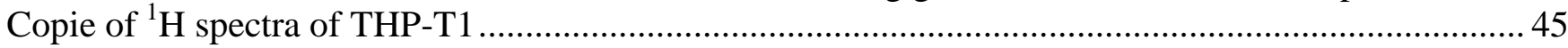

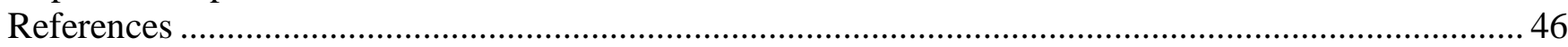

\section{Contents of Tables}

Table S1. Influence of SDS concentration on titrated CMC ……….................................................................. 15

Table S2. Influence of CTAB concentration on titrated CMC ................................................................................ 17

Table S3. Screen of the concentration of THP-T1 in CTAB titrated solution $(4 \mathrm{mM})$............................................. 17

Table S4. Influence of BS-12 concentration on titrated CMC ……........................................................................... 19

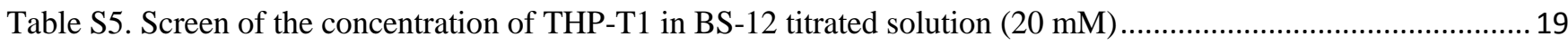

Table S6. Influence of Triton X-100 concentration on titrated CMC ………........................................................2 23 
Table S7. Screen of the concentration of THP-T1 in Triton X-100 titrated solution (5 mM)

Table S8. Screen of the concentration of THP-T1 in Triton X-100 titrated solution (10 mM) 24

Table S9. Influence of DDBAC concentration on titrated CMC ................................................................... 27

Table S10. Screen of the concentration of THP-T1 in DDBAC titrated solution $(30 \mathrm{mM})$......................................27

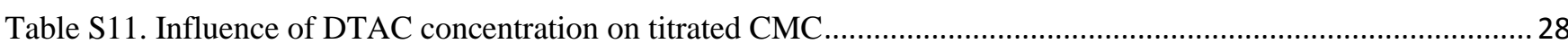

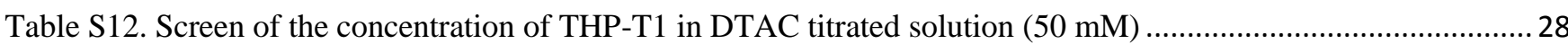

Table S13. CMC values of SDS, CTAB, BS-12, Trtion X-100, DDBAC and DTAC determined by titration method,

fluorescence method and reported in references. .............................................................................. 33

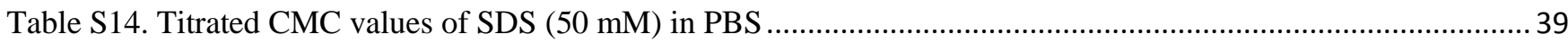

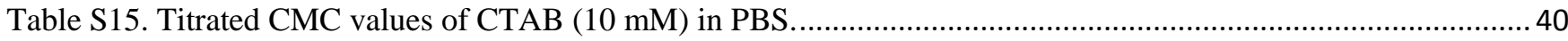

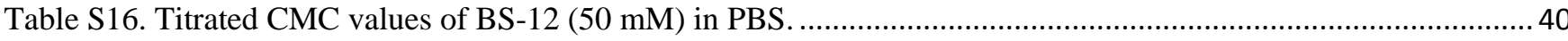

Table S17. Titrated CMC values of Triton X-100 (10 mM) in PBS. ................................................................ 41

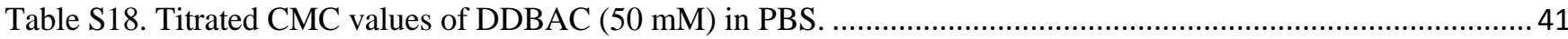

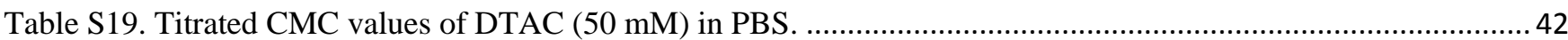

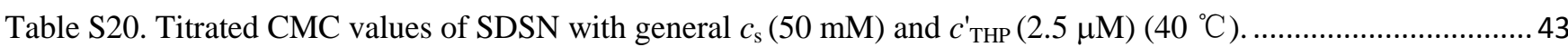

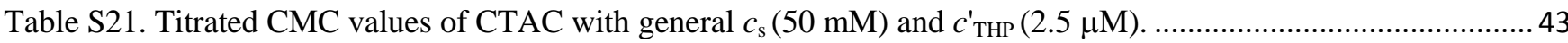

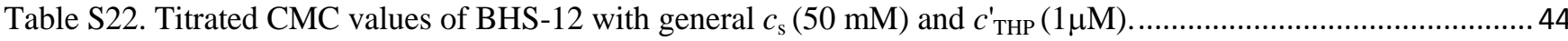

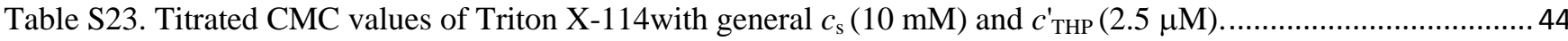

\section{Contents of Figures}

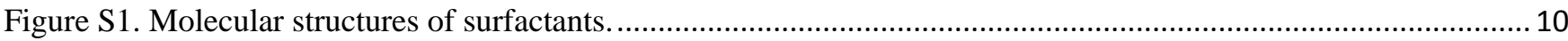

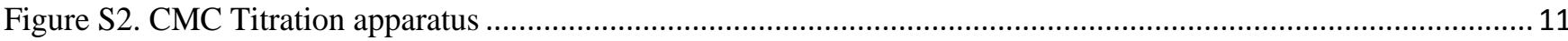

Figure S3. Titrated SDS solution before titration (no emission) and at titration end point (high emission). Photos were taken under a UV light with $365 \mathrm{~nm}$....

Figure S4. a)-d) Excitation (left) and emission (right) spectra of THP-T1 in samples kept 0, 10, 30 and 60 min, respectively. The concentration of SDS from 3 to $10 \mathrm{mM}$ and the concentration of THP-T1 from 0.45 to $1.5 \mu \mathrm{M}$. Emitted and excited at peaks marked in excitation and emission spectra, respectively. e) The relationship between the fluorescence intensity at mission peak of THP-T1 and the concentration of SDS in samples kept 0, 10,30 and $60 \mathrm{~min}$, respectively.

Figure S5. a) and b) Excitation (left) and emission (right) spectra of THP-T1 in samples kept 0 and 30 min, respectively. The concentration of SDS from 3 to $10 \mathrm{mM}$ and the concentration of THP-T1 from 0.6 to $2 \mu \mathrm{M}$. Emitted and excited at peaks marked in excitation and emission spectra, respectively. c) The relationship between the fluorescence intensity at emission peak of THP-T1 and the concentration of SDS in samples kept 0 and $30 \mathrm{~min}$, respectively. 
Figure S6. a) and b) Excitation (left) and emission (right) spectra of THP-T1 in samples kept 0 and 30 min, respectively. The concentration of SDS from 3 to $10 \mathrm{mM}$ and the concentration of THP-T1 from 1.2 to $4 \mu \mathrm{M}$. Emitted and excited at peaks marked in excitation and emission spectra, respectively. c) The relationship between the fluorescence intensity at emission peak of THP-T1 and the concentration of SDS in samples kept 0 and $30 \mathrm{~min}$, respectively. d) The excitation (left) and emission (right) spectra of THP-T1 in samples kept 30 min. The samples are the same as those in b) except the DMSO concentration is different. e) The relationship between the fluorescence intensity at emission peak of THP-T1 and the concentration of SDS in d).

Figure S7. a) and b) Excitation (left) and emission (right) spectra of THP-T1 in samples kept 0 and 30 min, respectively. The concentration of SDS from 3 to $10 \mathrm{mM}$ and the concentration of THP-T1 from 2.7 to $9 \mu \mathrm{M}$. Emitted and excited at peaks marked in excitation and emission spectra, respectively. c) The relationship between the fluorescence intensity at emission peak of THP-T1 and the concentration of SDS in samples kept 0 and $30 \mathrm{~min}$, respectively.

Figure S8. a) and b) Excitation (left) and emission (right) spectra of THP-T1 in samples kept 0 and 30 min, respectively. The concentration of CTAB from 0.2 to $2 \mathrm{mM}$ and the concentration of THP-T1 from 0.55 to 5.5 $\mu \mathrm{M}$. Emitted and excited at peaks marked in excitation and emission spectra, respectively. c) The relationship between the fluorescence intensity at emission peak of THP-T1 and the concentration of CTAB in samples kept 0 and $30 \mathrm{~min}$, respectively.

Figure S9. a) and b) Excitation (left) and emission (right) spectra of THP-T1 in samples kept 0 and 30 min, respectively. The concentration of BS-12 from 0.5 to $5 \mathrm{mM}$ and the concentration of THP-T1 from 0.2 to $2 \mu \mathrm{M}$. Emitted and excited at peaks marked in excitation and emission spectra, respectively. c) The relationship between the fluorescence intensity at emission peak of THP-T1 and the concentration of BS-12 in samples kept 0 and $30 \mathrm{~min}$, respectively.

Figure S10. a) and b) Excitation (left) and emission (right) spectra of THP-T1 in samples kept 0 and 30 min, respectively. The concentration of BS- 12 from 0.5 to $5 \mathrm{mM}$ and the concentration of THP-T1 from 0.35 to 3.5 $\mu \mathrm{M}$. Emitted and excited at peaks marked in excitation and emission spectra, respectively. c) The relationship between the fluorescence intensity at emission peak of THP-T1 and the concentration of BS-12 in samples kept 0 and $30 \mathrm{~min}$, respectively.

Figure S11. a) and b) Excitation (left) and emission (right) spectra of THP-T1 in samples kept 0 and 30 min, respectively. The concentration of BS- 12 from 0.5 to $5 \mathrm{mM}$ and the concentration of THP-T1 from 0.5 to $5 \mu \mathrm{M}$. Emitted and excited at peaks marked in excitation and emission spectra, respectively. c) The relationship between the fluorescence intensity at emission peak of THP-T1 and the concentration of BS-12 in samples kept 0 and 30 min, respectively.

Figure S12. a) and b) Excitation (left) and emission (right) spectra of THP-T1in samples kept 0 and 30 min, respectively. The concentration of Triton X-100 from 0.05 to $0.5 \mathrm{mM}$ and the concentration of THP-T1 from 0.1 to $1 \mu \mathrm{M}$. Emitted and excited at peaks marked in excitation and emission spectra, respectively. c) The relationship between the fluorescence intensity at emission peak of THP-T1 and the concentration of Triton X100 in samples kept 0 and 30 min, respectively. .25

Figure S13. a) Excitation (left) and emission (right) spectra of THP-T1 in Triton X-100 solutions with different concentrations in samples kept $30 \mathrm{~min}$. The concentration of Triton X-100 from 0.05 to $0.6 \mathrm{mM}$ and the 
concentration of THP-T1 from 0.3 to $3.6 \mu \mathrm{M}$. Emitted and excited at peaks marked in excitation and emission spectra, respectively. b) The relationship between the fluorescence intensity at emission peak of THP-T1 and the concentration of Triton X-100

Figure S14. a) and b) Excitation (left) and emission (right) spectra of THP-T1 in samples kept 0 and 30 min, respectively. The concentration of Triton X-100 from 0.05 to $0.5 \mathrm{mM}$ and the concentration of THP-T1 from 0.5 to $5 \mu \mathrm{M}$. Emitted and excited at peaks marked in excitation and emission spectra, respectively. c) The relationship between the fluorescence intensity at emission peak of THP-T1 and the concentration of Triton X100 in samples kept 0 and 30 min, respectively.

Figure S15. a) and b) Excitation (left) and emission (right) spectra of THP-T1 in samples kept 0 and 30 min, respectively. The concentration of DDBAC from 5 to $15 \mathrm{mM}$ and the concentration of THP-T1 from 1 to $3 \mu \mathrm{M}$. Emitted and excited at peaks marked in excitation and emission spectra, respectively. c) The relationship between the fluorescence intensity at emission peak of THP-T1 and the concentration of DDBAC in samples kept 0 and $30 \mathrm{~min}$, respectively.

Figure S16. a)-d) Excitation (left) and emission (right) spectra of THP-T1 in samples kept 0, 10, 30 and 60 min, respectively. The concentration of DTAC from 10 to $22 \mathrm{mM}$ and the concentration of THP-T1 from 1 to $2.2 \mu \mathrm{M}$. Emitted and excited at peaks marked in excitation and emission spectra, respectively. e) The relationship between the fluorescence intensity at emission peak of THP-T1 and the concentration of DTAC in samples kept $0,10,30$ and $60 \mathrm{~min}$, respectively.

Figure S17.a)-b) Excitation (left) and emission (right) spectra of THP-T1 in samples kept 0 and 30 min, respectively. The concentration of DTAC from 10 to $22 \mathrm{mM}$ and the concentration of THP-T1 from 1.8 to $3.96 \mu \mathrm{M}$. Emitted and excited at peaks marked in excitation and emission spectra, respectively. c) The relationship between the fluorescence intensity at emission peak of THP-T1 and the concentration of DTAC in samples kept 0 and 30 min, respectively.

Figure S18. a) and b) Excitation (left) and emission (right) spectra of THP-T1 in samples kept 0 and 30 min, respectively. The concentrations of Tween- 20 are from 0.01 to $0.1 \mathrm{mM}$ in different samples and the concentration of THP-T1 is $0.2 \mu \mathrm{M}$. Emitted and excited at peaks marked in excitation and emission spectra, respectively. c) The relationship between the fluorescence intensity at emission peak of THP-T1 and the concentration of Tween-20 in samples kept 0 and 30 min, respectively.

Figure S19. Determination of the approximate CMC of Triton X-100. Triton X-100 solutions with different concentrations $(0.1,0.2,0.3,0.4$ and $0.5 \mathrm{mM})$ containing $1 \mu \mathrm{M}$ of THP-T1 were prepared by adding $2 \mu \mathrm{L}$ of THP-T1 stock solution ( $1 \mathrm{mM}$ ) into different $5 \mathrm{~mL}$ test bottle containing different volumes of Triton X-100 stock solution $(5 \mathrm{mM})$, respectively, shaking well for about $3 \mathrm{~min}$, and then adding different amount of water into test tube to make the total volume $2 \mathrm{~mL}$, shaking well and kept for 0 and $30 \mathrm{~min}$. Photos were taken under a UV light with $365 \mathrm{~nm}$.

Figure S20. Determination of the approximate CMC of DDBAC. DDBAC solutions with different concentrations $(7,8$, 9, 10 and $11 \mathrm{mM}$ ) containing $1 \mu \mathrm{M}$ of THP-T1 were prepared by adding $2 \mu \mathrm{L}$ of THP-T1 stock solution ( $1 \mathrm{mM})$ into different $5 \mathrm{~mL}$ test bottle containing different volumes of DDBAC stock solution (30 mM), respectively, shaking well for about $3 \mathrm{~min}$, and then adding different amount of water into test tube to make the total volume 2 $\mathrm{mL}$, shaking well and kept for 0 and $30 \mathrm{~min}$. Photos were taken under a UV light with $365 \mathrm{~nm}$. 
Figure S21. Determination of the approximate CMC of DTAC. DTAC solutions with different concentrations (16, 17, $18,19$ and $20 \mathrm{mM}$ ) containing $2 \mu \mathrm{M}$ of THP-T1 were prepared by adding $4 \mu \mathrm{L}$ of THP-T1 stock solution ( $1 \mathrm{mM})$ into different $5 \mathrm{~mL}$ test bottle containing different volumes of DTAC stock solution $(50 \mathrm{mM})$, respectively, shaking well for about $3 \mathrm{~min}$, and then adding different amount of water into test tube to make the total volume 2 $\mathrm{mL}$, shaking well and kept for 0 and 30 min. Photos were taken under a UV light with $365 \mathrm{~nm}$ .35

Figure S22. Determination of the approximate CMC of Tween-20. Tween-20 solutions with different concentrations $(0.01,0.02,0.03,0.04$ and $0.05 \mathrm{mM})$ containing $0.2 \mu \mathrm{M}$ of THP-T1 were prepared by adding $4 \mu \mathrm{L}$ of THP-T1 solution $(0.1 \mathrm{mM})$ into different $5 \mathrm{~mL}$ test bottle containing different volumes of concentrated Tween-20 solution $(1 \mathrm{mM})$, respectively, shaking well for about $3 \mathrm{~min}$, and then adding different amount of water into test tube to make the total volume $2 \mathrm{~mL}$, shaking well and kept for 0 and $30 \mathrm{~min}$. Photos were taken under a UV light with $365 \mathrm{~nm}$........

Figure S23.a) Excitation (left) and emission (right) spectra of pyrene $(0.5 \mu \mathrm{M})$ in SDS solutions with different concentrations (4 to $10 \mathrm{mM}$ ). Emitted and excited at 373 and $334 \mathrm{~nm}$, respectively. b) The relationship between the ratio of the fluorescence intensity at 383 and $373 \mathrm{~nm}$ of pyrene and the concentration of SDS. Samples were prepared by diluting concentrated SDS solution $(20 \mathrm{mM})$ containing a certain concentration of pyrene $(0.5 \mu \mathrm{M})$ using pyrene water solution $(0.5 \mu \mathrm{M})$.

Figure S24. a) Excitation (left) and emission (right) spectra of pyrene $(0.5 \mu \mathrm{M})$ in CTAB solutions with different concentrations ( 0.2 to $2 \mathrm{mM}$ ). Emitted and excited at 373 and $334 \mathrm{~nm}$, respectively. b) The relationship between the ratio of the fluorescence intensity at 383 and $373 \mathrm{~nm}$ of pyrene and the concentration of CTAB. Samples were prepared by diluting concentrated CTAB solution $(2 \mathrm{mM})$ containing a certain concentration of pyrene $(0.5$ $\mu \mathrm{M})$ using pyrene water solution $(0.5 \mu \mathrm{M})$.

Figure S25. a) Excitation (left) and emission (right) spectra of pyrene $(0.5 \mu \mathrm{M})$ in BS-12 solutions with different concentrations ( 1 to $5 \mathrm{mM}$ ). Emitted and excited at 373 and $334 \mathrm{~nm}$, respectively. b) The relationship between the ratio of the fluorescence intensity at 383 and $373 \mathrm{~nm}$ of pyrene and the concentration of BS-12. Samples were prepared by diluting concentrated BS-12 solution $(5 \mathrm{mM})$ containing a certain concentration of pyrene $(0.5 \mu \mathrm{M})$ using pyrene water solution $(0.5 \mu \mathrm{M})$. 37

Figure S26. a) Excitation (left) and emission (right) spectra of pyrene $(0.5 \mu \mathrm{M})$ in Triton X-100 solutions with different concentrations ( 0.1 to $0.4 \mathrm{mM}$ ). Emitted and excited at 373 and $334 \mathrm{~nm}$, respectively. b) The relationship between the ratio of the fluorescence intensity at 383 and $373 \mathrm{~nm}$ of pyrene and the concentration of Triton X100. Samples were prepared by diluting concentrated Triton X-100 solution $(0.4 \mathrm{mM})$ containing a certain concentration of pyrene $(0.5 \mu \mathrm{M})$ using pyrene water solution $(0.5 \mu \mathrm{M})$.

Figure S27.a) Excitation (left) and emission (right) spectra of pyrene $(0.5 \mu \mathrm{M})$ in DDBAC solutions with different concentrations ( 5 to $15 \mathrm{mM}$ ). Emitted and excited at 373 and $334 \mathrm{~nm}$, respectively. b) The relationship between the ratio of the fluorescence intensity at 383 and $373 \mathrm{~nm}$ of pyrene and the concentration of DDBAC. Samples were prepared by diluting concentrated DDBAC solution $(20 \mathrm{mM})$ containing a certain concentration of pyrene $(0.5 \mu \mathrm{M})$ using pyrene water solution $(0.5 \mu \mathrm{M})$.

Figure S28. a) Excitation (left) and emission (right) spectra of pyrene $(0.5 \mu \mathrm{M})$ in DTAC solutions with different concentrations (10 to $22 \mathrm{mM}$ ). Emitted and excited at 373 and $334 \mathrm{~nm}$, respectively. b) The relationship between the ratio of the fluorescence intensity at 383 and $373 \mathrm{~nm}$ of pyrene and the concentration of DTAC. Samples 
were prepared by diluting concentrated DTAC solution $(25 \mathrm{mM})$ containing a certain concentration of pyrene $(0.5 \mu \mathrm{M})$ using pyrene water solution $(0.5 \mu \mathrm{M})$.

Figure S29. a) Excitation (left) and emission (right) spectra of pyrene $(0.5 \mu \mathrm{M})$ in Tween-20 solutions with different concentrations (0.01 to $0.1 \mathrm{mM})$. Emitted and excited at 373 and $334 \mathrm{~nm}$, respectively. b) The relationship between the ratio of the fluorescence intensity at 383 and $373 \mathrm{~nm}$ of pyrene and the concentration of Tween-20. Samples were prepared by diluting concentrated Tween-20 solution $(1 \mathrm{mM})$ containing a certain concentration of pyrene $(0.5 \mu \mathrm{M})$ using pyrene water solution $(0.5 \mu \mathrm{M})$. 38

Figure S30. Determination of the CMC values of DDBAC (left) and DTAC(right) by conductive method. Relationship between the conductivity and concentration of DDBAC (left) and DTAC(right) DTAC solutions. 39

Figure S31. a) Excitation (left) and emission (right) spectra of THP-T1 in samples kept 30 min. The concentration of CHAPS from 3 to $10 \mathrm{mM}$ and the concentration of THP-T1 from 0.6 to $2 \mu \mathrm{M}$. Emitted and excited at peaks marked in excitation and emission spectra, respectively. b) The relationship between the fluorescence intensity at emission peak of THP-T1 and the concentration of DDBAC in samples. 


\section{Materials and instruments}

All chemicals used in this paper were obtained from commercial suppliers and used without further purification. SDS were purchased from Guangzhou Whiga Technology Co., Ltd, DDBAC was purchased from Meryer, DTAC and CTAC were purchased from Innochem, CTAB, Triton X-100 and Triton X-114 were purchased from Aladdin, BS-12 and BHS-12 were purchased from Shanghai Shengxuan Biology Chemical Co., Ltd, and SDSN was purchased from Tianjin Rgent Chemical Co., Ltd. Phosphate buffer saline (PBS, $10 \mathrm{mM}, \mathrm{pH}=7.4$ ) was purchased from Thermo Fisher. CMC titration was conducted in a $5 \mathrm{~mL}$ bottle with a magnetic stirrer under a UV light (365 nm). Photos were taken by Huawei Honor 8 under a UV light $(365 \mathrm{~nm})$. All measurements were carried out at $25 \pm 1^{\circ} \mathrm{C}$ except SDSN $\left(40^{\circ} \mathrm{C}\right)$. Water was purified via deionization and filtrated by the Millipore purification to the resistivity higher than $18 \mathrm{M} \Omega \cdot \mathrm{cm}^{-1} .{ }^{1} \mathrm{H} \mathrm{NMR}(400 \mathrm{MHz})$ spectra were recorded using a Bruker Avance $400 \mathrm{MHz}$ NMR spectrometer with TMS as internal standard. Excitation and emission spectra were determined by FluoroMax-4 spectrofluorophotometer. The conductivity was measured by a DDS-11A conductivity meter. THP-T1 was synthesized by the five-component reaction that we developed ${ }^{[1]}$ and identified by ${ }^{1} \mathrm{H}$ NMR reported in our previous work. ${ }^{[2]}$

\section{Determination of the approximate CMC of surfactants}

Approximate CMC values were determined by method II reported in our previous paper. ${ }^{[2]}$ Generally, a certain volume of THP-T1 solution $(10 \mu \mathrm{L}$ of $0.5 \mathrm{mM}$ THP-T1 for CMC $>0.1 \mathrm{mM}$ and $4 \mu \mathrm{L}$ of $0.1 \mathrm{mM}$ THP-T1 for CMC $\leq 0.1 \mathrm{mM}$ ) were added into different $5 \mathrm{~mL}$ bottles containing different volumes of the surfactant stock solution, respectively, shaking well for about 3 min (it is very important for dispersion of THP-T1 in concentrated surfactant solutions, if the surfactant stock solution is too viscous to disperse THP-T1, the shaking procedure is needed to be conducted in a hot water bath.), and then adding different amount of water into bottles to make the total volume $2 \mathrm{~mL}$, shaking well (the concentration of THP-T1 in each sample is $2.5 \mu \mathrm{M}$ for surfactants with CMC $>0.1 \mathrm{mM}$ and $0.2 \mu \mathrm{M}$ for surfactants with 
$\mathrm{CMC} \leq 0.1 \mathrm{mM})$. With decrease of the concentration of surfactants, THP-T1 is no emissive above CMC, becomes emission near to $\mathrm{CMC}$, and shows strong emission at/below CMC.

\section{Preparation of samples for CMC determination by fluorometric method using THP-T1 as probe}

The samples for fluorescence measurement can be prepared by two methods (methods I and II). Method $\mathrm{I}^{[3]}$ and $\mathrm{II}^{[2]}$ were reported in our previous work on the application of THPs as unique fluorescence-turnon probes for $\mathrm{CMC}$, and the practical applications and comparison of methods I and II were discussed in detail. ${ }^{[2]}$ Method I has advantages of omitting addition of micro amount of probe in each samples, decreasing the operation errors and promoting the dispersion of aggregate THPs in solution. Method I is suitable to prepare samples containing THP for regular, semi-micro, high throughput CMC determination of surfactants with relative high CMC $(>0.1 \mathrm{mM})$, and Method II is a an alternative method to prepare samples for regular CMC determination of surfactants with relative low CMC $(\leq 0.1$ $\mathrm{mM}$ ) and new surfactants.

The samples prepared by method $\mathrm{I}^{[3]}$ contain different concentrations of surfactant and THP-T1. Generally, different volumes of concentrated surfactant solution $\left(c_{\mathrm{s}}\right)\left(c_{\mathrm{s}}\right.$ is about $\mathrm{CMC}+10 \mathrm{mM}$ for surfactants with $\mathrm{CMC}>1 \mathrm{mM}$ or $5 \mathrm{mM}$ for surfactants with $\mathrm{CMC}=0.1-1 \mathrm{mM}$ ) containing certain concentration $\left(c_{\mathrm{THP}}\right)$ of THP-T1 $\left(c_{\mathrm{THP}}=c_{\mathrm{THP}}^{\prime} \times c_{\mathrm{S}} / \mathrm{CMC}\right.$, here, $c_{\mathrm{THP}}^{\prime}$, the concentration of THP-T1 in surfactant solution at $\mathrm{CMC}$, is $2.5 \pm 0.5 \mu \mathrm{M}$ ) were added into different $5 \mathrm{~mL}$ volumetric flasks and then filling the flask to the mark with water, shaking well and keeping for $30 \mathrm{~min}$ before measurement. The concentrated surfactant solutions containing certain THP-T1 were prepared by adding a certain volume $\left(V_{\mathrm{THP}}\right)\left(V_{\mathrm{THP}} \times 0.5 \mathrm{mM}=25 \mathrm{~mL} \times c_{\mathrm{THP}}\right)$ of THP-T1 solution $(0.5 \mathrm{mM})$ into a $25 \mathrm{~mL}$ of volumetric flask containing a certain amount of surfactant stock solution $(50 \mathrm{mM})$, shaking well for about 3 min (it is very important for dispersion of THPs in surfactant solutions) and then filling the flask to the mark with water. 
The samples prepared by method $\mathrm{II}^{[2]}$ contain different concentrations of surfactant and a certain amount of THP-T1 $(2.5 \pm 0.5 \mu \mathrm{M}$ for surfactants with CMC $>0.1 \mathrm{mM}$ and $0.2 \mu \mathrm{M}$ for surfactants with $\mathrm{CMC} \leq 0.1 \mathrm{mM})$. That is, different volumes of concentrated surfactant solution $\left(c_{\mathrm{s}}\right)\left(c_{\mathrm{s}}\right.$ is as large as possible, and at least equal to $\mathrm{CMC}+30 \mathrm{mM}$ for $\mathrm{CMC}>1 \mathrm{mM}, 10 \mathrm{mM}$ for $\mathrm{CMC}=0.1-1 \mathrm{mM}$, and 1 $\mathrm{mM}$ for $\mathrm{CMC}<0.1 \mathrm{mM})$ and a certain amount of THP-T1 solution $(25 \mu \mathrm{L}$ of $0.5 \mathrm{mM}$ THP-T1 for surfactants with CMC $>0.1 \mathrm{mM}$ and $10 \mu \mathrm{L}$ of $0.1 \mathrm{mM}$ THP-T1 for surfactants with CMC $<0.1 \mathrm{mM}$ ) were added into different $5 \mathrm{~mL}$ volumetric flasks, shaking well for about $3 \mathrm{~min}$ (it is very important for dispersion of THP-T1 in surfactant solutions) and then filling the flask to the mark with water and keeping for 30 min before measurement.

\section{Structure characteristics of THP-T1}

Dimethyl 1,3-di-p-tolyl-2-(4-(trifluoromethyl)phenyl)-1,2,3,6-tetrahydropyrimidine-4,5-dicarboxylate (THP-T1) yellow solid, $\mathrm{mp}=172.8-173.1{ }^{\circ} \mathrm{C} ;{ }^{1} \mathrm{H}$ NMR $(400 \mathrm{MHz}$, Chloroform- $d) \delta 7.81(\mathrm{~d}, J=8.3 \mathrm{~Hz}, 2 \mathrm{H}), 7.73(\mathrm{~d}, J=8.3$ $\mathrm{Hz}, 2 \mathrm{H}), 7.05(\mathrm{~d}, J=8.3 \mathrm{~Hz}, 2 \mathrm{H}), 7.00(\mathrm{~d}, J=8.2 \mathrm{~Hz}, 2 \mathrm{H}), 6.97$ (d, $J=8.5 \mathrm{~Hz}, 2 \mathrm{H}), 6.82(\mathrm{~d}, J=8.3 \mathrm{~Hz}, 2 \mathrm{H}), 6.03$ (s, $1 \mathrm{H}), 4.24(\mathrm{~m}, 1 \mathrm{H}), 3.68(\mathrm{~d}, J=2.1 \mathrm{~Hz}, 6 \mathrm{H}), 3.52(\mathrm{~d}, J=17.9 \mathrm{~Hz}, 1 \mathrm{H}), 2.30(\mathrm{~d}, J=3.5 \mathrm{~Hz}, 6 \mathrm{H}) \mathrm{ppm} .{ }^{1} \mathrm{H}$ spectra was consistent with the previous literature. ${ }^{[2]}$ 


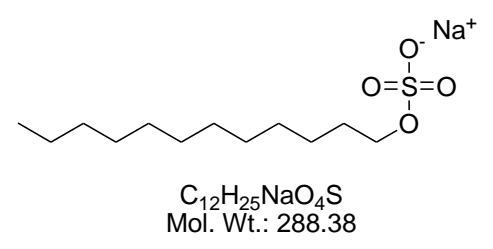

Sodium dodecyl sulfate (SDS)

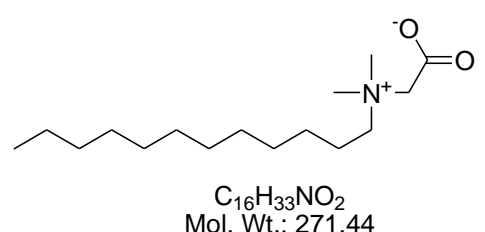

Dodecyl dimethyl betaine (BS-12)

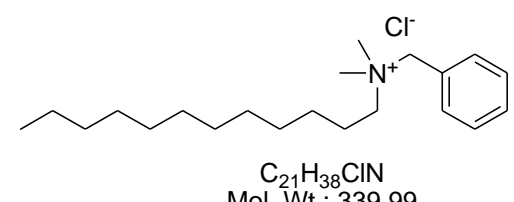

Dodecyldimethylbenzylammonium chloride (DDBAC)

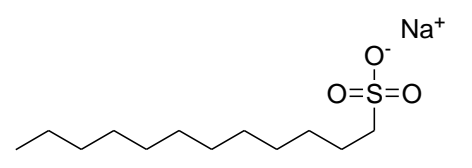

$$
\mathrm{C}_{12} \mathrm{H}_{25} \mathrm{NaO}_{3} \mathrm{~S}
$$$$
\text { Mol. Wt.: } 272.38
$$

Sodium dodecyl sulfonate(SDSN)

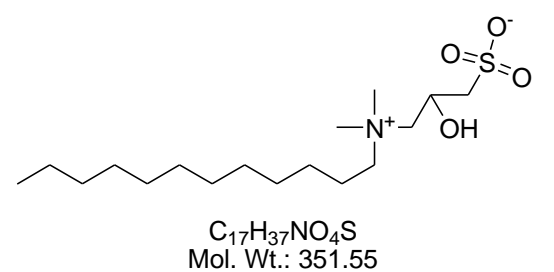

Dodecyl dimethyl hydroxyl sulfopropyl sulfobe taine (BHS-12)

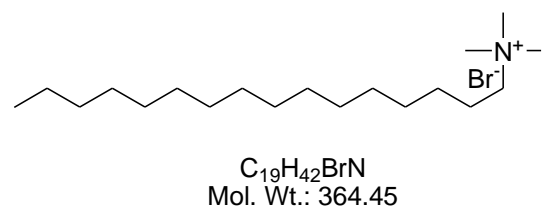

Cetyltrimethylammonium bromide (CTAB)

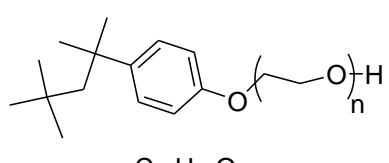

$\mathrm{C}_{34} \mathrm{H}_{62} \mathrm{O}_{11}$

Mol. Wt.:646.85 $\mathrm{n} \approx 10$

Polyethylene glycol tert-octylphenyl ether (Triton X-100)

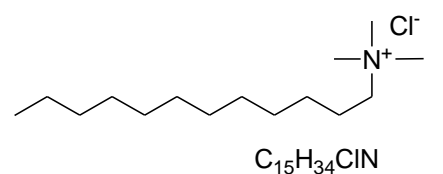

Mol. Wt.:263.89

Dodecyltrimethylammonium chloride (DTAC)
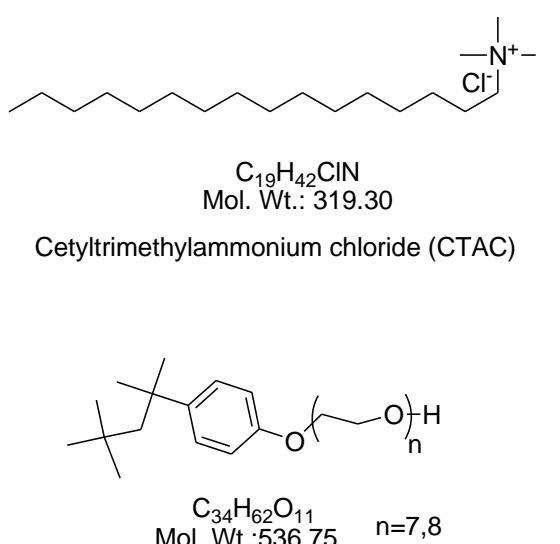

Mol. Wt:536.75 $\mathrm{n}=7,8$

Polyethylene glycol tert-octylphenyl ether (Triton X-114)

Figure S1. Molecular structures of surfactants. 


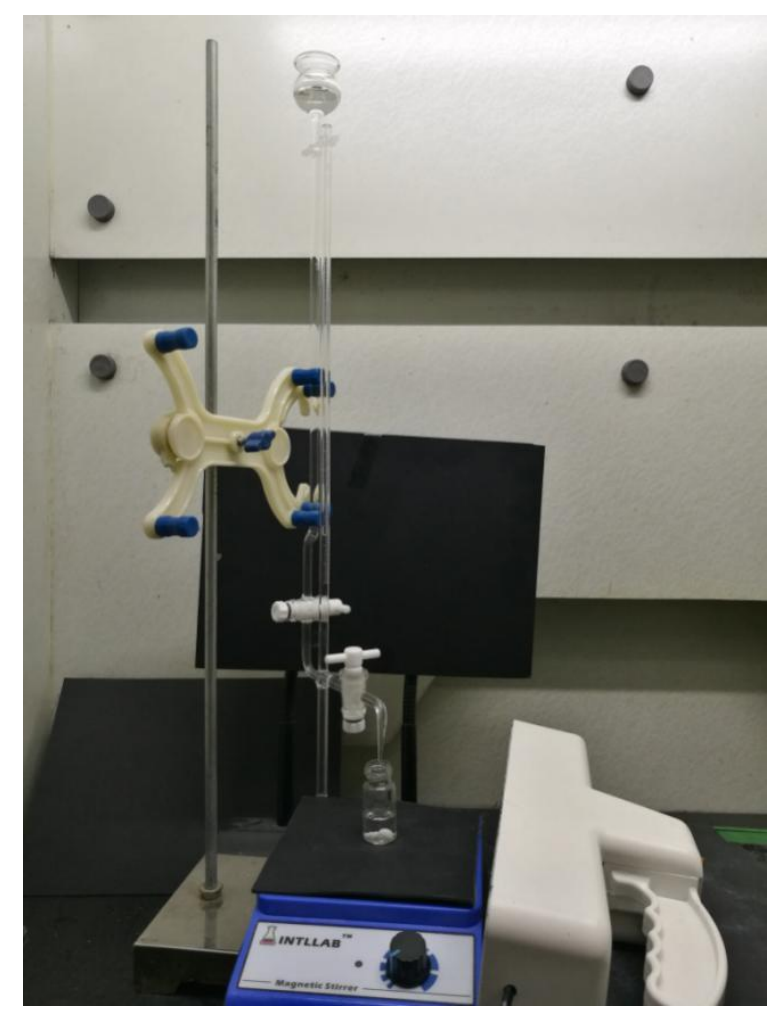

Figure S2. CMC Titration apparatus

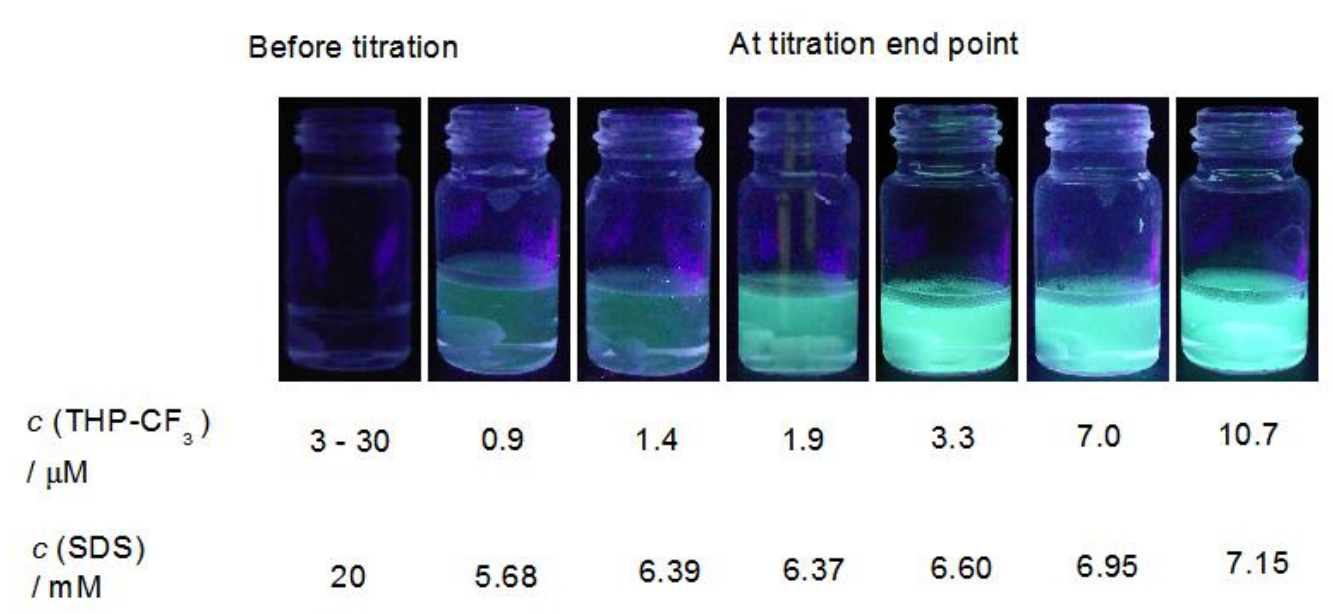

Figure S3. Titrated SDS solution before titration (no emission) and at titration end point (high emission). Photos were taken under a UV light with $365 \mathrm{~nm}$. 

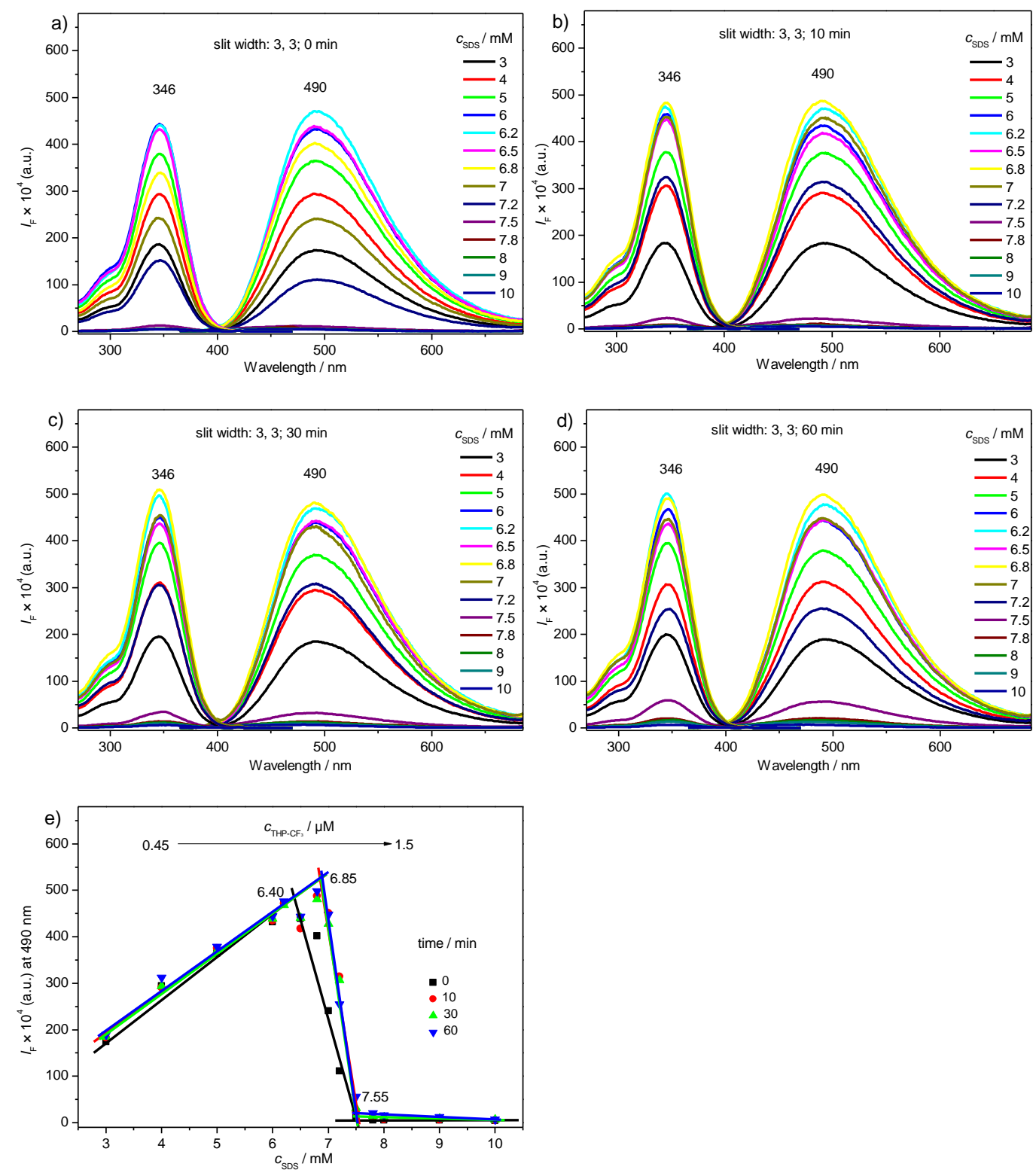

Figure S4. a)-d) Excitation (left) and emission (right) spectra of THP-T1 in samples kept 0, 10, 30 and $60 \mathrm{~min}$, respectively. The concentration of SDS from 3 to $10 \mathrm{mM}$ and the concentration of THP-T1 from 0.45 to $1.5 \mu \mathrm{M}$. Emitted and excited at peaks marked in excitation and emission spectra, respectively. e) The relationship between the fluorescence intensity at mission peak of THP-T1 and the concentration of SDS in samples kept 0, 10, 30 and 60 min, respectively. 

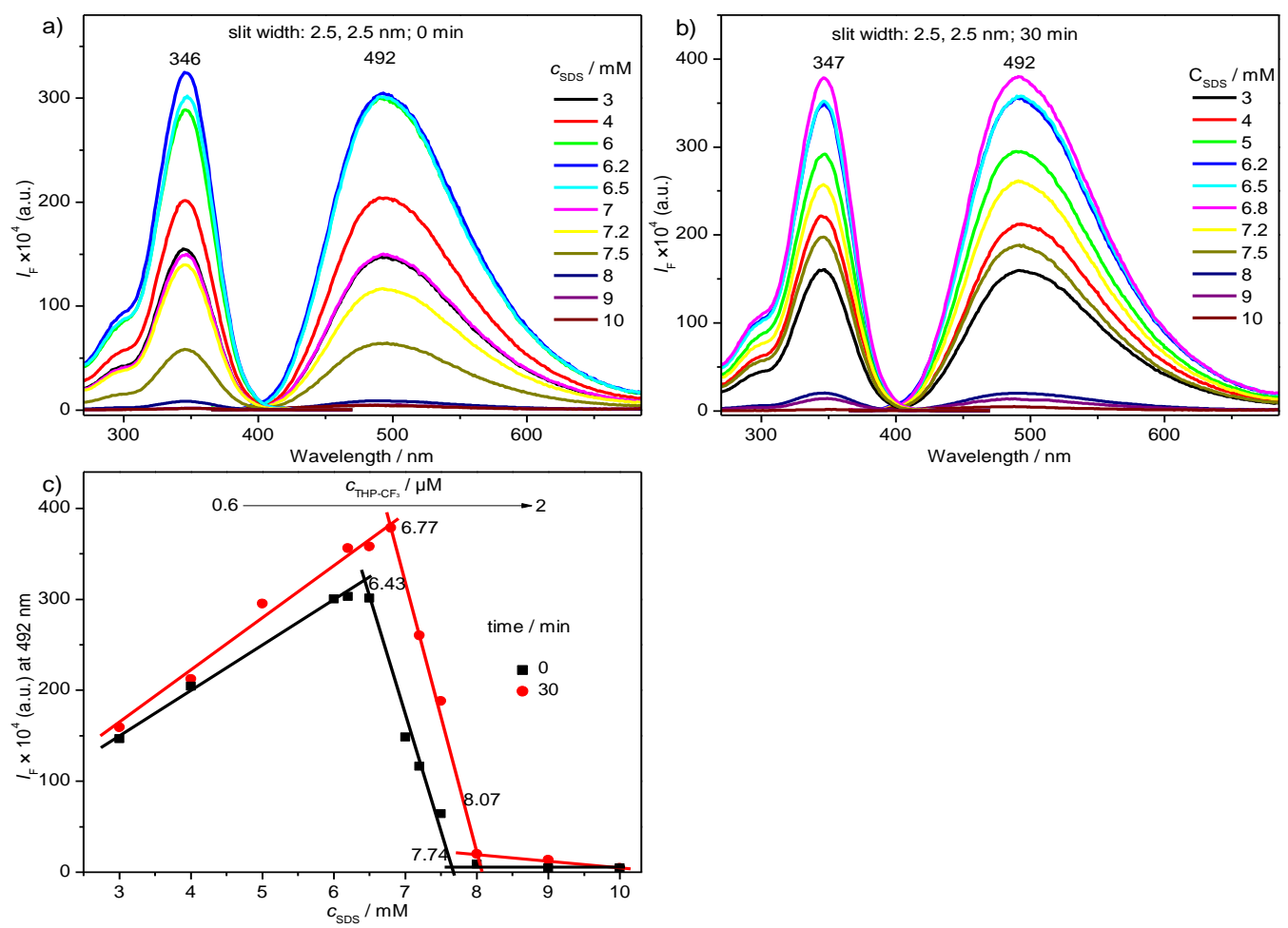

Figure S5. a) and b) Excitation (left) and emission (right) spectra of THP-T1 in samples kept 0 and 30 min, respectively. The concentration of SDS from 3 to $10 \mathrm{mM}$ and the concentration of THP-T1 from 0.6 to $2 \mu \mathrm{M}$. Emitted and excited at peaks marked in excitation and emission spectra, respectively. c) The relationship between the fluorescence intensity at emission peak of THP-T1 and the concentration of SDS in samples kept 0 and $30 \mathrm{~min}$, respectively.
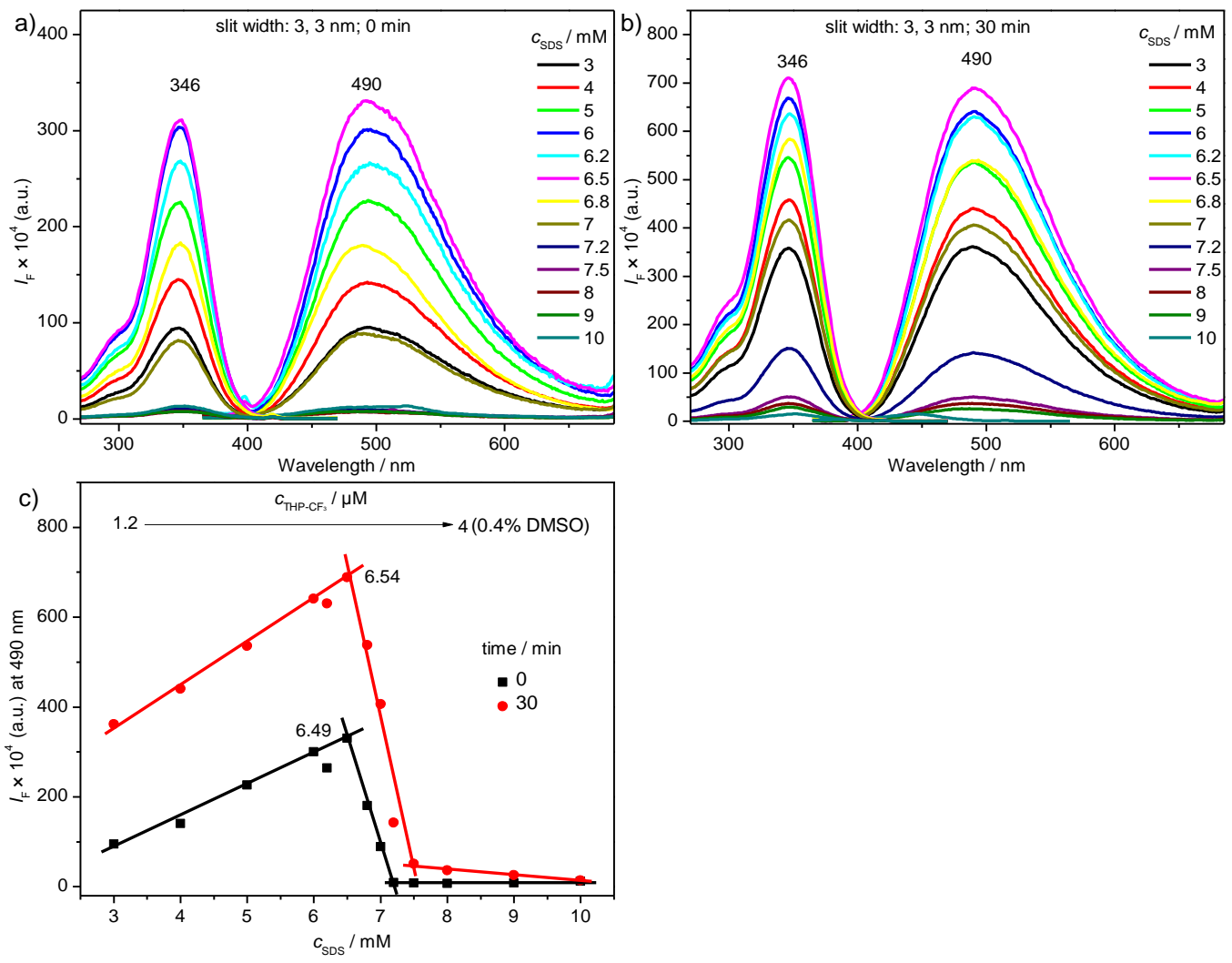

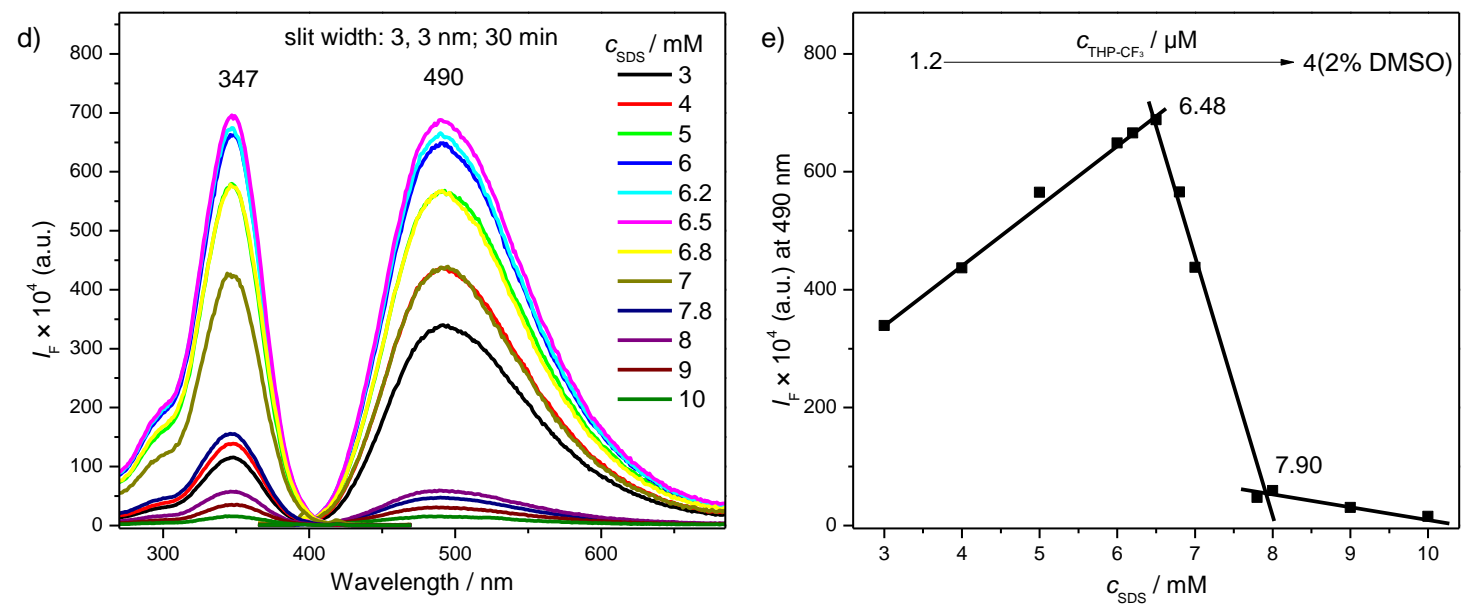

Figure S6. a) and b) Excitation (left) and emission (right) spectra of THP-T1 in samples kept 0 and 30 min, respectively. The concentration of SDS from 3 to $10 \mathrm{mM}$ and the concentration of THP-T1 from 1.2 to $4 \mu \mathrm{M}$. Emitted and excited at peaks marked in excitation and emission spectra, respectively. c) The relationship between the fluorescence intensity at emission peak of THP-T1 and the concentration of SDS in samples kept 0 and 30 min, respectively. d) The excitation (left) and emission (right) spectra of THP-T1 in samples kept $30 \mathrm{~min}$. The samples are the same as those in b) except the DMSO concentration is different. e) The relationship between the fluorescence intensity at emission peak of THP-T1 and the concentration of SDS in d).
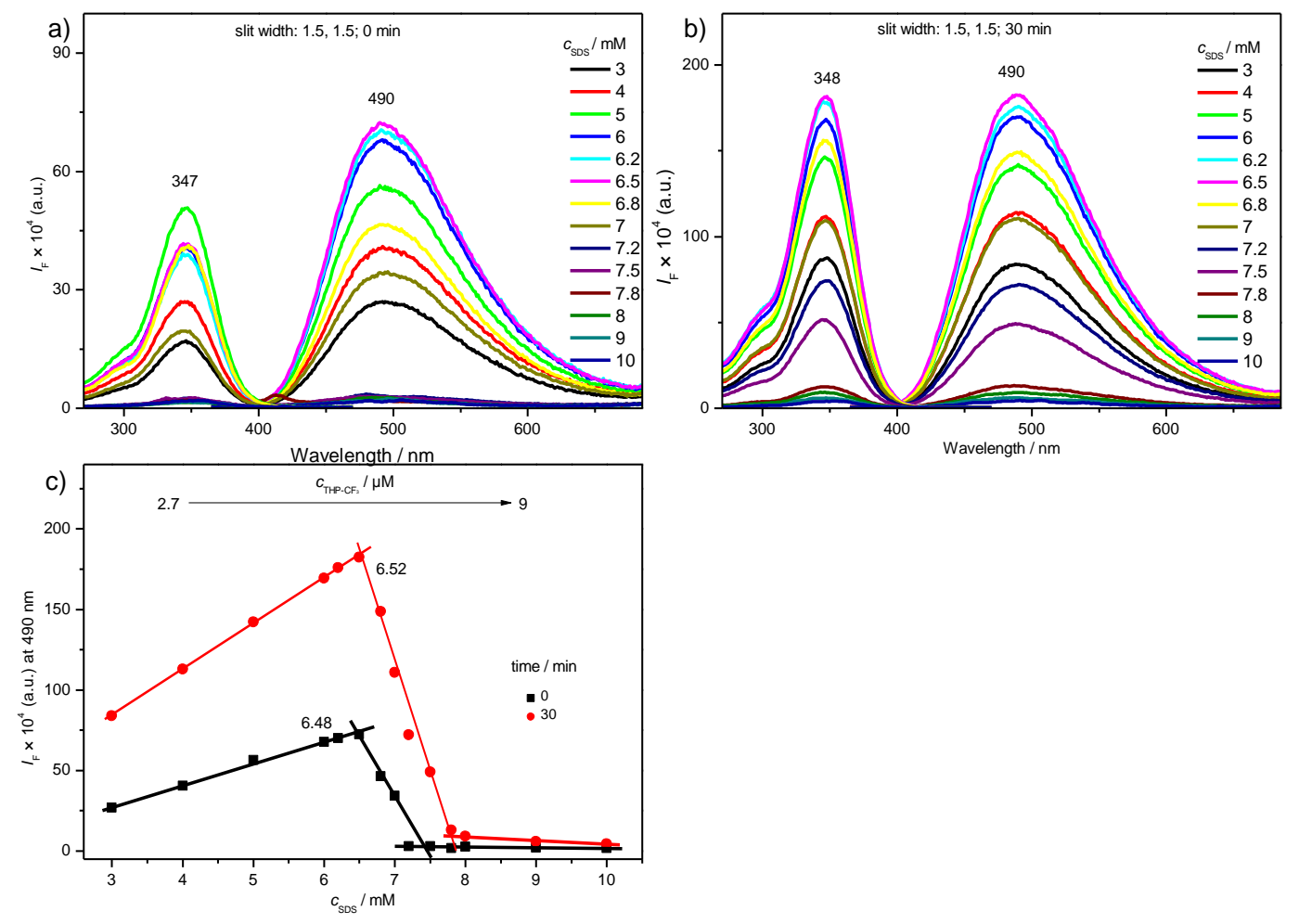

Figure S7. a) and b) Excitation (left) and emission (right) spectra of THP-T1 in samples kept 0 and 30 min, respectively. The concentration of SDS from 3 to $10 \mathrm{mM}$ and the concentration of THP-T1 from 2.7 to $9 \mu \mathrm{M}$. Emitted and excited at peaks marked in excitation and emission spectra, respectively. c) The relationship between the fluorescence intensity at emission peak of THP-T1 and the concentration of SDS in samples kept 0 and 30 min, respectively. 


\section{Influence of SDS concentration in initial titration solution on titrated CMC value}

As shown in Table S1, the titrated CMC value increases from 5.40 to $5.74 \mathrm{mM}$ when $c_{\text {SDS }}$ changes from 10 to $15 \mathrm{mM}$ (entries 1 and 2), but almost keeps the same $(6.60,6.68$ and $6.64 \mathrm{mM})$ when $c_{\text {SDS }}$ changes from 20,30 to $35 \mathrm{mM}$, which indicates that the suitable concentration of SDS in initial titrated solution is $\geq 20 \mathrm{mM}$.

Since THP-T1 prefers dissolving in micelles, with the same amounts of THP-T1 and SDS in initial titrated solution, the larger the concentration of SDS is, the more THP-T1 in micelles is. Therefore, it is expected that the influence of SDS concentration in initial titrated solution on titrated CMC values is because the more the amount of THP-T1 in micelles/solution is, the faster/slower the aggregation rate of THP-T1 at titration end point is, and THP-T1 can aggregate immediately at titration end point (CMC) until its amount in micelles is much more than that in solution.

Table S1. Influence of SDS concentration on titrated CMC

\begin{tabular}{lllllllll}
\hline Entry & $\begin{array}{lllllll}V_{\mathrm{SDS}}{ }^{a} \\
\end{array}$ & $\begin{array}{l}c_{\mathrm{SDS}} \\
/ \mathrm{mL}\end{array}$ & $\begin{array}{l}V_{\mathrm{THP}}{ }^{b} \\
1 \mathrm{mM}\end{array}$ & $\begin{array}{l}c_{\mathrm{THP}}{ }^{c} \\
/ \mu \mathrm{L}\end{array}$ & $\begin{array}{l}V_{\mathrm{H} 2 \mathrm{O}}{ }^{d} \\
/ \mathrm{mL}\end{array}$ & $\begin{array}{l}V_{\mathrm{H} 2 \mathrm{O}}{ }^{e} \\
/ \mathrm{mL}\end{array}$ & $\begin{array}{l}c^{\prime}{ }^{f} \\
/ \mu \mathrm{M}\end{array}$ & $\begin{array}{l}\mathrm{CMC}^{g} \\
/ \mathrm{mM}\end{array}$ \\
\hline 1 & 1 & 10 & 5 & 5 & $0.78 \pm 0.03$ & $0.85 \pm 0.02$ & 2.70 & $5.40 \pm 0.06$ \\
3 & 1 & 15 & 7.5 & 5 & $1.52 \pm 0.02$ & $1.61 \pm 0.02$ & 2.87 & $5.74 \pm 0.05$ \\
4 & 1 & 20 & 10 & 5 & $1.94 \pm 0.02$ & $2.03 \pm 0.02$ & 3.30 & $6.60 \pm 0.04$ \\
5 & 1 & 30 & 15 & 5 & $3.42 \pm 0.02$ & $3.49 \pm 0.01$ & 3.34 & $6.68 \pm 0.02$ \\
\hline
\end{tabular}

${ }^{a}$ Volume of concentrated SDS solution with different concentration $\left(c_{\text {SDS }}\right) .{ }^{b}$ Volume of THP-T1 stock solution (1 mM) in concentrated SDS solution: $V_{\mathrm{THP}} \times 1 \mathrm{mM}=\left(1 \mathrm{~mL} \times c_{\mathrm{SDS}} / 10 \mathrm{mM}\right) \times 5 \mu \mathrm{M} .{ }^{c}$ Concentration of THP-T1 in SDS titrated solution with concentration equal to $10 \mathrm{mM} .{ }^{d}$ Volume of added water near titrating end point. ${ }^{e}$ Volume of added water at titrating end point. ${ }^{f}$ Concentration of THP-T1 in SDS titration-end-point solution. ${ }^{g} \mathrm{CMC}(\mathrm{mM})=c_{\mathrm{SDS}} \times V_{\mathrm{SDS}} /$ $\left(V_{\mathrm{SDS}}+V_{\mathrm{H} 2 \mathrm{O}}^{\prime}\right)=c_{\mathrm{SDS}} \times 1 /\left(1+V_{\mathrm{H} 2 \mathrm{O}}^{\prime}\right)$. 


\section{Factors influencing the $\Delta V_{\mathrm{H} 20}$ value from near CMC to CMC}

From near $\mathrm{CMC}$ to $\mathrm{CMC}$, the concentration $\left(c_{\mathrm{s}}\right)$ of surfactant, the average aggregation number $\left(N_{\mathrm{ag}}\right)$ and concentration $\left(c_{\text {micelle }}\right)$ of micelles, the volume $\left(V_{\mathrm{t}}\right)$ of the titrated solution and the concentration $\left(c_{\text {ind }}\right)$ of an indicator (THP-1 or other organic dye) change from $c_{\mathrm{s}-1,}, N_{\mathrm{ag}-1}, c_{\text {micelle-1 }}$ and $V_{\mathrm{t}-1}$ near CMC to $c_{\mathrm{s}-2,}, N_{\mathrm{ag}-2,}, c_{\text {micelle-2 }}$ and $V_{\mathrm{t}-2}$ at CMC. At CMC, $c_{\mathrm{s}-2}=\mathrm{CMC}$, all micelles disassemble, which means $c_{\text {micelle-2 }}=0 . \quad$ These changes are listed in the table below:

\begin{tabular}{ccc}
\hline & Near CMC & CMC \\
\hline$V_{\mathrm{t}}$ & $V_{\mathrm{t}-1}$ & $V_{\mathrm{t}-2}$ \\
$c_{\mathrm{s}}$ & $c_{\mathrm{s}-1}$ & $c_{\mathrm{s}-2}$ \\
$c_{\text {micelle }}$ & $c_{\text {micelle-1 }}$ & 0 \\
$N_{\mathrm{ag}}$ & $N_{\mathrm{ag}-1}$ & - \\
$c_{\text {ind }}$ & $c_{\text {ind-1 }}$ & $c_{\text {ind-2 }}$ \\
\hline
\end{tabular}

From near CMC to $\mathrm{CMC}$, the $\Delta V_{\mathrm{H} 2 \mathrm{O}}$ value added into titrated solution is equal to the change in the volume of titrated solution from $V_{\mathrm{t}-1}$ to $V_{\mathrm{t}-2}$, that is,

$\Delta V_{\mathrm{H} 2 \mathrm{O}}=V_{\mathrm{t}-2}-V_{\mathrm{t}-1}$

Since the molar amounts of surfactant from near CMC to CMC are the same, the equation below can be obtianed, $c_{\mathrm{s}-1} \times V_{\mathrm{t}-1}=c_{\mathrm{s}-2} \times V_{\mathrm{t}-2}$

The change in $c_{\mathrm{s}}$ from near $\mathrm{CMC}$ to $\mathrm{CMC}$ can be presented as:

$\Delta c_{\mathrm{s}}=c_{\mathrm{s}-2}-c_{\mathrm{s}-1}$, that is,

$c_{\mathrm{s}-1}=c_{\mathrm{s}-2}-\Delta c_{\mathrm{s}}=\mathrm{CMC}-\Delta c_{\mathrm{s}}$

Replace the $c_{\mathrm{s}-1}$ and $c_{\mathrm{s}-2}$ in equation (2) with $\left[c_{\mathrm{s}-2}-\Delta c_{\mathrm{s}}\right]$ and CMC, respectively, then, equation (2) can be changed as:

$\left(\mathrm{CMC}-\Delta c_{\mathrm{s}}\right) \times V_{\mathrm{t}-1}=\mathrm{CMC} \times V_{\mathrm{t}-2}$, that is,

$\operatorname{CMC}\left(V_{\mathrm{t}-2}-V_{\mathrm{t}-1}\right)=-\Delta c_{\mathrm{s}} \times V_{\mathrm{t}-1}$

Since $V_{\mathrm{t}-2}-V_{\mathrm{t}-1}=\Delta V_{\mathrm{H} 2 \mathrm{O}}$, the above equation can be changed as:

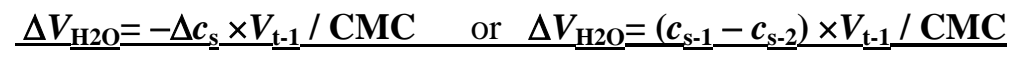

Since $c_{\text {micelle }}=\left(c_{\mathrm{s}-\mathrm{CMC}}\right) / N_{\mathrm{ag}}$, the $c_{\text {micelle-1 }}$ can be presented as:

$c_{\text {micelle- } 1}=\left(c_{\mathrm{s}-1}-\mathrm{CMC}\right) / N_{\mathrm{ag}-1}$ 
Since $c_{\mathrm{s}-1}-\mathrm{CMC}=c_{\mathrm{s}-1}-c_{\mathrm{s}-2}=-\Delta c_{\mathrm{s}}$, replacing the $\left(c_{\mathrm{s}-1}-\mathrm{CMC}\right)$ in equation (5) with $-\Delta c_{\mathrm{s}}$, the equation below can be obtained:

$\underline{-\Delta c_{\mathrm{s}}} \underline{\underline{ }} \underline{\underline{m i c e l l e}-1}_{\underline{X}} \underline{N_{\mathrm{ag}-1}}$

Replace the $-\Delta c_{\mathrm{s}}$ in equation (4) with $\left[c_{\text {micelle-1 }} \times N_{\mathrm{ag}-1}\right]$, then, equation (4) can be changed as:

$$
\underline{\Delta V_{\mathrm{H} 2 \mathrm{O}}}=c_{\text {micelle- } 1} \underline{\times N_{\mathrm{ag}-1}} \times \underline{V_{\mathrm{t}-1}} \underline{/ \mathrm{CMC}}
$$

According to CMC titration mechanism, $c_{\text {micelle-1 }}$ depends on the indicator concentration $\left(c_{\text {ind-1 }}\right)$ near CMC, that is, the higher the $c_{\text {ind-1 }}$ (slighty higher than $c_{\text {ind-2) }}$ ) is, the higher the $c_{\text {micelle-1 }}$ is. For THP-T1, $c_{\text {ind-2 }}=c_{\text {THP }}^{\prime}$ (only about $1 \mu \mathrm{M}$ for zwitterionic surfactants and $2.5 \mu \mathrm{M}$ for other kinds of surfactants, see the later section of General concentration of THP-T1 for CMC determination).

\section{CMC determination of cationic CTAB by titration and fluorescence methods using THP-T1 as probe}

As shown in Table $\mathrm{S} 2$, the screen of the concentration $\left(c_{\mathrm{CTAB}}\right)$ of CTAB in initial titrated solution indicates that the suitable $c_{\text {СТАВ }}$ is $\geq 4 \mathrm{mM}$, at which the titrated CMC value of CTAB is $(0.80 \pm 0.02 \mathrm{mM})$. As shown in Table $\mathrm{S} 3$, the suitable $c_{\mathrm{THP}}$ is $11-15 \mu \mathrm{M}\left(c_{\mathrm{THP}}^{\prime}=2.2-3.1 \mu \mathrm{M}\right)$, at which the titrated $\mathrm{CMC}$ value of CTAB $(0.82 \pm 0.01 \mathrm{mM})$ is almost the same as that $(0.81 \pm 0.01 \mathrm{mM})$ determined by fluorometric method (Figure $\mathrm{S} 8$ ).

Table S2. Influence of CTAB concentration on titrated CMC

\begin{tabular}{|c|c|c|c|c|c|c|c|c|}
\hline Entry & $\begin{array}{l}V_{\mathrm{CTAB}}{ }^{a} \\
/ \mathrm{mL}\end{array}$ & $\begin{array}{l}c_{\mathrm{CTAB}} \\
/ \mathrm{mM}\end{array}$ & $\begin{array}{l}V_{\mathrm{THP}}^{b} \\
/ \mu \mathrm{L}\end{array}$ & $\begin{array}{l}c_{\mathrm{THP}}{ }^{c} \\
/ \mu \mathrm{M}\end{array}$ & $\begin{array}{l}V_{\mathrm{H} 2 \mathrm{O}}^{d} \\
/ \mathrm{mL}\end{array}$ & $\begin{array}{l}V_{\mathrm{H} 2 \mathrm{O}}^{\prime} \\
/ \mathrm{mL}\end{array}$ & $\begin{array}{l}c^{\prime}{ }_{\mathrm{THP}}^{f} \\
/ \mu \mathrm{M}\end{array}$ & $\begin{array}{l}\mathrm{CMC}^{g} \\
/ \mathrm{mM}\end{array}$ \\
\hline 1 & 1 & 4 & 12 & 12 & $3.69 \pm 0.02$ & $3.91 \pm 0.03$ & 2.43 & $0.81 \pm 0.01$ \\
\hline 2 & 0.8 & 5 & 12 & 12 & $3.88 \pm 0.03$ & $4.11 \pm 0.02$ & 2.43 & $0.81 \pm 0.01$ \\
\hline 3 & 0.4 & 10 & 12 & 12 & $4.40 \pm 0.02$ & $4.58 \pm 0.02$ & 2.40 & $0.80 \pm 0.01$ \\
\hline 4 & 0.2 & 20 & 12 & 12 & $4.74 \pm 0.04$ & $4.93 \pm 0.03$ & 2.34 & $0.78 \pm 0.01$ \\
\hline
\end{tabular}

${ }^{a}$ Volume of concentrated CTAB solution with different concentration $\left(c_{\mathrm{CTAB}}\right)$ but the same amount of CTAB $(4 \mu \mathrm{mol})$ : $V_{\mathrm{CTAB}} \times c_{\mathrm{CTAB}}=4 \mu \mathrm{mol} .{ }^{b}$ Volume of THP-T1 stock solution $(1 \mathrm{mM})$ in concentrated CTAB solution. ${ }^{c}$ Concentration of THP-T1 in CTAB titrated solution with concentration equal to $4 \mathrm{mM} .{ }^{d}$ Volume of added water near titrating end point. ${ }^{e}$ Volume of added water at titrating end point. ${ }^{f}$ Concentration of THP-T1 in CTAB titration-end-point solution. ${ }^{g} \mathrm{CMC}$ $(\mathrm{mM})=c_{\mathrm{CTAB}} \times V_{\mathrm{CTAB}} /\left(V_{\mathrm{CTAB}}+V_{\mathrm{H} 2 \mathrm{O}}^{\prime}\right)$.

Table S3. Screen of the concentration of THP-T1 in CTAB titrated solution (4 mM) 


\begin{tabular}{|c|c|c|c|c|c|c|c|c|}
\hline Entry & $\begin{array}{l}V_{\mathrm{CTAB}}{ }^{a} \\
/ \mathrm{mL}\end{array}$ & $\begin{array}{l}V_{\mathrm{THP}}^{b} \\
/ \mu \mathrm{L}\end{array}$ & $\begin{array}{l}c_{\mathrm{THP}}{ }^{c} \\
/ \mu \mathrm{M}\end{array}$ & $\begin{array}{l}V_{\mathrm{H} 2 \mathrm{O}}^{d} \\
/ \mathrm{mL}\end{array}$ & $\begin{array}{l}V_{\mathrm{H} 2 \mathrm{O}}^{e} \\
/ \mathrm{mL}\end{array}$ & $\begin{array}{l}c^{\prime}{ }_{\mathrm{THP}}^{f} \\
/ \mu \mathrm{M}\end{array}$ & $\begin{array}{l}\mathrm{CMC}^{g} \\
/ \mathrm{mM}\end{array}$ & $\begin{array}{l}\mathrm{CMC}^{h} \\
/ \mathrm{mM}\end{array}$ \\
\hline $1^{i}$ & 1 & 10 & 10 & & & & & \\
\hline 2 & 1 & 11 & 11 & $3.80 \pm 0.02$ & $3.96 \pm 0.02$ & 2.22 & $0.81 \pm 0.01$ & $0.80 / 0.81$ \\
\hline 3 & 1 & 12 & 12 & $3.69 \pm 0.02$ & $3.91 \pm 0.03$ & 2.43 & $0.81 \pm 0.01$ & \\
\hline 4 & 1 & 15 & 15 & $3.62 \pm 0.01$ & $3.82 \pm 0.02$ & 3.11 & $0.83 \pm 0.01$ & \\
\hline 5 & 1 & 20 & 20 & $3.23 \pm 0.03$ & $3.64 \pm 0.05$ & 4.30 & $0.86 \pm 0.01$ & \\
\hline
\end{tabular}

${ }^{a}$ Volume of concentrated CTAB solution (4 mM). ${ }^{b}$ Volume of THP-T1 stock solution (1 mM). ${ }^{c}$ Concentration of THP$\mathrm{T} 1$ in initial CTAB titrated solution. ${ }^{d}$ Volume of added water near titrating end point. ${ }^{e}$ Volume of added water at titrating end point. ${ }^{f}$ Concentration of THP-T1 in CTAB titration-end-point solution. ${ }^{g} \mathrm{CMC}(\mathrm{mM})=c_{\mathrm{CTAB}} \times V_{\mathrm{CTAB}} /$ $\left(V_{\mathrm{CTAB}}+V_{\mathrm{H} 2 \mathrm{O}}^{\prime}\right)=4 \times 1 /\left(1+V_{\mathrm{H} 2 \mathrm{O}}^{\prime}\right) .{ }^{h} \mathrm{CMC}$ value determined from samples kept $0 / 30 \mathrm{~min}$ prepared as our previous reported fluorescence method ${ }^{[3]}$ with the same concentration of CTAB $(4 \mathrm{mM})$ and $c_{\mathrm{THP}}$ as titration method. ${ }^{i}$ THP-T1 showed emission till it was kept for 30 min after titrating end point.
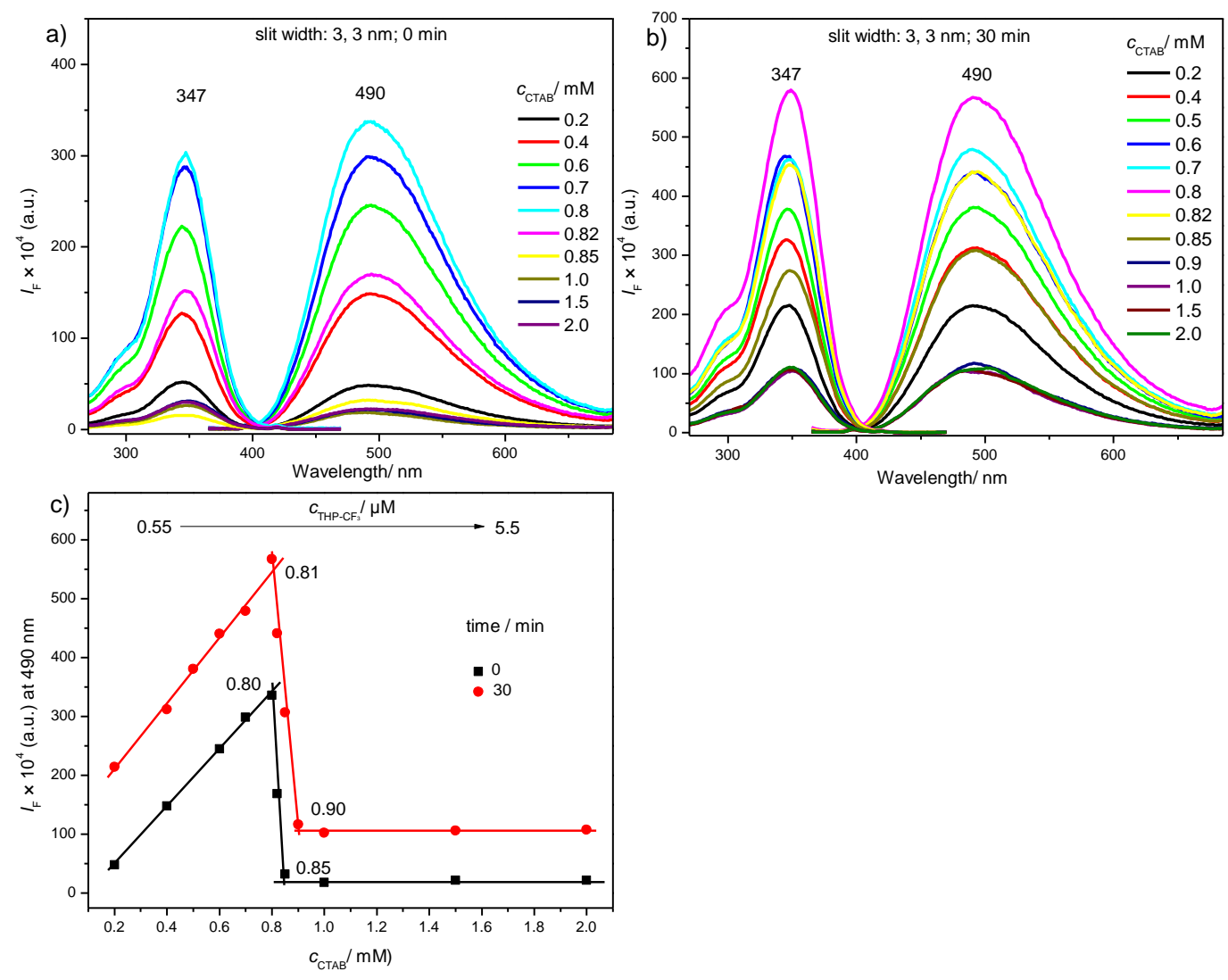

Figure S8. a) and b) Excitation (left) and emission (right) spectra of THP-T1 in samples kept 0 and 30 min, respectively. The concentration of CTAB from 0.2 to $2 \mathrm{mM}$ and the concentration of THP-T1 from 0.55 to $5.5 \mu \mathrm{M}$. 
Emitted and excited at peaks marked in excitation and emission spectra, respectively. c) The relationship between the fluorescence intensity at emission peak of THP-T1 and the concentration of CTAB in samples kept 0 and 30 min, respectively.

\section{CMC determination of zwitterionic surfactant BS-12 by titration and fluorescence methods using THP-T1 as probe}

The screen of the concentration of BS-12 in initial titrated solution shows that the suitable concentration of BS-12 is $\geq$ $20 \mathrm{mM}$ (Table S4). Similar to SDS, the titrated CMC value of BS-12 increases with $c_{\mathrm{THP}}$ (Table S5). To identify actual $\mathrm{CMC}$ value and suitable $c_{\mathrm{THP}}$, the CMC value of BS-12 was determined by our previous reported fluorometric method. ${ }^{[2-3]}$ The samples for fluorescence measurement were prepared by diluting concentrated BS-12 solution (20 $\mathrm{mM}$ ) containing 8/14/20 $\mu \mathrm{M}$ of THP-T1 and kept for 0 and $30 \mathrm{~min}$ (Figures S9-S11). As shown in Table S5, also similar to SDS, the CMC values of BS-12 determined from samples kept 0 min with different $c_{\mathrm{THP}}(8-20 \mu \mathrm{M})$ are similar (2.31-2.53 mM) and the CMC value determined from samples kept 30 min changes from 3.21 to $2.56 \mathrm{mM}$ with $c_{\mathrm{THP}}$ when $c_{\mathrm{THP}}$ is relative low $(8-14 \mu \mathrm{M})$ but does not change $(\mathrm{CMC}=2.54 \pm 0.04 \mathrm{mM})$ when $c_{\mathrm{THP}}$ is relative high $(14-20 \mu \mathrm{M})$ (Table S5). Therefore, for the fluorometric method, the suitable $c_{\mathrm{THP}}$ is $8-20 \mu \mathrm{M}\left(c_{\mathrm{THP}}^{\prime}=1-3.3 \mu \mathrm{M}\right)$ for samples kept $0 \mathrm{~min}$ and $14-20 \mu \mathrm{M}\left(c^{\prime}{ }_{\mathrm{THP}}=2.2-3.3 \mu \mathrm{M}\right)$ for samples kept $30 \mathrm{~min}$. For the titration method, the suitable $c_{\mathrm{THP}}$ is $8-12 \mu \mathrm{M}\left(c^{\prime}{ }_{\mathrm{THP}}=0.96-1.72 \mu \mathrm{M}\right)$, at which the titrated $\mathrm{CMC}(2.67 \pm 0.25 \mathrm{mM})$ is similar to that $(2.52$ $\pm 0.04 \mathrm{mM}$ ) determined by fluorometric method with suitable $c_{\mathrm{THP}}$.

Table S4. Influence of BS-12 concentration on titrated CMC

\begin{tabular}{lllllllll}
\hline Entry & $\begin{array}{l}V_{\mathrm{BS}-12}{ }^{a} \\
/ \mathrm{mL}\end{array}$ & $\begin{array}{c}c_{\mathrm{BS}-12} \\
/ \mathrm{mM}\end{array}$ & $\begin{array}{l}V_{\mathrm{THP}}{ }^{b} \\
/ \mu \mathrm{L}\end{array}$ & $\begin{array}{l}c_{\mathrm{THP}}{ }^{c} \\
/ \mu \mathrm{M}\end{array}$ & $\begin{array}{l}V_{\mathrm{H} 2 \mathrm{O}^{d}} \\
/ \mathrm{mL}\end{array}$ & $\begin{array}{l}V^{\prime}{ }^{2}{ }^{e} \\
/ \mathrm{mL}\end{array}$ & $\begin{array}{l}c^{\prime}{ }^{f} \\
/ \mu \mathrm{M}\end{array}$ & $\begin{array}{l}\mathrm{CMC}^{g} \\
1 \mathrm{mM}\end{array}$ \\
\hline 1 & 0.5 & 10 & 3 & 6 & $1.53 \pm 0.02$ & $1.62 \pm 0.02$ & 1.42 & $2.36 \pm 0.02$ \\
3 & 0.5 & 20 & 6 & 6 & $2.88 \pm 0.03$ & $3.00 \pm 0.01$ & 1.71 & $2.86 \pm 0.01$ \\
3 & 0.5 & 25 & 7.5 & 6 & $3.71 \pm 0.02$ & $3.81 \pm 0.01$ & 1.74 & $2.90 \pm 0.01$ \\
\hline
\end{tabular}

${ }^{a}$ Volume of concentrated BS-12 solution with different concentration $\left(c_{\mathrm{BS}-12}\right) .{ }^{b}$ Volume of THP-T1 stock solution (1 $\mathrm{mM})$ in concentrated BS-12 titrated solution: $V_{\mathrm{THP}} \times 1 \mathrm{mM}=\left(0.5 \mathrm{~mL} \times c_{\mathrm{BS}-12} / 10 \mathrm{mM}\right) \times 6 \mu \mathrm{M}$. ${ }^{c}$ Concentration of THPT1 in BS-12 titrated solution with concentration equal to $10 \mathrm{mM} .{ }^{d}$ Volume of added water near titrating end point. ${ }^{e}$ Volume of added water at titrating end point. ${ }^{f}$ Concentration of THP-T1 in BS-12 titration-end-point solution. ${ }^{g} \mathrm{CMC}$ $(\mathrm{mM})=c_{\mathrm{BS}-12} \times V_{\mathrm{BS}-12} /\left(V_{\mathrm{BS}-12}+V_{\mathrm{H} 2 \mathrm{O}}^{\prime}\right)=c_{\mathrm{BS}-12} \times 0.5 /\left(0.5+V_{\mathrm{H} 2 \mathrm{O}}^{\prime}\right)$.

Table S5. Screen of the concentration of THP-T1 in BS-12 titrated solution (20 mM)

\begin{tabular}{lllllllll}
\hline & $V_{\mathrm{BS}-12}{ }^{a}$ & $V_{\mathrm{THP}}{ }^{b}$ & $c_{\mathrm{THP}}{ }^{c}$ & $V_{\mathrm{H} 2 \mathrm{O}}{ }^{d}$ & $V_{\mathrm{H} 2 \mathrm{O}}{ }^{e}$ & $c^{\prime}{ }^{f}{ }^{f}$ & $\mathrm{CMC}^{g}$ & $\mathrm{CMC}^{h}$ \\
& $/ \mathrm{mL}$ & $/ \mu \mathrm{L}$ & $/ \mu \mathrm{M}$ & $/ \mathrm{mL}$ & $/ \mathrm{mL}$ & $/ \mu \mathrm{M}$ & $/ \mathrm{mM}$ & $/ \mathrm{mM}$ \\
\hline $1^{i}$ & 0.5 & 3 & 6 & & & & &
\end{tabular}




$\begin{array}{ccccccccc}2 & 0.5 & 4 & 8 & 3.56 \pm 0.01 & 3.68 \pm 0.03 & 0.96 & 2.39 \pm 0.01 & 2.31 / 3.21 \\ 3 & 0.5 & 5 & 10 & 2.98 \pm 0.03 & 3.11 \pm 0.02 & 1.39 & 2.77 \pm 0.01 & \\ 4 & 0.5 & 6 & 12 & 2.88 \pm 0.03 & 3.00 \pm 0.01 & 1.72 & 2.86 \pm 0.01 & \\ 5 & 0.5 & 7 & 14 & 2.53 \pm 0.03 & 2.72 \pm 0.02 & 2.18 & 3.11 \pm 0.02 & 2.47 / 2.56 \\ 6 & 0.5 & 7.8 & 15.6 & 2.45 \pm 0.02 & 2.63 \pm 0.02 & 2.49 & 3.19 \pm 0.02 & \\ 7 & 0.5 & 8 & 16 & 2.37 \pm 0.02 & 2.56 \pm 0.01 & 2.62 & 3.27 \pm 0.01 & \\ 8 & 0.5 & 9 & 18 & 2.38 \pm 0.02 & 2.52 \pm 0.03 & 2.98 & 3.31 \pm 0.03 & \\ 9 & 0.5 & 10 & 20 & 2.33 \pm 0.03 & 2.51 \pm 0.02 & 3.33 & 3.33 \pm 0.02 & 2.53 / 2.51 \\ 10 & 0.5 & 11 & 22 & 2.20 \pm 0.02 & 2.36 \pm 0.02 & 3.85 & 3.50 \pm 0.02 & \\ 11^{j} & 0.5 & 12 & 24 & & & & \end{array}$

${ }^{a}$ Volume of concentrated BS-12 solution (20 mM). ${ }^{b}$ Volume of THP-T1 stock solution (1 mM) in concentrated BS-12 solution. ${ }^{c}$ Concentration of THP-T1 in initial BS-12 titrated solution: $c_{\mathrm{THP}}=\left(V_{\mathrm{THP}} \times 1 \mathrm{mM}\right) / 0.5 \mathrm{~mL} .{ }^{d}$ Volume of added water near titrating end point. ${ }^{e}$ Volume of added water at titrating end point. ${ }^{f}$ Concentration of THP-T1 in BS-12 titration-end-point solution. ${ }^{g} \mathrm{CMC}(\mathrm{mM})=c_{\mathrm{BS}-12} \times V_{\mathrm{BS}-12} /\left(V_{\mathrm{BS}-12}+V_{\mathrm{H} 2 \mathrm{O}}^{\prime}\right)=20 \times 0.5 /\left(0.5+V_{\mathrm{H} 2 \mathrm{O}}^{\prime}\right) .{ }^{h} \mathrm{CMC}$ value determined from samples kept $0 / 30$ min prepared as our previous reported fluorescence method ${ }^{[3]}$ with the same concentration of BS-12 (20 mM) and $c_{\mathrm{THP}}$ as titration method. ${ }^{i}$ The fluorescence of THP-T1 at titrating end point is too weak to be observed. ${ }^{j}$ THP-T1 aggregates in initial BS-12 titrated solution. 

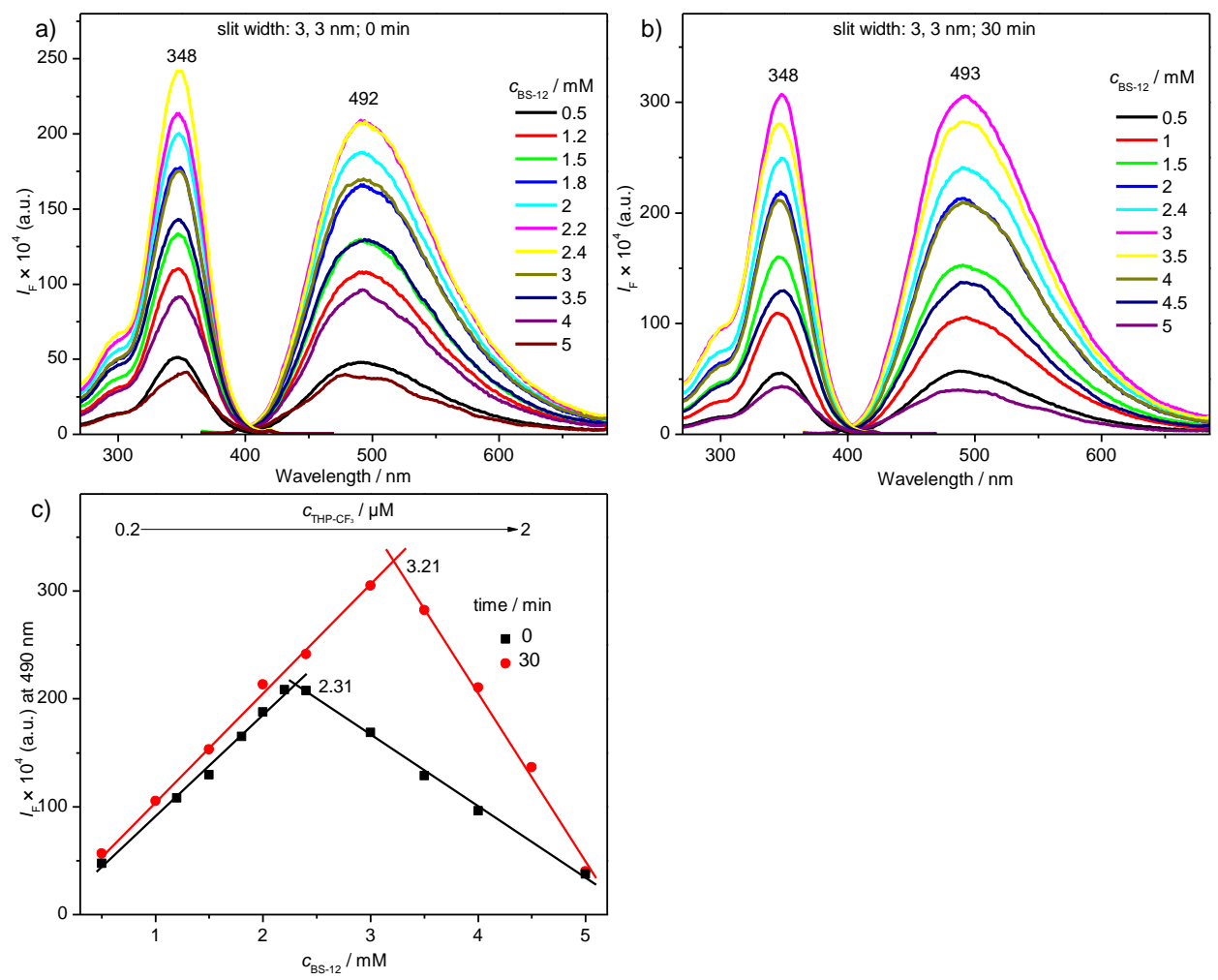

Figure S9. a) and b) Excitation (left) and emission (right) spectra of THP-T1 in samples kept 0 and 30 min, respectively. The concentration of BS-12 from 0.5 to $5 \mathrm{mM}$ and the concentration of THP-T1 from 0.2 to $2 \mu \mathrm{M}$. Emitted and excited at peaks marked in excitation and emission spectra, respectively. c) The relationship between the fluorescence intensity at emission peak of THP-T1 and the concentration of BS-12 in samples kept 0 and 30 min, respectively.
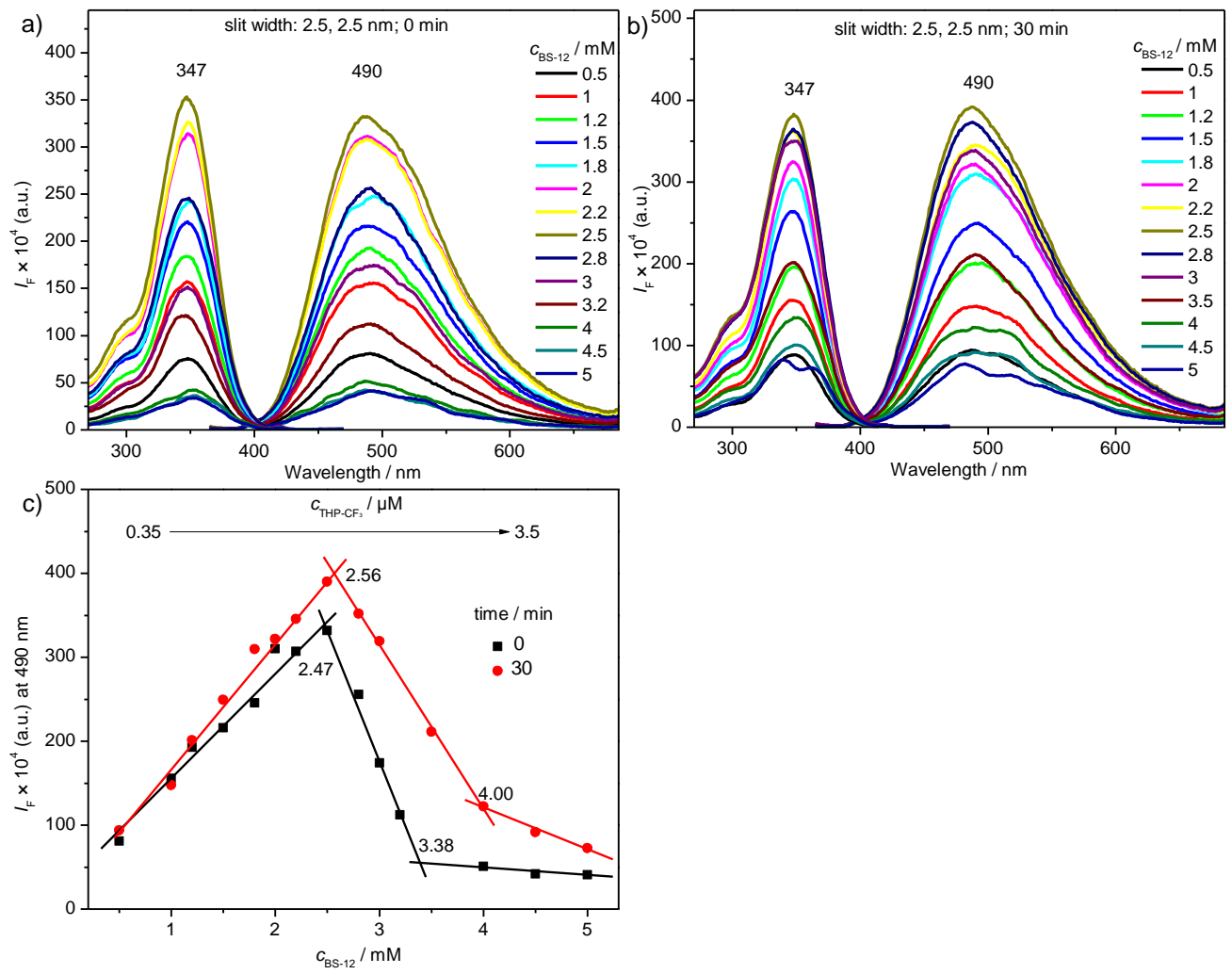
Figure S10. a) and b) Excitation (left) and emission (right) spectra of THP-T1 in samples kept 0 and 30 min, respectively. The concentration of BS-12 from 0.5 to $5 \mathrm{mM}$ and the concentration of THP-T1 from 0.35 to $3.5 \mu \mathrm{M}$. Emitted and excited at peaks marked in excitation and emission spectra, respectively. c) The relationship between the fluorescence intensity at emission peak of THP-T1 and the concentration of BS-12 in samples kept 0 and 30 min, respectively.
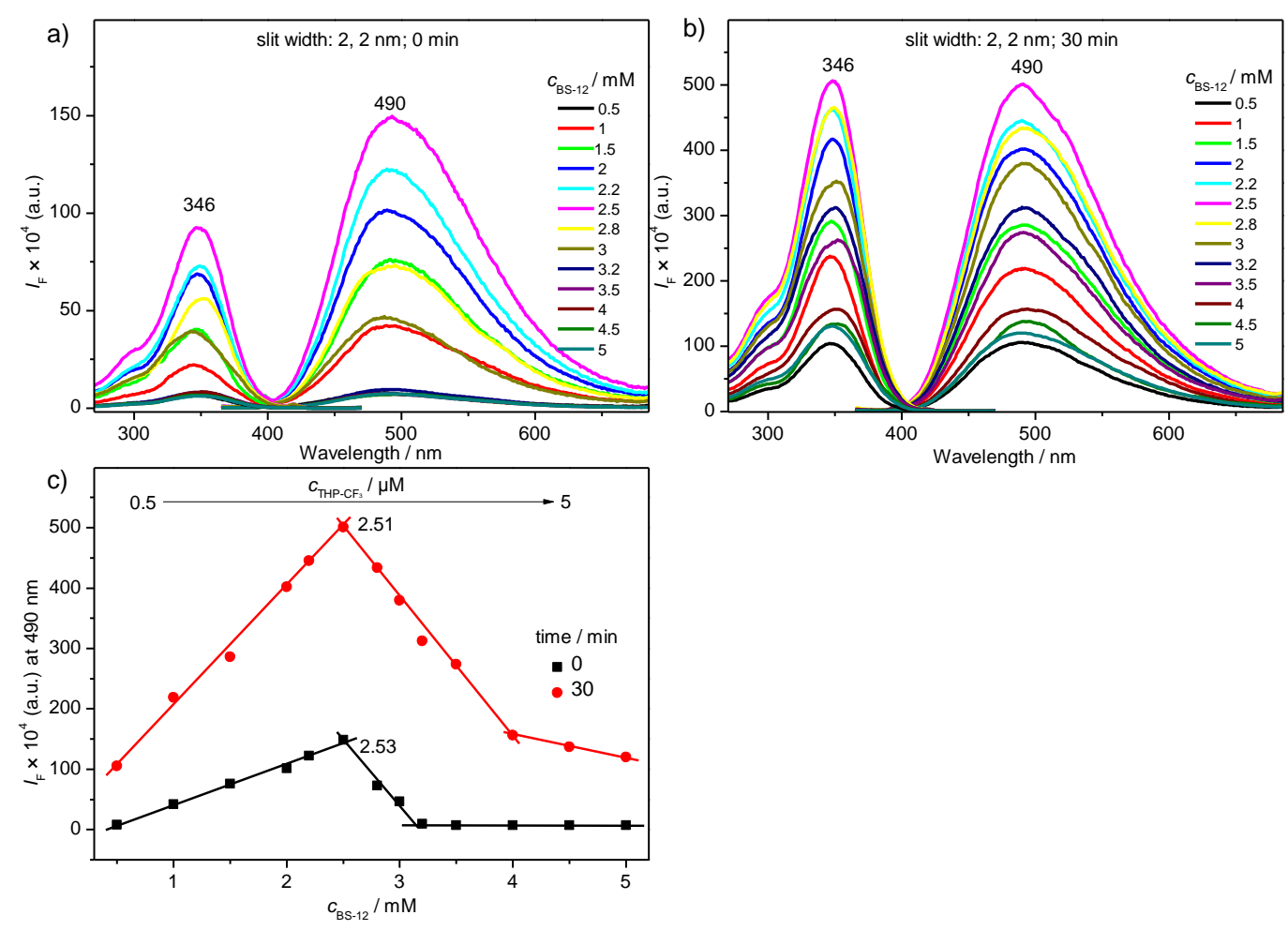

Figure S11. a) and b) Excitation (left) and emission (right) spectra of THP-T1 in samples kept 0 and $30 \mathrm{~min}$, respectively. The concentration of BS-12 from 0.5 to $5 \mathrm{mM}$ and the concentration of THP-T1 from 0.5 to $5 \mu \mathrm{M}$. Emitted and excited at peaks marked in excitation and emission spectra, respectively. c) The relationship between the fluorescence intensity at emission peak of THP-T1 and the concentration of BS-12 in samples kept 0 and 30 min, respectively.

\section{CMC determination of nonionic surfactant Triton X-100 by titration and fluorescence methods using THP-T1} as probe

The screen of the concentration ( $c_{\text {triton }}$ ) of Triton X-100 in initial titrated solution shows that the suitable $c_{\text {triton }}$ is $\geq 5$ $\mathrm{mM}$ (Table S6), at which the titrated CMC of Triton X-100 is $0.27 \pm 0.02 \mathrm{mM}$. Then, we screened the concentration $\left(c_{\mathrm{THP}}\right)$ of THP-T1 in Triton X-100 titrated solution $(5 \mathrm{mM})$. However, THP-T1 could not dissolve when $c_{\mathrm{THP}}$ increased to $40 \mu \mathrm{M}$ (Table S7). Considering that the more micelles is, the larger the solubility of THP-T1 is, the $c_{\mathrm{THP}}$ was screened in $10 \mathrm{mM}$ Triton X-100 solution. As shown in Table $\mathrm{S} 8$, when $c_{\text {triton }}$ increases from 5 to $10 \mathrm{mM}, c_{\mathrm{THP}}$ value increases from 40 to $120 \mu \mathrm{M}$. Since the titrated CMC value $(0.20$ to $0.34 \mathrm{mM})$ of Triton X-100 increases with $c_{\text {triton }}$, the CMC value of Triton X-100 was determined by fluorometric method ${ }^{[2-3]}$ using different concentrations of THP-T1 (Figure S12-S14) to confirm the actual CMC value and suitable $c_{\mathrm{THP}}$. Similar to SDS, the CMC value of Triton X-100 
relates to time and $c_{\mathrm{THP}}$ at relative low $c_{\mathrm{THP}}(<1 \mu \mathrm{M})$ but is independent of time and $c_{\mathrm{THP}}$ at relative high $c_{\mathrm{THP}}(>1.7$

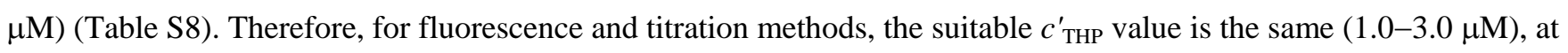
which the CMC values of Triton X-100 determined by fluorometric method and titration are $0.30 \mathrm{mM}$ and $0.28 \pm 0.02$ $\mathrm{mM}$, respectively.

Table S6. Influence of Triton X-100 concentration on titrated CMC

\begin{tabular}{llllllllll}
\hline Entry & $V_{\text {Triton }}{ }^{a}$ & $c_{\text {Triton }}$ & $V_{\mathrm{THP}}{ }^{b}$ & $c_{\mathrm{THP}}{ }^{c}$ & $V_{\mathrm{H} 2 \mathrm{O}}{ }^{d}$ & $V_{\mathrm{H} 2 \mathrm{O}}{ }^{e}$ & $c^{\prime}{ }^{\prime}$ & $\mathrm{CMC}^{g}$ \\
& $/ \mathrm{mL}$ & $/ \mathrm{mM}$ & $/ \mu \mathrm{L}$ & $/ \mu \mathrm{M}$ & $/ \mathrm{mL}$ & $/ \mathrm{mL}$ & $/ \mathrm{mM}$ \\
\hline 1 & 0.25 & 5 & 5 & 20 & $3.63 \pm 0.04$ & $4.05 \pm 0.03$ & 1.16 & 0.29 \\
2 & 0.1 & 10 & 4 & 20 & $3.77 \pm 0.02$ & $3.98 \pm 0.03$ & 1.00 & 0.25 \\
\hline
\end{tabular}

${ }^{a}$ Volume of concentrated Triton X-100 solution with different concentration $\left(c_{\text {Triton }}\right)$. ${ }^{b}$ Volume of THP-T1 stock solution $(1 \mathrm{mM})$ in concentrated Triton $\mathrm{X}-100$ solution: $V_{\mathrm{THP}} \times 1 \mathrm{mM}=\left(V_{\text {Triton }} \mathrm{mL} \times c_{\text {Triton }} / 5 \mathrm{mM}\right) \times 20 \mu \mathrm{M}$. ${ }^{c}$ Concentration of THP-T1 in Triton X-100 titrated solution with concentration equal to 5 mM. ${ }^{d}$ Volume of added water near titrating end point. ${ }^{e}$ Volume of added water at titrating end point. ${ }^{f}$ Concentration of THP-T1 in Triton X100 titration-end-point solution. ${ }^{g} \mathrm{CMC}(\mathrm{mM})=c_{\text {Triton }} \times V_{\text {Triton }} /\left(V_{\text {Triton }}+V_{\mathrm{H} 2 \mathrm{O}}^{\prime}\right)$. 
Table S7. Screen of the concentration of THP-T1 in Triton X-100 titrated solution (5 mM)

\begin{tabular}{|c|c|c|c|c|c|c|c|}
\hline Entry & $\begin{array}{l}V_{\text {Triton }}^{a} \\
/ \mathrm{mL}\end{array}$ & $\begin{array}{l}V_{\mathrm{THP}}^{b} \\
/ \mu \mathrm{L}\end{array}$ & $\begin{array}{l}c_{\mathrm{THP}}{ }^{c} \\
/ \mu \mathrm{M}\end{array}$ & $\begin{array}{l}V_{\mathrm{H} 2 \mathrm{O}}^{d} \\
/ \mathrm{mL}\end{array}$ & $\begin{array}{l}V_{\mathrm{H} 2 \mathrm{O}}^{\prime}{ }^{e} \\
/ \mathrm{mL}\end{array}$ & $\begin{array}{l}c_{\mathrm{THP}}^{\prime} \\
/ \mu \mathrm{M}\end{array}$ & $\begin{array}{l}\mathrm{CMC}^{g} \\
/ \mathrm{mM}\end{array}$ \\
\hline $1^{h}$ & 0.25 & 1.25 & 5 & & & & \\
\hline 2 & 0.25 & 2.5 & 10 & $3.79 \pm 0.03$ & $4.36 \pm 0.05$ & 0.54 & 0.27 \\
\hline 3 & 0.25 & 5 & 20 & $3.63 \pm 0.04$ & $4.05 \pm 0.03$ & 1.16 & 0.29 \\
\hline 4 & 0.25 & 7.5 & 30 & $3.02 \pm 0.02$ & $3.50 \pm 0.01$ & 1.98 & 0.33 \\
\hline $5^{i}$ & 0.25 & 10 & 40 & & & & \\
\hline
\end{tabular}

${ }^{a}$ Volume of concentrated Triton X-100 solution $(5 \mathrm{mM}) .{ }^{b}$ Volume of THP-T1 stock solution $(1 \mathrm{mM})$ in concentrated Triton X-100 solution. ${ }^{c}$ Concentration of THP-T1 in initial Triton X-100 titrated solution: $c_{\mathrm{THP}}=\left(V_{\mathrm{THP}} \times 1 \mathrm{mM}\right) / 0.25$ mL. ${ }^{d}$ Volume of added water near titrating end point. ${ }^{e}$ Volume of added water at titrating end point. ${ }^{f}$ Concentration of THP-T1 in Triton X-100 titration-end-point solution. ${ }^{g} \mathrm{CMC}(\mathrm{mM})=c_{\text {Triton }} \times V_{\text {Triton }} /\left(V_{\text {Triton }}+V_{\mathrm{H} 2 \mathrm{O}}^{\prime}\right)=5 \times 0.25 /(0.25+$ $\left.V_{\mathrm{H} 2 \mathrm{O}}^{\prime}\right) .{ }^{h}$ The fluorescence of THP-T1 at titrating end point is too weak to be observed. ${ }^{i}$ THP-T1 aggregates in initial Triton X-100 titrated solution.

Table S8. Screen of the concentration of THP-T1 in Triton X-100 titrated solution (10 mM)

\begin{tabular}{|c|c|c|c|c|c|c|c|c|}
\hline Entry & $\begin{array}{l}V_{\text {Triton }}^{a} \\
/ \mathrm{mL}\end{array}$ & $\begin{array}{l}V_{\mathrm{THP}}^{b} \\
/ \mu \mathrm{L}\end{array}$ & $\begin{array}{l}c_{\mathrm{THP}}{ }^{c} \\
/ \mu \mathrm{M}\end{array}$ & $\begin{array}{l}V_{\mathrm{H} 2 \mathrm{O}}^{d} \\
/ \mathrm{mL}\end{array}$ & $\begin{array}{l}V_{\mathrm{H} 2 \mathrm{O}}^{\prime} \\
/ \mathrm{mL}\end{array}$ & $\begin{array}{l}c_{\mathrm{THP}}^{\prime} \\
/ \mu \mathrm{M}\end{array}$ & $\begin{array}{l}\mathrm{CMC}^{g} \\
/ \mathrm{mM}\end{array}$ & $\begin{array}{l}\mathrm{CMC}^{h} \\
/ \mathrm{mM}\end{array}$ \\
\hline 1 & 0.1 & 2 & 20 & $4.69 \pm 0.04$ & $4.89 \pm 0.02$ & 0.40 & 0.20 & $0.19 / 0.25$ \\
\hline 2 & 0.1 & 4 & 40 & $3.77 \pm 0.02$ & $3.98 \pm 0.03$ & 1.00 & 0.25 & \\
\hline 3 & 0.1 & 6 & 60 & $3.30 \pm 0.02$ & $3.46 \pm 0.01$ & 1.68 & 0.28 & $-/ 0.30$ \\
\hline 4 & 0.1 & 8 & 80 & $3.24 \pm 0.04$ & $3.42 \pm 0.02$ & 2.24 & 0.28 & \\
\hline 5 & 0.1 & 10 & 100 & $2.96 \pm 0.05$ & $3.27 \pm 0.04$ & 3.00 & 0.30 & $0.30 / 0.30$ \\
\hline 6 & 0.1 & 12 & 120 & $2.31 \pm 0.06$ & $2.85 \pm 0.05$ & 4.08 & 0.34 & \\
\hline $7^{i}$ & 0.1 & 15 & 150 & & & & & \\
\hline
\end{tabular}

${ }^{a}$ Volume of concentrated Triton X-100 solution (10 mM). ${ }^{b}$ Volume of THP-T1 stock solution $(1 \mathrm{mM})$ in concentrated Triton X-100 solution. ${ }^{c}$ Concentration of THP-T1 in initial Triton X-100 titrated solution: $c_{\mathrm{THP}}=\left(V_{\mathrm{THP}} \times 1 \mathrm{mM}\right) / 0.1$ $\mathrm{mL} .{ }^{d}$ Volume of added water near titrating end point. ${ }^{e}$ Volume of added water at titrating end point. ${ }^{f}$ Concentration of THP-T1 in Triton X-100 titration-end-point solution. ${ }^{g} \mathrm{CMC}(\mathrm{mM})=c_{\text {Triton }} \times V_{\text {Triton }} /\left(V_{\text {Triton }}+V_{\mathrm{H} 2 \mathrm{O}}^{\prime}\right)=10 \times 0.1 /(0.1+$ $\left.V_{\mathrm{H} 2 \mathrm{O}}^{\prime}\right) .{ }^{h} \mathrm{CMC}$ value determined from samples kept 0 min prepared as our previous reported fluorescence method ${ }^{[3]}$ 
with the same concentration of Triton X-100 $(10 \mathrm{mM})$ and $c_{\mathrm{THP}}$ as titration method. ${ }^{i}$ THP-T1 aggregates in initial Triton X-100 titrated solution.
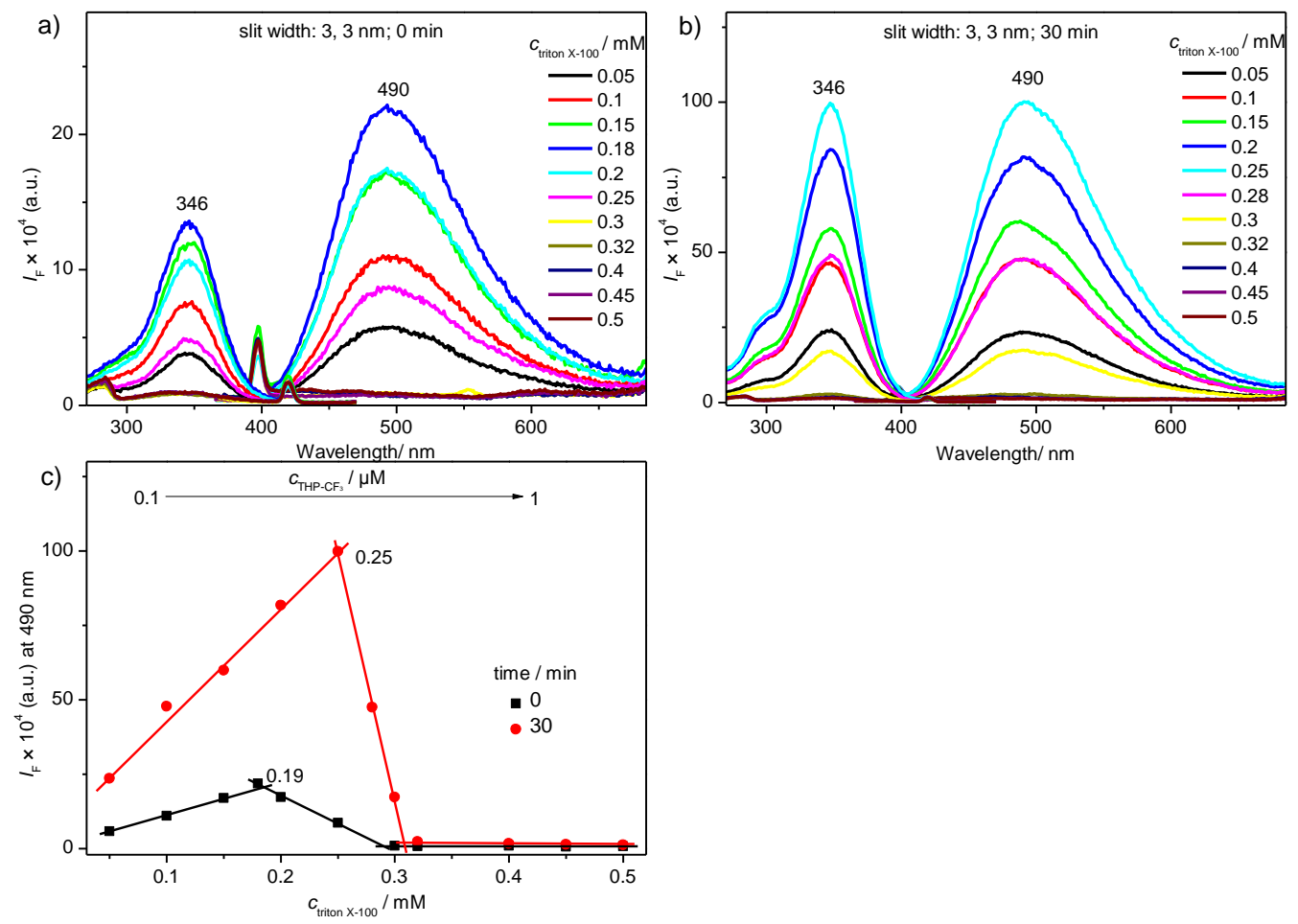

Figure S12. a) and b) Excitation (left) and emission (right) spectra of THP-T1in samples kept 0 and 30 min, respectively. The concentration of Triton X-100 from 0.05 to $0.5 \mathrm{mM}$ and the concentration of THP-T1 from 0.1 to 1 $\mu \mathrm{M}$. Emitted and excited at peaks marked in excitation and emission spectra, respectively. c) The relationship between the fluorescence intensity at emission peak of THP-T1 and the concentration of Triton X-100 in samples kept 0 and 30 min, respectively.
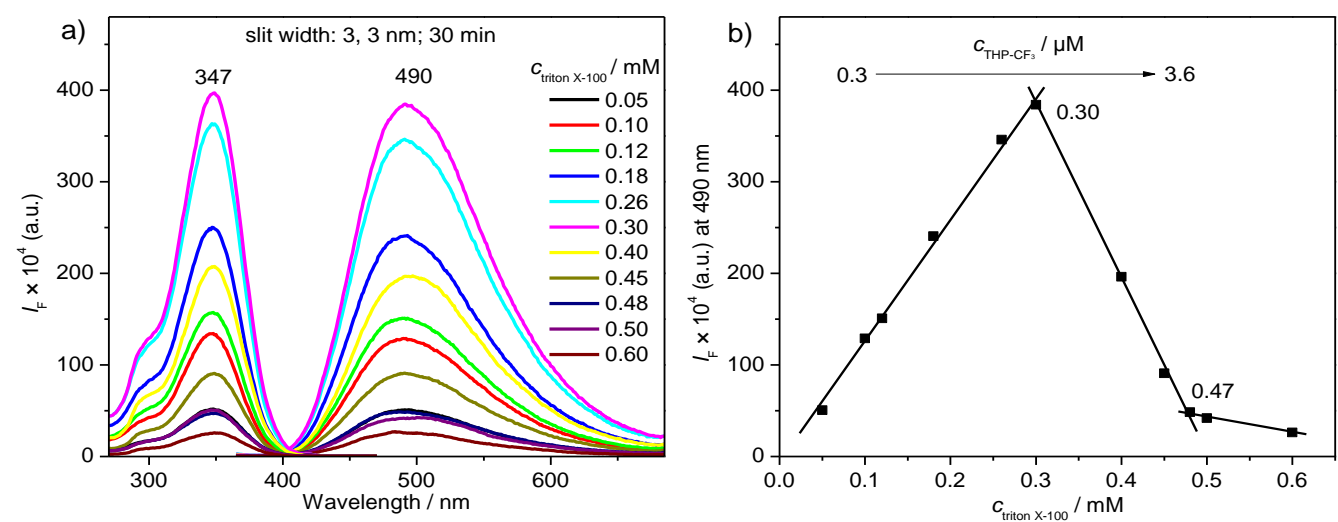

Figure S13. a) Excitation (left) and emission (right) spectra of THP-T1 in Triton X-100 solutions with different concentrations in samples kept $30 \mathrm{~min}$. The concentration of Triton X-100 from 0.05 to $0.6 \mathrm{mM}$ and the concentration of THP-T1 from 0.3 to $3.6 \mu \mathrm{M}$. Emitted and excited at peaks marked in excitation and emission spectra, respectively. 
b) The relationship between the fluorescence intensity at emission peak of THP-T1 and the concentration of Triton X100.
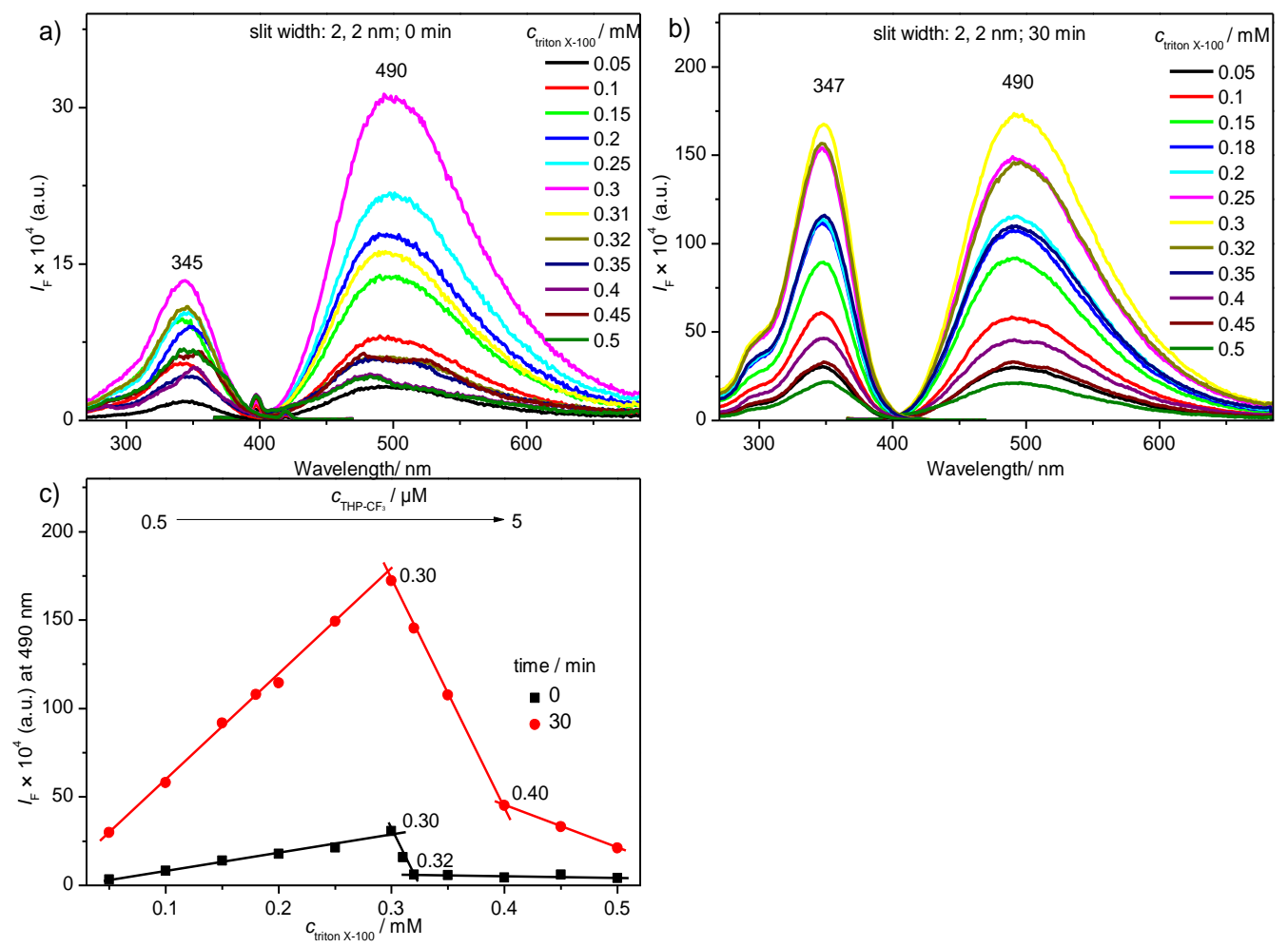

Figure S14. a) and b) Excitation (left) and emission (right) spectra of THP-T1 in samples kept 0 and 30 min, respectively. The concentration of Triton X-100 from 0.05 to $0.5 \mathrm{mM}$ and the concentration of THP-T1 from 0.5 to 5 $\mu \mathrm{M}$. Emitted and excited at peaks marked in excitation and emission spectra, respectively. c) The relationship between the fluorescence intensity at emission peak of THP-T1 and the concentration of Triton X-100 in samples kept 0 and 30 min, respectively.

\section{CMC determination of cationic surfactants with relative high CMC values (DDBAC and DTAC) by titration and fluorescence methods using THP-T1 as probe}

The suitable concentration $\left(c_{\mathrm{DDBAC}}\right)$ of DDBAC initial titrated solution is larger than $30 \mathrm{mM}$ (Table $\mathrm{S} 9$ ) and the

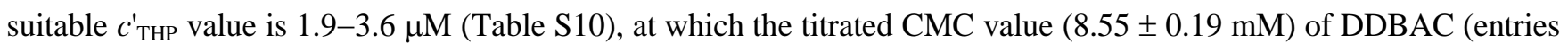
4-6 in Table S10) is almost the same as that $(8.56 \mathrm{mM})$ determined from samples kept 0 min by fluorometric method (Figure S15). The suitable concentration ( $c_{\mathrm{DTAC}}$ ) of DTAC initial titrated solution is larger than $45 \mathrm{mM}$ (Table S11) and the suitable $c_{\text {THP }}^{\prime}$ value is $1.6-3.0 \mu \mathrm{M}$ (Table S12), at which the titrated CMC value $(16.27 \pm 0.23 \mathrm{mM}$ ) of DTAC (entries 2 and 3 in Table S12) is similar to that $(16.41 \pm 0.19 \mathrm{mM})$ determined from samples kept 0 min by fluorometric method (Figure S16 and S17). 
Table S9. Influence of DDBAC concentration on titrated CMC

\begin{tabular}{lllllllll}
\hline Entry & $V_{\mathrm{DDBAC}}{ }^{a}$ & $C_{\mathrm{DDBAC}}{ }^{b}$ & $V_{\mathrm{THP}}{ }^{c}$ & $c_{\mathrm{THP}}{ }^{d}$ & $V_{\mathrm{H} 2 \mathrm{O}}{ }^{e}$ & $V_{\mathrm{H} 2 \mathrm{O}}^{f}$ & $c^{\prime}{ }^{g}$ & $\mathrm{CMC}^{h}$ \\
\hline 1 & 1 & 25 & 7.5 & 9 & $2.00 \pm 0.01$ & $2.11 \pm 0.03$ & 2.41 & $8.03 \pm 0.06$ \\
2 & 0.5 & 30 & 4.5 & 9 & $1.09 \pm 0.03$ & $1.23 \pm 0.03$ & 2.60 & $8.67 \pm 0.13$ \\
3 & 0.5 & 40 & 6 & 9 & $1.63 \pm 0.03$ & $1.82 \pm 0.03$ & 2.59 & $8.62 \pm 0.11$
\end{tabular}

${ }^{a}$ Volume of concentrated DDBAC solution with different concentration $\left(c_{\mathrm{DDBAC}}\right) .{ }^{b}$ Concentration of DDBAC in initial titrated solution. ${ }^{c}$ Volume of THP-T1 stock solution (1 mM) in the DDBAC titrated solution (30 mM) with THP-T1 (9 $\mu \mathrm{M})$ dilute from concentrated DDBAC titrated solution with different volume and concentration ( $V_{\mathrm{DDBAC}}$ and $\left.c_{\mathrm{DDBAC}}\right)$ : $V_{\mathrm{THP}} \times 1 \mathrm{mM}=\left(V_{\mathrm{DDBAC}} \mathrm{mL} \times c_{\mathrm{DDBAC}} / 30 \mathrm{mM}\right) \times 9 \mu \mathrm{M} .{ }^{d}$ Concentration of THP-T1 in DDBAC titrated solution with concentration equal to $30 \mathrm{mM}$. ${ }^{e}$ Volume of added water near titrating end point. ${ }^{f}$ Volume of added water at titrating end point. ${ }^{g}$ Concentration of THP-T1 in DDBAC titration-end-point solution. ${ }^{h} \mathrm{CMC}(\mathrm{mM})=c_{\mathrm{DDBAC}} \times V_{\mathrm{DDBAC}}$ $\left(V_{\mathrm{DDBAC}}+V_{\mathrm{H} 2 \mathrm{O}}^{\prime}\right)$.

Table S10. Screen of the concentration of THP-T1 in DDBAC titrated solution (30 mM)

\begin{tabular}{|c|c|c|c|c|c|c|c|c|}
\hline Entry & $\begin{array}{l}V_{\mathrm{DDBAC}}{ }^{a} \\
/ \mathrm{mL}\end{array}$ & $\begin{array}{l}V_{\mathrm{THP}}^{b} \\
/ \mu \mathrm{L}\end{array}$ & $\begin{array}{l}c_{\mathrm{THP}}{ }^{c} \\
/ \mu \mathrm{M}\end{array}$ & $\begin{array}{l}V_{\mathrm{H} 2 \mathrm{O}}^{d} \\
/ \mathrm{mL}\end{array}$ & $\begin{array}{l}V_{\mathrm{H} 2 \mathrm{O}}^{\prime} \\
/ \mathrm{mL}\end{array}$ & $\begin{array}{l}c^{\prime}{ }_{\mathrm{THP}}^{f} \\
/ \mu \mathrm{M}\end{array}$ & $\begin{array}{l}\mathrm{CMC}^{g} \\
/ \mathrm{mM}\end{array}$ & $\begin{array}{l}\mathrm{CMC}^{h} \\
/ \mathrm{mM}\end{array}$ \\
\hline $1^{i}$ & 1 & 2 & 2 & & & & & \\
\hline 2 & 1 & 5 & 5 & $2.93 \pm 0.03$ & $3.03 \pm 0.03$ & 1.24 & $7.44 \pm 0.05$ & \\
\hline 3 & 1 & 6 & 6 & $2.59 \pm 0.01$ & $2.70 \pm 0.01$ & 1.62 & $8.10 \pm 0.01$ & $8.56 / 8.47$ \\
\hline 4 & 1 & 7 & 7 & $2.48 \pm 0.02$ & $2.60 \pm 0.01$ & 1.94 & $8.33 \pm 0.01$ & \\
\hline 5 & 1 & 10 & 10 & $2.34 \pm 0.04$ & $2.48 \pm 0.02$ & 2.88 & $8.63 \pm 0.04$ & \\
\hline 6 & 1 & 11 & 11 & $2.27 \pm 0.02$ & $2.45 \pm 0.01$ & 3.55 & $8.69 \pm 0.01$ & \\
\hline 7 & 1 & 12 & 12 & $2.16 \pm 0.01$ & $2.35 \pm 0.02$ & 3.58 & $8.95 \pm 0.04$ & \\
\hline 8 & 1 & 15 & 15 & $2.10 \pm 0.01$ & $2.29 \pm 0.01$ & 4.57 & $9.13 \pm 0.03$ & \\
\hline $9^{j}$ & 1 & 16 & 16 & & & & & \\
\hline
\end{tabular}

${ }^{a}$ Volume of concentrated DDBAC solution $(30 \mathrm{mM}) .{ }^{b}$ Volume of THP-T1 stock solution $(1 \mathrm{mM})$ in concentrated DDBAC solution. ${ }^{c}$ Concentration of THP-T1 in initial DDBAC titrated solution: $c_{\mathrm{THP}}=\left(V_{\mathrm{THP}} \times 1 \mathrm{mM}\right) / 1 \mathrm{~mL}$. ${ }^{d}$ Volume of added water near titrating end point. ${ }^{e}$ Volume of added water at titrating end point. ${ }^{f}$ Concentration of THP$\mathrm{T} 1$ in DDBAC titration-end-point solution. ${ }^{g} \mathrm{CMC}(\mathrm{mM})=c_{\mathrm{DDBAC}} \times V_{\mathrm{DDBAC}} /\left(V_{\mathrm{DDBAC}}+V_{\mathrm{H} 2 \mathrm{O}}^{\prime}\right)=30 \times 1 /\left(1+V_{\mathrm{H} 2 \mathrm{O}}^{\prime}\right)$. 
${ }^{h} \mathrm{CMC}$ value determined from samples kept 0 min prepared as our previous reported fluorescence method ${ }^{[3]}$ with the same concentration of DDBAC $(30 \mathrm{mM})$ and $c_{\mathrm{THP}}$ as titration method. ${ }^{i}$ The fluorescence of THP-T1 at titrating end point is too weak to be observed. ${ }^{j}$ THP-T1 aggregates in initial DDBAC titrated solution.

Table S11. Influence of DTAC concentration on titrated CMC

\begin{tabular}{lllllllll}
\hline Entry & $\begin{array}{l}V_{\mathrm{DTAC}}{ }^{a} \\
/ \mathrm{mL}\end{array}$ & $\begin{array}{l}C_{\mathrm{DTAC}} \\
\mathrm{mM}\end{array}$ & $\begin{array}{l}V_{\mathrm{THP}}{ }^{b} \\
/ \mu \mathrm{L}\end{array}$ & $\begin{array}{l}c_{\mathrm{THP}}{ }^{c} \\
/ \mu \mathrm{M}\end{array}$ & $\begin{array}{l}V_{\mathrm{H} 20}{ }^{d} \\
/ \mathrm{mL}\end{array}$ & $\begin{array}{l}V^{\prime}{ }^{2}{ }^{e} \\
/ \mathrm{mL}\end{array}$ & $\begin{array}{l}c^{\prime}{ }^{f} \\
/ \mu \mathrm{M}\end{array}$ & $\begin{array}{l}\mathrm{CMC}^{g} \\
/ \mathrm{mM}\end{array}$ \\
\hline 1 & 1 & 30 & 4.2 & 7 & $1.58 \pm 0.03$ & $1.72 \pm 0.02$ & 1.47 & $11.03 \pm 0.07$ \\
2 & 1 & 40 & 5.6 & 7 & $1.56 \pm 0.02$ & $1.69 \pm 0.01$ & 2.04 & $14.85 \pm 0.06$ \\
3 & 1 & 45 & 6.3 & 7 & $1.67 \pm 0.04$ & $1.80 \pm 0.03$ & 2.14 & $16.07 \pm 0.02$ \\
4 & 1 & 50 & 7 & 7 & $1.97 \pm 0.01$ & $2.06 \pm 0.01$ & 2.28 & $16.32 \pm 0.03$ \\
5 & 1 & 55 & 7.7 & 7 & $2.15 \pm 0.01$ & $2.34 \pm 0.02$ & 2.39 & $16.45 \pm 0.08$ \\
\hline
\end{tabular}

${ }^{a}$ Volume of concentrated DTAC solution with different concentration $\left(c_{\text {DTAC }}\right) .{ }^{b}$ Volume of THP-T1 stock solution (1 $\mathrm{mM})$ in concentratedDTAC solution: $V_{\mathrm{THP}} \times 1 \mathrm{mM}=\left(1 \mathrm{~mL} \times c_{\mathrm{DTAC}} / 50 \mathrm{mM}\right) \times 7 \mu \mathrm{M}$. ${ }^{c}$ Concentration of THP-T1 in DTAC titrated solution with concentration equal to $50 \mathrm{mM}$. ${ }^{d}$ Volume of added water near titrating end point. ${ }^{e}$ Volume of added water at titrating end point. ${ }^{f}$ Concentration of THP-T1 in DTAC titration-end-point solution. ${ }^{g} \mathrm{CMC}(\mathrm{mM})=$ $c_{\mathrm{DTAC}} \times V_{\mathrm{DTAC}} /\left(V_{\mathrm{DTAC}}+V_{\mathrm{H} 2 \mathrm{O}}^{\prime}\right)=c_{\mathrm{DTAC}} \times 1 /\left(1+V_{\mathrm{H} 2 \mathrm{O}}^{\prime}\right)$.

Table S12. Screen of the concentration of THP-T1 in DTAC titrated solution $(50 \mathrm{mM})$

\begin{tabular}{|c|c|c|c|c|c|c|c|c|}
\hline Entry & $\begin{array}{l}V_{\text {DTAC }}{ }^{a} \\
/ \mathrm{mL}\end{array}$ & $\begin{array}{l}V_{\mathrm{THP}}^{b} \\
/ \mu \mathrm{L}\end{array}$ & $\begin{array}{l}c_{\mathrm{THP}}{ }^{c} \\
/ \mu \mathrm{M}\end{array}$ & $\begin{array}{l}V_{\mathrm{H} 2 \mathrm{O}}^{d} \\
/ \mathrm{mL}\end{array}$ & $\begin{array}{l}V_{\mathrm{H} 2 \mathrm{O}}^{\prime} \\
/ \mathrm{mL}\end{array}$ & $\begin{array}{l}c_{\mathrm{THP}}^{\prime} \\
/ \mu \mathrm{M}\end{array}$ & $\begin{array}{l}\mathrm{CMC}^{g} \\
/ \mathrm{mM}\end{array}$ & $\begin{array}{l}\mathrm{CMC}^{h} \\
/ \mathrm{mM}\end{array}$ \\
\hline 1 & 1 & 4 & 4 & $2.30 \pm 0.03$ & $2.39 \pm 0.01$ & 1.18 & $14.73 \pm 0.05$ & \\
\hline 2 & 1 & 5 & 5 & $1.99 \pm 0.01$ & $2.10 \pm 0.01$ & 1.61 & $16.11 \pm 0.03$ & $16.27 / 17.03$ \\
\hline 3 & 1 & 9 & 9 & $1.95 \pm 0.01$ & $2.04 \pm 0.01$ & 2.96 & $16.43 \pm 0.03$ & $16.54 / 16.59$ \\
\hline 4 & 1 & 10 & 10 & $1.72 \pm 0.02$ & $1.90 \pm 0.01$ & 3.44 & $17.22 \pm 0.03$ & \\
\hline 5 & 1 & 14 & 14 & $1.71 \pm 0.01$ & $1.84 \pm 0.03$ & 4.94 & $17.63 \pm 0.20$ & \\
\hline 6 & 1 & 15 & 15 & $1.50 \pm 0.01$ & $1.74 \pm 0.02$ & 5.48 & $18.27 \pm 0.10$ & \\
\hline 7 & 1 & 18 & 18 & $1.40 \pm 0.01$ & $1.57 \pm 0.02$ & 7.01 & $19.48 \pm 0.16$ & \\
\hline 8 & 1 & 20 & 20 & $1.31 \pm 0.01$ & $1.51 \pm 0.02$ & 7.97 & $19.92 \pm 0.16$ & \\
\hline
\end{tabular}




\begin{tabular}{llllllll}
\hline 9 & 1 & 36 & 36 & $1.16 \pm 0.03$ & $1.34 \pm 0.02$ & 15.36 & $21.34 \pm 0.14$ \\
$10^{j}$ & 1 & 38 & 38 & & & & \\
\hline
\end{tabular}

${ }^{a}$ Volume of concentrated DTAC solution $(50 \mathrm{mM}) .{ }^{b}$ Volume of THP-T1 stock solution $(1 \mathrm{mM})$ in concentrated DTAC solution. ${ }^{c}$ Concentration of THP-T1 in initial DTAC titrated solution: $c_{\mathrm{THP}}=\left(V_{\mathrm{THP}} \times 1 \mathrm{mM}\right) / 1 \mathrm{~mL}$. ${ }^{d}$ Volume of added water near titrating end point. ${ }^{e}$ Volume of added water at titrating end point. ${ }^{f}$ Concentration of THP-T1 in DTAC titration-end-point solution. ${ }^{g} \mathrm{CMC}(\mathrm{mM})=c_{\mathrm{DTAC}} \times V_{\mathrm{DTAC}} /\left(V_{\mathrm{DTAC}}+V_{\mathrm{H} 2 \mathrm{O}}^{\prime}\right)=50 \times 1 /\left(1+V_{\mathrm{H} 2 \mathrm{O}}^{\prime}\right) .{ }^{h} \mathrm{CMC}$ value determined from samples kept 0 min prepared as our previous reported fluorescence method ${ }^{[3]}$ with the same concentration of DTAC $(50 \mathrm{mM})$ and $c_{\mathrm{THP}}$ as titration method. ${ }^{i}$ The fluorescence of THP-T1 at titrating end point is too weak to be observed. ${ }^{j}$ THP-T1 aggregates in initial DTAC titrated solution.
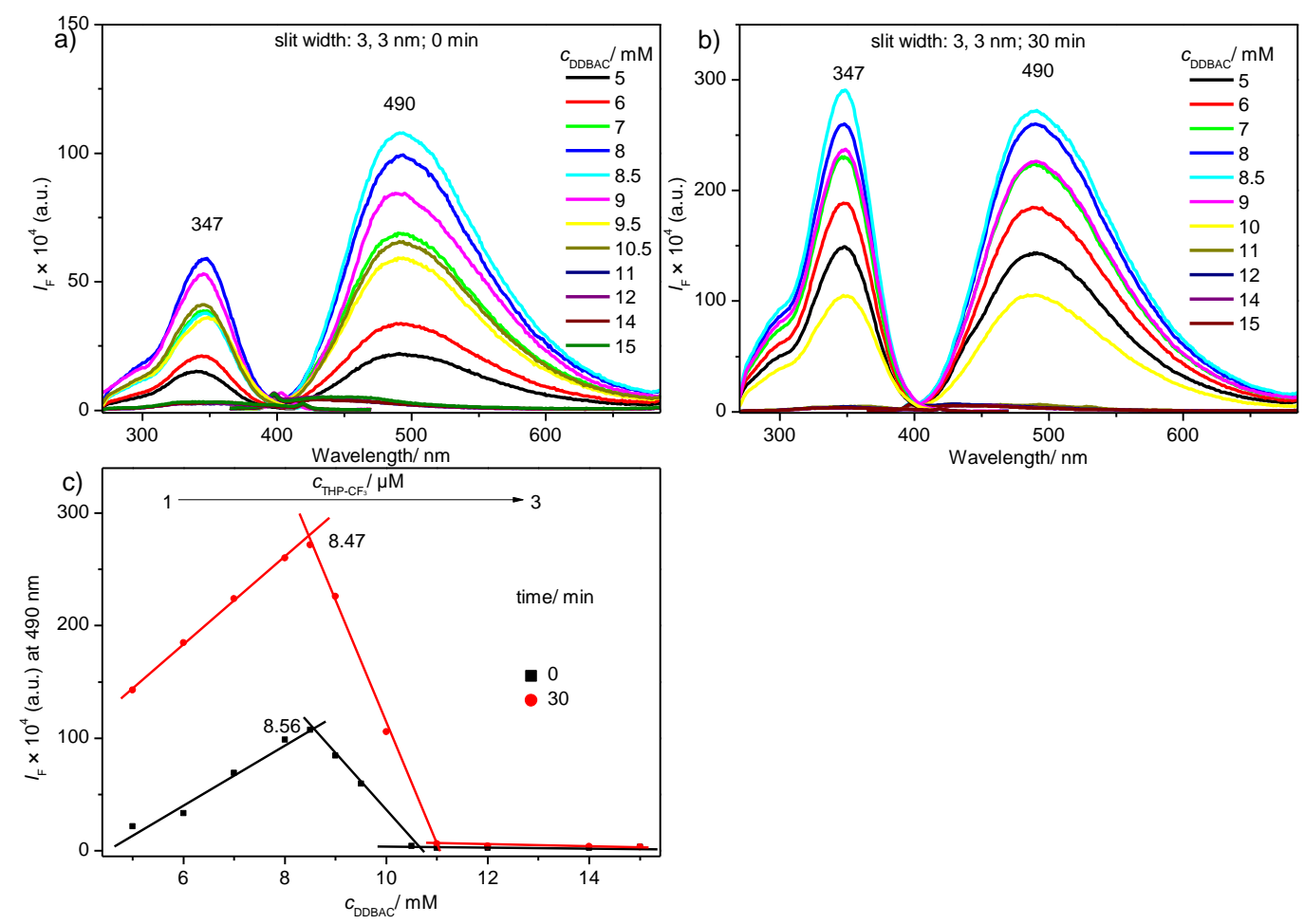

Figure S15. a) and b) Excitation (left) and emission (right) spectra of THP-T1 in samples kept 0 and 30 min, respectively. The concentration of DDBAC from 5 to $15 \mathrm{mM}$ and the concentration of THP-T1 from 1 to $3 \mu \mathrm{M}$. Emitted and excited at peaks marked in excitation and emission spectra, respectively. c) The relationship between the fluorescence intensity at emission peak of THP-T1 and the concentration of DDBAC in samples kept 0 and 30 min, respectively. 

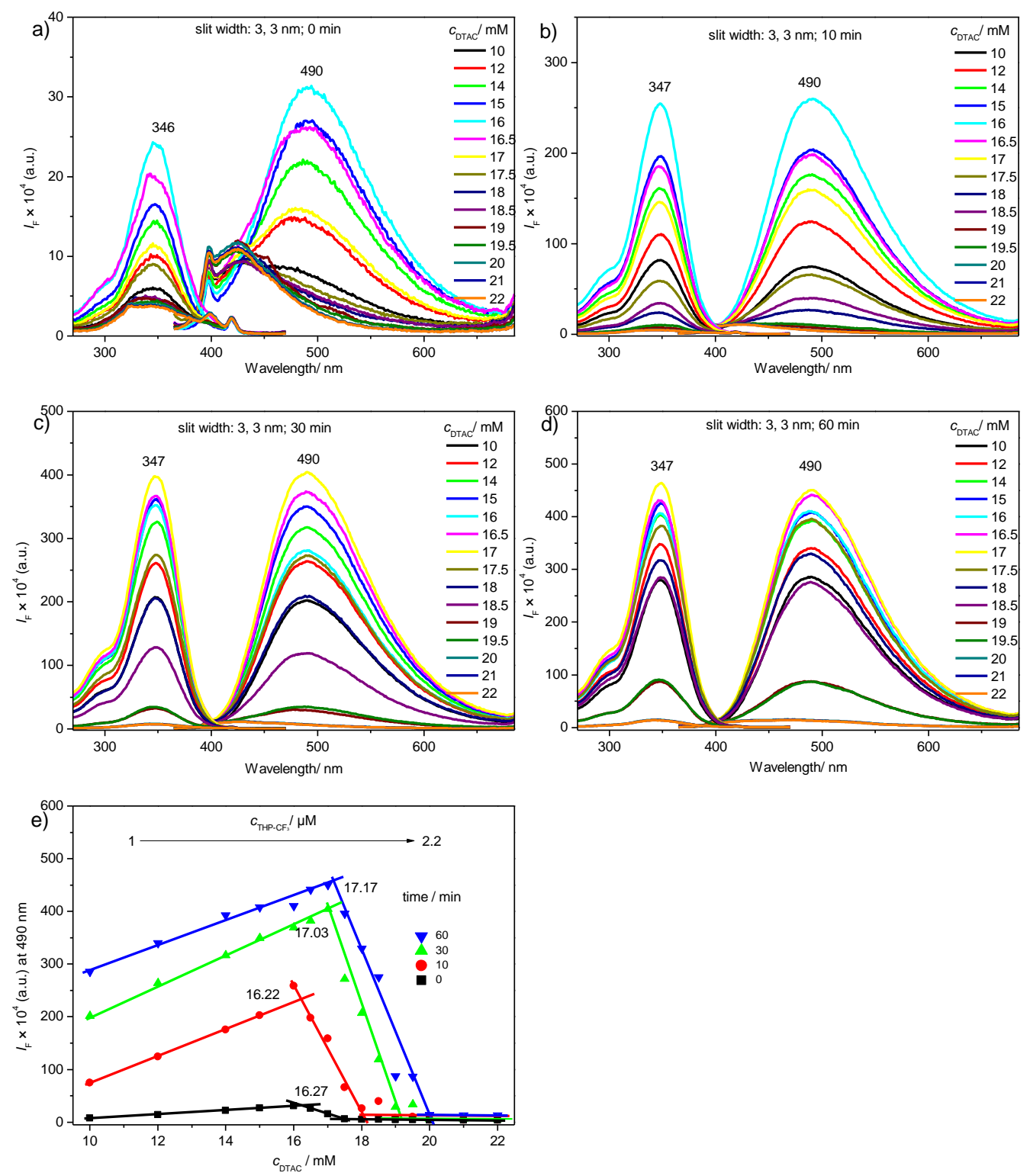

Figure S16. a)-d) Excitation (left) and emission (right) spectra of THP-T1 in samples kept 0, 10, 30 and 60 min, respectively. The concentration of DTAC from 10 to $22 \mathrm{mM}$ and the concentration of THP-T1 from 1 to $2.2 \mu \mathrm{M}$. Emitted and excited at peaks marked in excitation and emission spectra, respectively. e) The relationship between the fluorescence intensity at emission peak of THP-T1 and the concentration of DTAC in samples kept 0, 10, 30 and 60 min, respectively. 

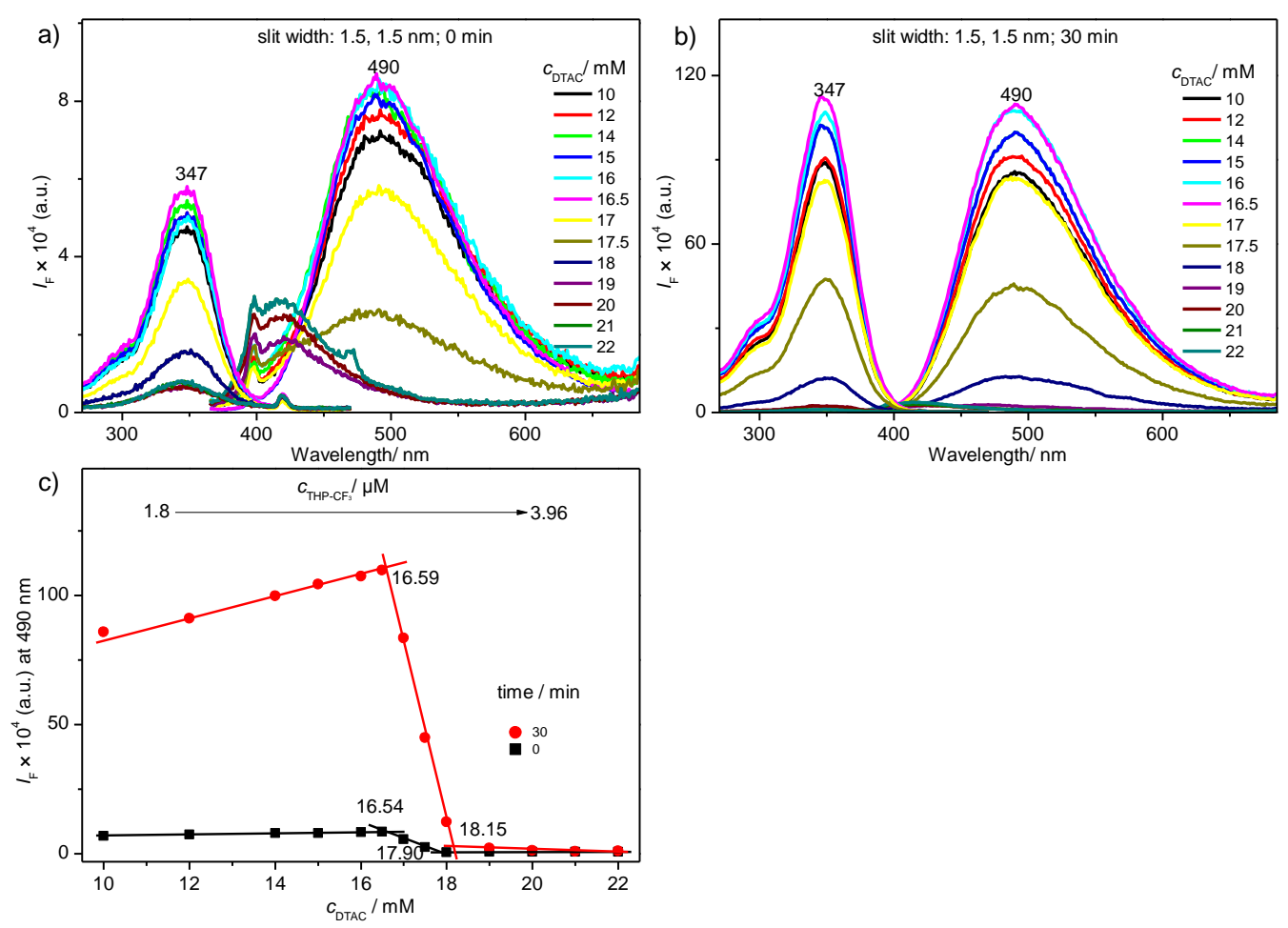

Figure S17.a)-b) Excitation (left) and emission (right) spectra of THP-T1 in samples kept 0 and 30 min, respectively. The concentration of DTAC from 10 to $22 \mathrm{mM}$ and the concentration of THP-T1 from 1.8 to $3.96 \mu \mathrm{M}$. Emitted and excited at peaks marked in excitation and emission spectra, respectively. c) The relationship between the fluorescence intensity at emission peak of THP-T1 and the concentration of DTAC in samples kept 0 and 30 min, respectively.

\section{CMC determination of nonionic surfactant with very low CMC value (Tween-20) by fluorescence methods using THP-T1 as probe}

Since the more the micelles from near CMC to CMC are, the more sensitive the change in the fluorescence of THP-T1 is, the CMC titration using THP-T1 as indicator is more suitable for surfactants with relative high CMC values (>0.1 $\mathrm{mM}$ ) but not suitable for surfactants with very low CMC values. The CMC value (only $0.029 \mathrm{mM}$ ) of Tween-20 could not be determined by titration because its micelles about CMC are too less to include THP-T1. However, when the concentration of THP-T1 in different concentrations of Tween-20 decreases to $0.2 \mu \mathrm{M}$, it can be used as a good probe for the CMC determination by fluorometric method (Figure S18). 

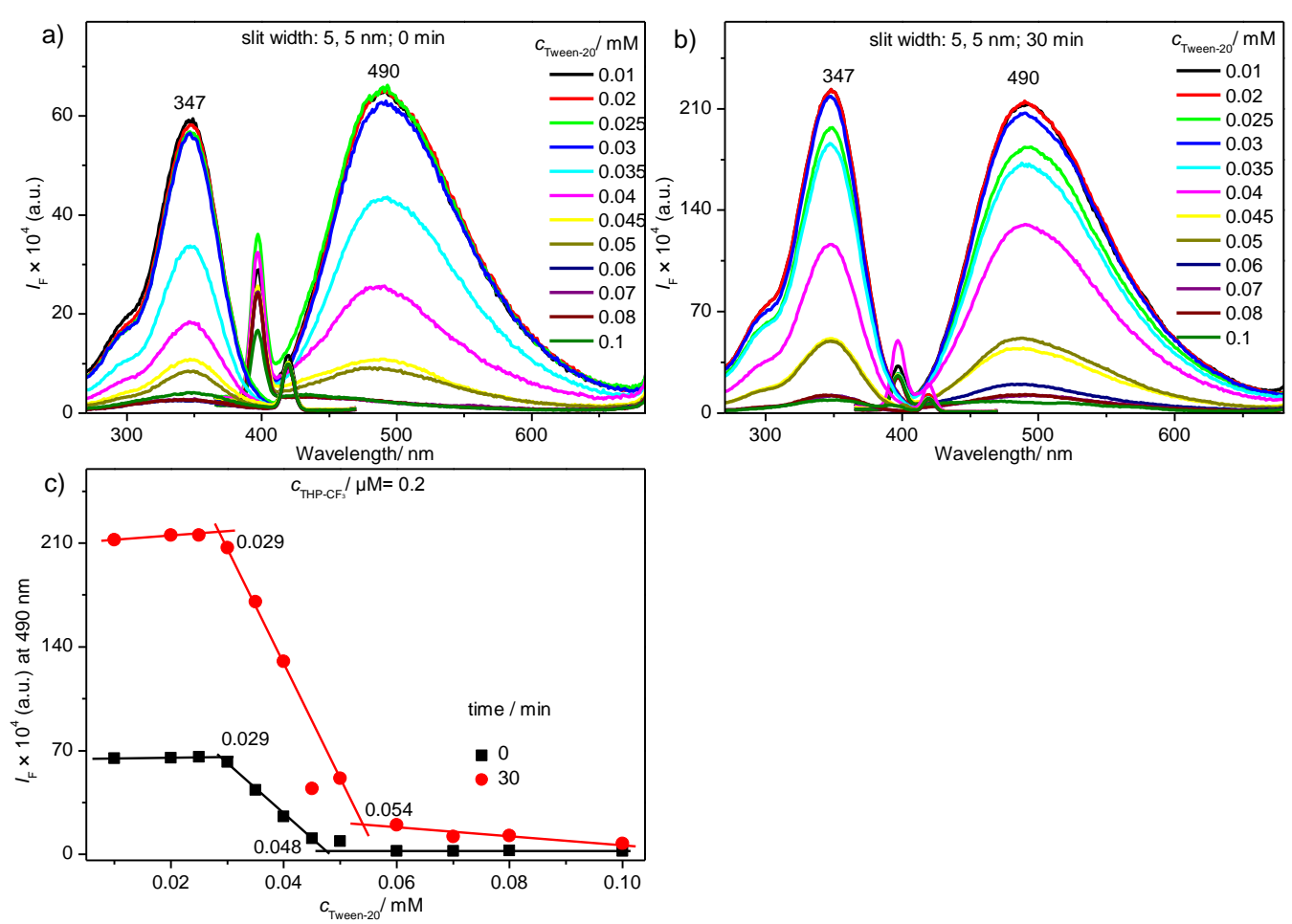

Figure S18. a) and b) Excitation (left) and emission (right) spectra of THP-T1 in samples kept 0 and $30 \mathrm{~min}$, respectively. The concentrations of Tween-20 are from 0.01 to $0.1 \mathrm{mM}$ in different samples and the concentration of THP-T1 is $0.2 \mu \mathrm{M}$. Emitted and excited at peaks marked in excitation and emission spectra, respectively. c) The relationship between the fluorescence intensity at emission peak of THP-T1 and the concentration of Tween-20 in samples kept 0 and $30 \mathrm{~min}$, respectively.

Suitable concentration range of THP-T1 for CMC titration of different kinds of surfactants and comparison of the CMC values determined by titration and other methods

The ranges of the suitable concentrations ( $c_{\mathrm{THP}}$ and $c_{\mathrm{THP}}^{\prime}$ ) of THP-T1 in initial and titration-end-point titrated solutions, and the CMC values determined by titration and fluorometric methods using THP-T1 as fluorescence-turn-on probe are listed in Table S13. 
Table S13. CMC values of SDS, CTAB, BS-12, Trtion X-100, DDBAC and DTAC determined by titration method, fluorescence method and reported in references.

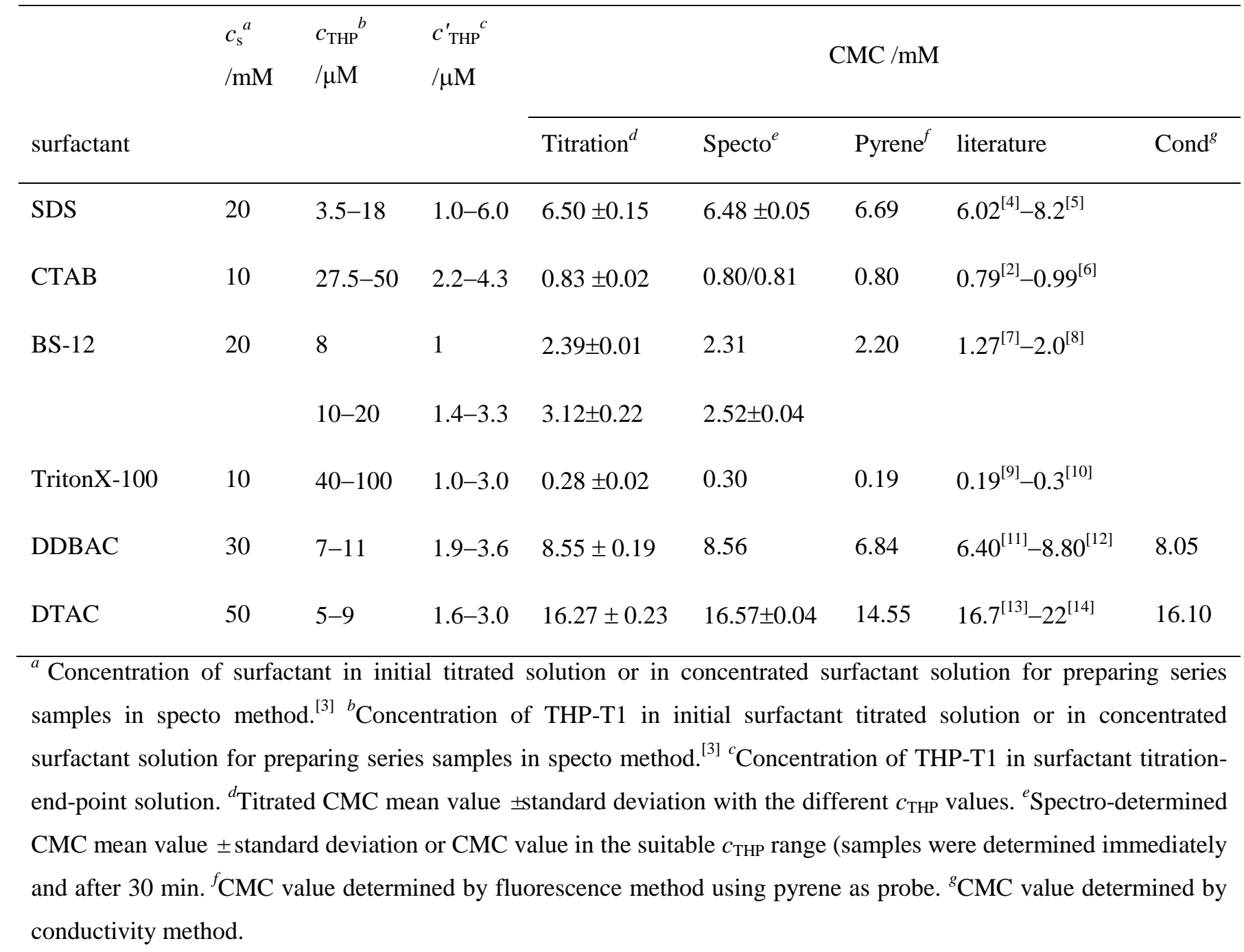

\section{Determination of the approximate CMC values of new surfactants or surfactants from different supplie using THP-T1 as probe}

Approximate CMC values were determined by method II reported in our previous paper. ${ }^{[2]}$ Generally, a certain volume of THP-T1 solution ( $10 \mu \mathrm{L}$ of $0.5 \mathrm{mM}$ THP-T1 for CMC $>0.1 \mathrm{mM}$ and $4 \mu \mathrm{L}$ of $0.1 \mathrm{mM}$ THP-T 1 for CMC $\leq 0.1 \mathrm{mM}$ ) were added into different $5 \mathrm{~mL}$ bottles containing different volumes of the surfactant stock solution, respectively, shaking well for about $3 \mathrm{~min}$ (it is very important for dispersion of THP-T1 in concentrated surfactant solutions, if the surfactant stock solution is too viscous to disperse THP-T1, the shaking procedure is needed to be conducted in a hot water bath.), and then adding different amount of water into bottles to make the total volume $2 \mathrm{~mL}$, shaking well (the concentration of THP-T1 in each sample is $2.5 \mu \mathrm{M}$ for surfactants with CMC $>0.1 \mathrm{mM}$ and $0.2 \mu \mathrm{M}$ for surfactants with $\mathrm{CMC} \leq 0.1 \mathrm{mM}$ ). With decrease of the concentration of surfactants, THP-T1 is no emissive above CMC, becomes emission near to CMC, and shows strong emission at/below CMC. 


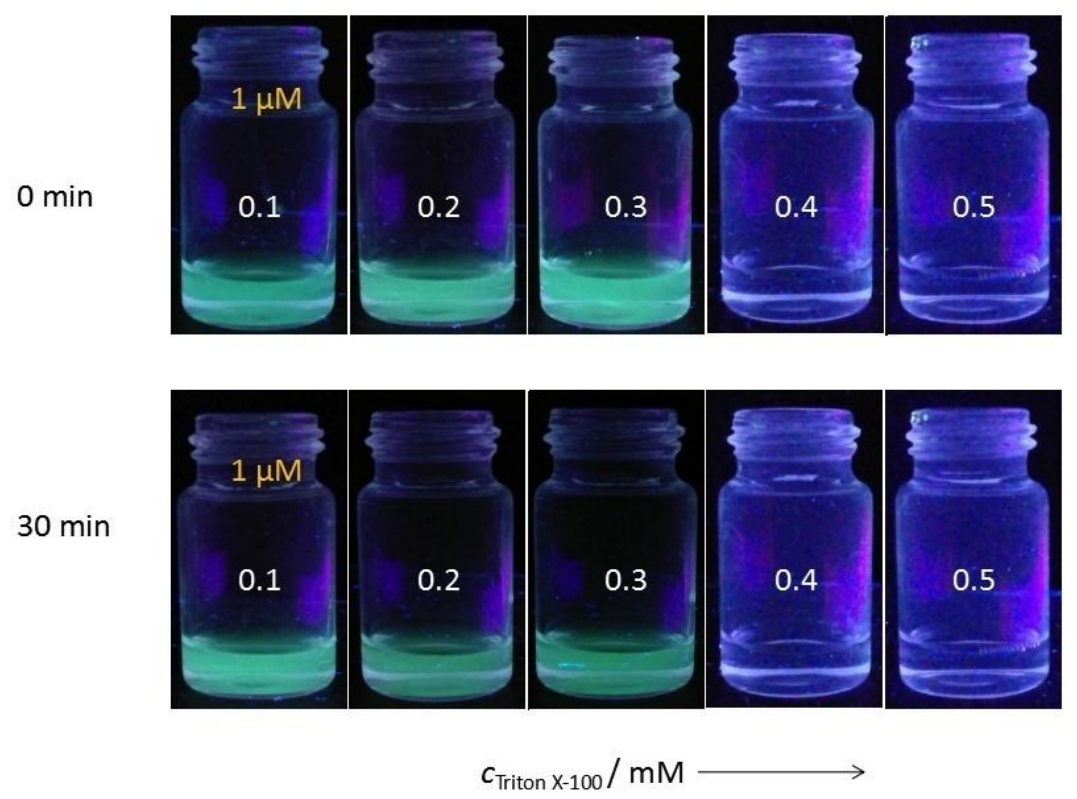

Figure S19. Determination of the approximate CMC of Triton X-100. Triton X-100 solutions with different concentrations $(0.1,0.2,0.3,0.4$ and $0.5 \mathrm{mM})$ containing $1 \mu \mathrm{M}$ of THP-T1 were prepared by adding $2 \mu \mathrm{L}$ of THP-T1 stock solution $(1 \mathrm{mM})$ into different $5 \mathrm{~mL}$ test bottle containing different volumes of Triton X-100 stock solution (5 $\mathrm{mM}$ ), respectively, shaking well for about $3 \mathrm{~min}$, and then adding different amount of water into test tube to make the total volume $2 \mathrm{~mL}$, shaking well and kept for 0 and 30 min. Photos were taken under a UV light with $365 \mathrm{~nm}$.

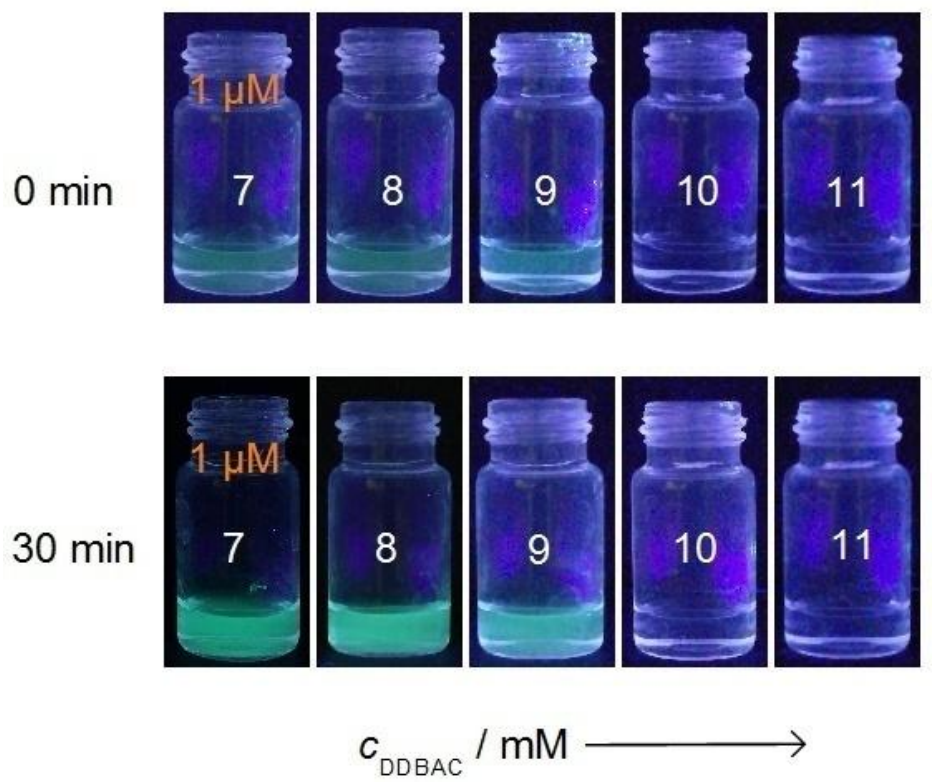

Figure S20. Determination of the approximate CMC of DDBAC. DDBAC solutions with different concentrations $(7,8$, 9, 10 and $11 \mathrm{mM})$ containing $1 \mu \mathrm{M}$ of THP-T1 were prepared by adding $2 \mu \mathrm{L}$ of THP-T1 stock solution $(1 \mathrm{mM})$ into different $5 \mathrm{~mL}$ test bottle containing different volumes of DDBAC stock solution $(30 \mathrm{mM})$, respectively, shaking well for about $3 \mathrm{~min}$, and then adding different amount of water into test tube to make the total volume $2 \mathrm{~mL}$, shaking well and kept for 0 and $30 \mathrm{~min}$. Photos were taken under a UV light with $365 \mathrm{~nm}$. 


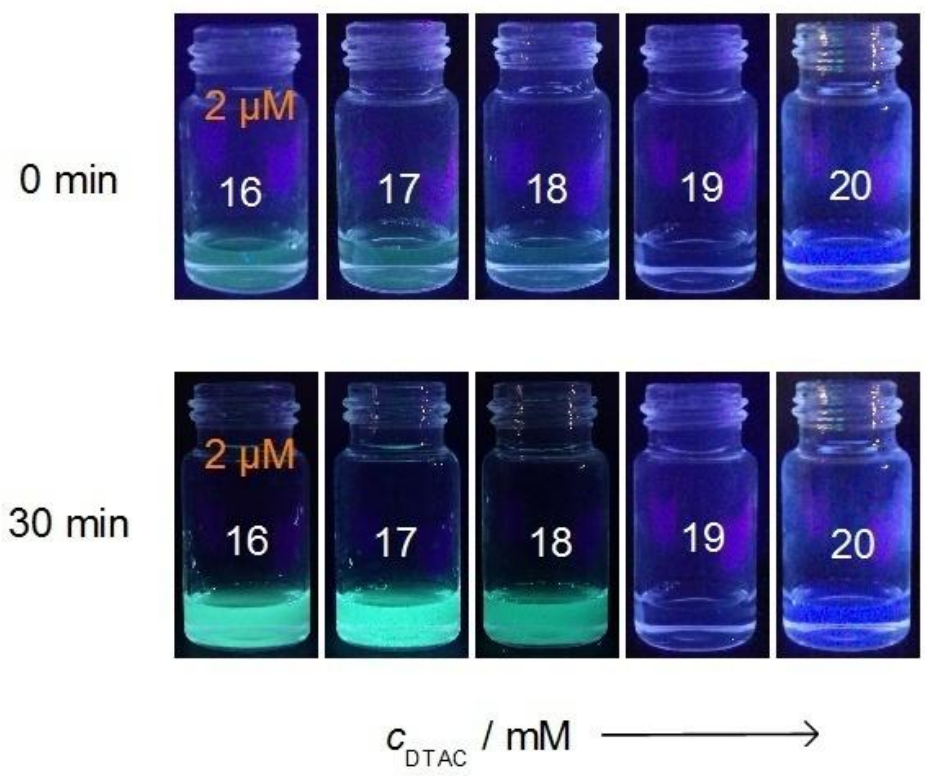

Figure S21. Determination of the approximate CMC of DTAC. DTAC solutions with different concentrations (16, 17, $18,19$ and $20 \mathrm{mM}$ ) containing $2 \mu \mathrm{M}$ of THP-T1 were prepared by adding $4 \mu \mathrm{L}$ of THP-T1 stock solution ( $1 \mathrm{mM})$ into different $5 \mathrm{~mL}$ test bottle containing different volumes of DTAC stock solution $(50 \mathrm{mM})$, respectively, shaking well for about $3 \mathrm{~min}$, and then adding different amount of water into test tube to make the total volume $2 \mathrm{~mL}$, shaking well and kept for 0 and $30 \mathrm{~min}$. Photos were taken under a UV light with $365 \mathrm{~nm}$.

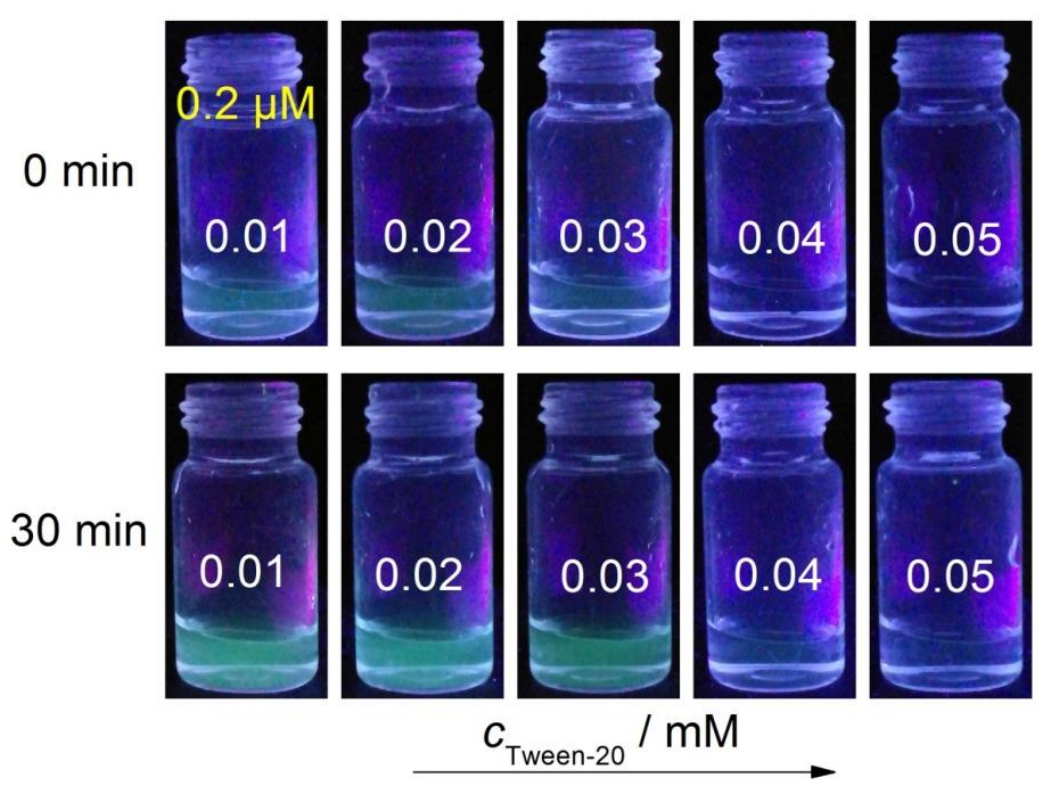

Figure S22. Determination of the approximate CMC of Tween-20. Tween-20 solutions with different concentrations $(0.01,0.02,0.03,0.04$ and $0.05 \mathrm{mM})$ containing $0.2 \mu \mathrm{M}$ of THP-T1 were prepared by adding $4 \mu \mathrm{L}$ of THP-T1 solution $(0.1 \mathrm{mM})$ into different $5 \mathrm{~mL}$ test bottle containing different volumes of concentrated Tween-20 solution $(1 \mathrm{mM})$, respectively, shaking well for about $3 \mathrm{~min}$, and then adding different amount of water into test tube to make the total volume $2 \mathrm{~mL}$, shaking well and kept for 0 and $30 \mathrm{~min}$. Photos were taken under a UV light with $365 \mathrm{~nm}$. 

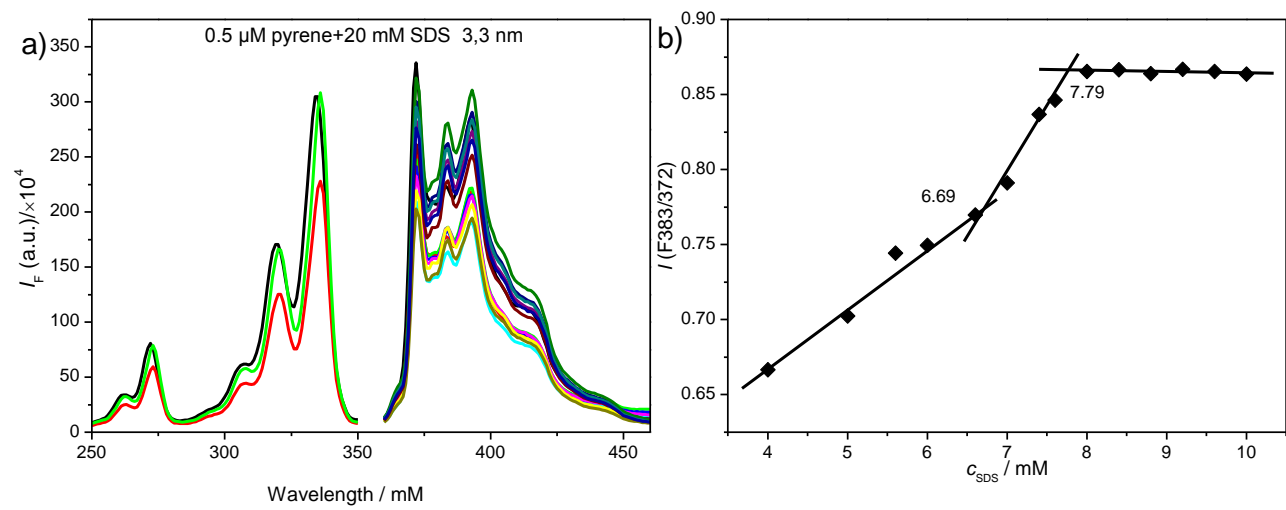

Figure S23.a) Excitation (left) and emission (right) spectra of pyrene $(0.5 \mu \mathrm{M})$ in SDS solutions with different concentrations (4 to $10 \mathrm{mM}$ ). Emitted and excited at 373 and $334 \mathrm{~nm}$, respectively. b) The relationship between the ratio of the fluorescence intensity at 383 and $373 \mathrm{~nm}$ of pyrene and the concentration of SDS. Samples were prepared by diluting concentrated SDS solution $(20 \mathrm{mM})$ containing a certain concentration of pyrene $(0.5 \mu \mathrm{M})$ using pyrene water solution $(0.5 \mu \mathrm{M})$.
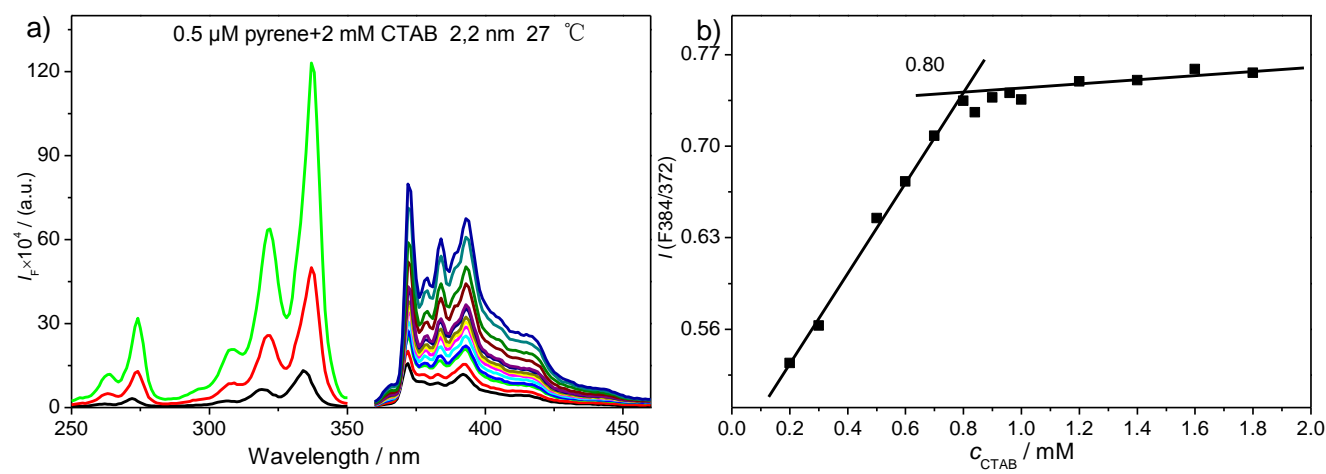

Figure S24. a) Excitation (left) and emission (right) spectra of pyrene $(0.5 \mu \mathrm{M})$ in CTAB solutions with different concentrations ( 0.2 to $2 \mathrm{mM}$ ). Emitted and excited at 373 and $334 \mathrm{~nm}$, respectively. b) The relationship between the ratio of the fluorescence intensity at 383 and $373 \mathrm{~nm}$ of pyrene and the concentration of CTAB. Samples were prepared by diluting concentrated CTAB solution $(2 \mathrm{mM})$ containing a certain concentration of pyrene $(0.5 \mu \mathrm{M})$ using pyrene water solution $(0.5 \mu \mathrm{M})$. 

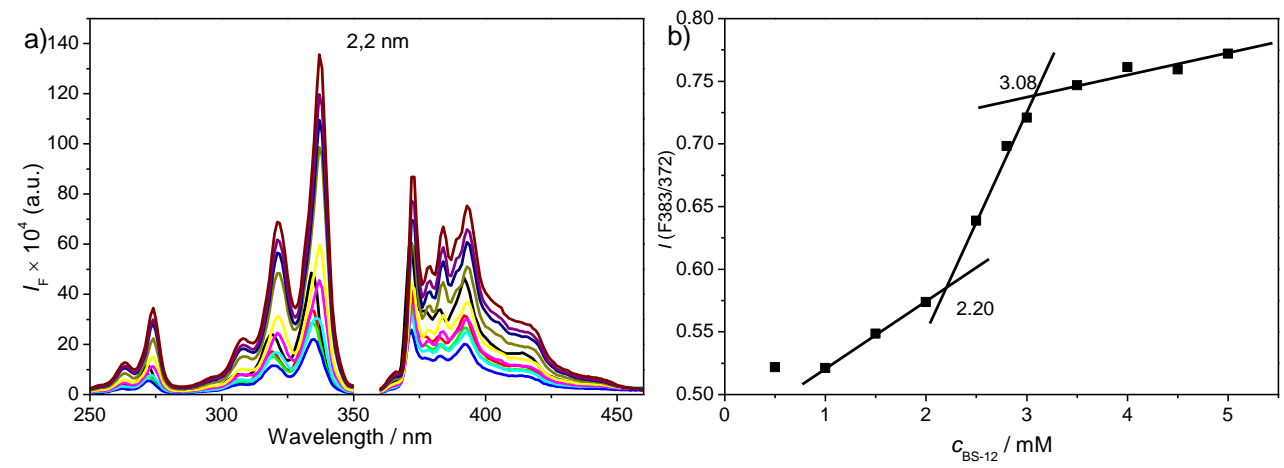

Figure S25. a) Excitation (left) and emission (right) spectra of pyrene $(0.5 \mu \mathrm{M})$ in BS-12 solutions with different concentrations (1 to $5 \mathrm{mM}$ ). Emitted and excited at 373 and $334 \mathrm{~nm}$, respectively. b) The relationship between the ratio of the fluorescence intensity at 383 and $373 \mathrm{~nm}$ of pyrene and the concentration of BS-12. Samples were prepared by diluting concentrated BS-12 solution $(5 \mathrm{mM})$ containing a certain concentration of pyrene $(0.5 \mu \mathrm{M})$ using pyrene water solution $(0.5 \mu \mathrm{M})$.
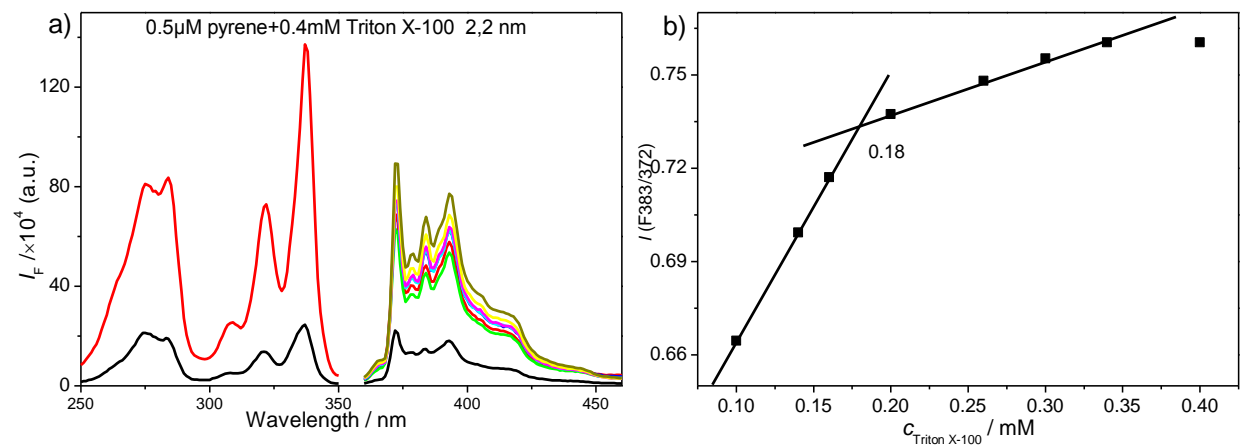

Figure S26. a) Excitation (left) and emission (right) spectra of pyrene $(0.5 \mu \mathrm{M})$ in Triton $\mathrm{X}-100$ solutions with different concentrations ( 0.1 to $0.4 \mathrm{mM}$ ). Emitted and excited at 373 and $334 \mathrm{~nm}$, respectively. b) The relationship between the ratio of the fluorescence intensity at 383 and $373 \mathrm{~nm}$ of pyrene and the concentration of Triton X-100. Samples were prepared by diluting concentrated Triton X-100 solution $(0.4 \mathrm{mM})$ containing a certain concentration of pyrene $(0.5 \mu \mathrm{M})$ using pyrene water solution $(0.5 \mu \mathrm{M})$.
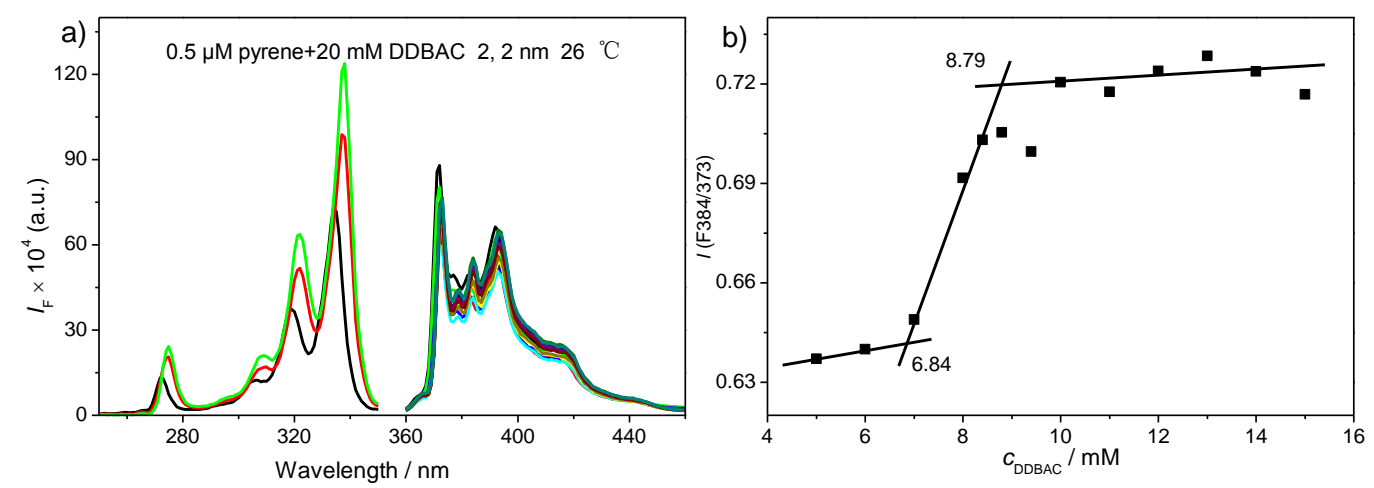

Figure S27.a) Excitation (left) and emission (right) spectra of pyrene $(0.5 \mu \mathrm{M})$ in DDBAC solutions with different concentrations (5 to $15 \mathrm{mM}$ ). Emitted and excited at 373 and $334 \mathrm{~nm}$, respectively. b) The relationship between the ratio of the fluorescence intensity at 383 and $373 \mathrm{~nm}$ of pyrene and the concentration of DDBAC. Samples were 
prepared by diluting concentrated DDBAC solution $(20 \mathrm{mM})$ containing a certain concentration of pyrene $(0.5 \mu \mathrm{M})$ using pyrene water solution $(0.5 \mu \mathrm{M})$.
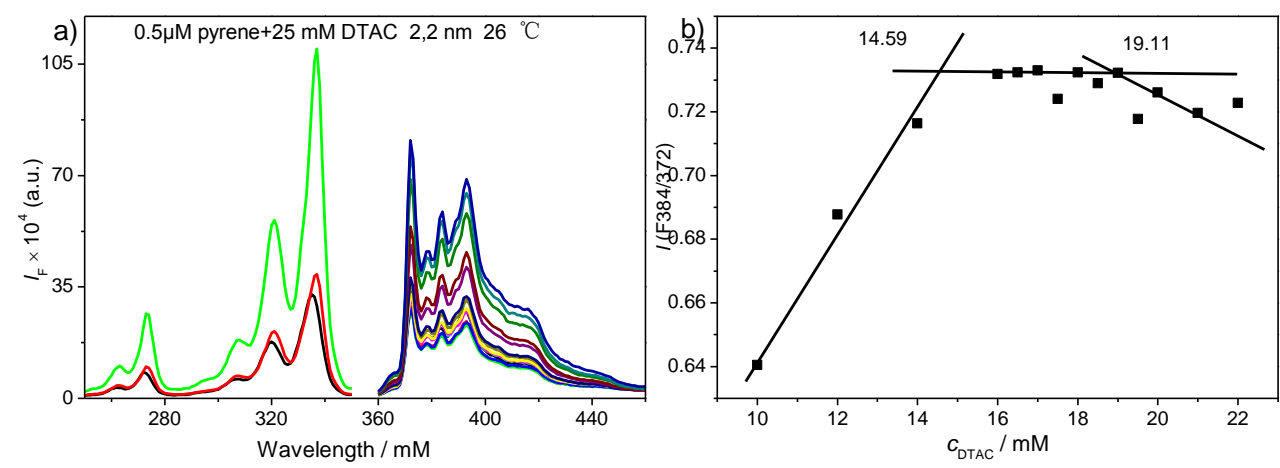

Figure S28. a) Excitation (left) and emission (right) spectra of pyrene $(0.5 \mu \mathrm{M})$ in DTAC solutions with different concentrations (10 to $22 \mathrm{mM}$ ). Emitted and excited at 373 and $334 \mathrm{~nm}$, respectively. b) The relationship between the ratio of the fluorescence intensity at 383 and $373 \mathrm{~nm}$ of pyrene and the concentration of DTAC. Samples were prepared by diluting concentrated DTAC solution $(25 \mathrm{mM})$ containing a certain concentration of pyrene $(0.5 \mu \mathrm{M})$ using pyrene water solution $(0.5 \mu \mathrm{M})$.
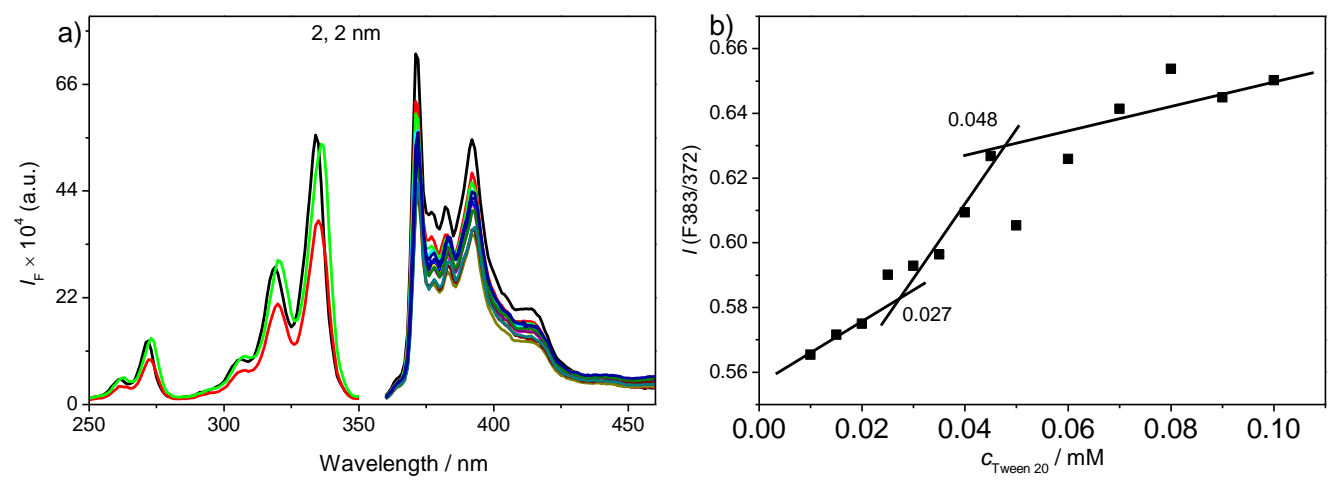

Figure S29. a) Excitation (left) and emission (right) spectra of pyrene $(0.5 \mu \mathrm{M})$ in Tween-20 solutions with different concentrations ( 0.01 to $0.1 \mathrm{mM}$ ). Emitted and excited at 373 and $334 \mathrm{~nm}$, respectively. b) The relationship between the ratio of the fluorescence intensity at 383 and $373 \mathrm{~nm}$ of pyrene and the concentration of Tween-20. Samples were prepared by diluting concentrated Tween-20 solution $(1 \mathrm{mM})$ containing a certain concentration of pyrene $(0.5 \mu \mathrm{M})$ using pyrene water solution $(0.5 \mu \mathrm{M})$.

\section{Determination of the CMC values of DDBAC and DTAC by conductivity method}

DDBAC/DTAC solutions with different concentrations were prepared by adding different volumes of concentrated DDBAC/DTAC ( $50 \mathrm{mM}$ ) solutions into $5 \mathrm{~mL}$ volumetric flasks and filling the flasks with double distilled water. The conductivity of each solution was measured using a DDS-11A conductivity meter at room temperature. 

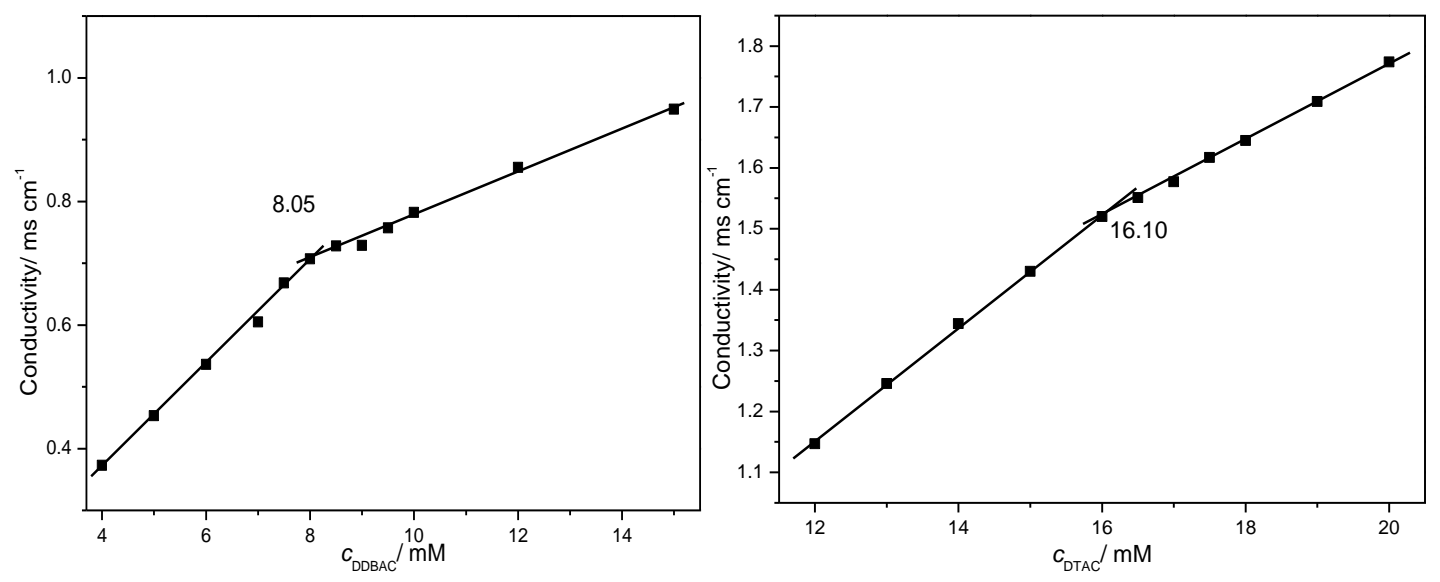

Figure S30. Determination of the CMC values of DDBAC (left) and DTAC(right) by conductive method. Relationship between the conductivity and concentration of DDBAC (left) and DTAC(right) DTAC solutions.

\section{Determination of the CMC values of surfactants in phosphate buffer saline (PBS)}

Table S14. Titrated CMC values of SDS (50 mM) in PBS

\begin{tabular}{lllllllll}
\hline Entry & $\begin{array}{l}V_{\mathrm{SDS}}{ }^{a} \\
/ \mathrm{mL}\end{array}$ & $\begin{array}{c}V_{\mathrm{THP}}{ }^{b} \\
/ \mu \mathrm{L}\end{array}$ & $\begin{array}{l}c_{\mathrm{THP}}{ }^{c} \\
/ \mu \mathrm{M}\end{array}$ & $\begin{array}{l}V_{\mathrm{PBS}}{ }^{d} \\
/ \mathrm{mL}\end{array}$ & $\begin{array}{l}V_{\mathrm{PBS}}^{\prime}{ }^{e} \\
/ \mathrm{mL}\end{array}$ & $\begin{array}{l}c^{\prime}{ }_{\mathrm{THP}}^{f} \\
/ \mu \mathrm{M}\end{array}$ & $\begin{array}{l}\mathrm{CMC}^{g} \\
/ \mathrm{mM}\end{array}$ & $\begin{array}{l}\mathrm{CMC}^{h} \\
/ \mathrm{mM}\end{array}$ \\
\hline 1 & 0.4 & 15 & 37.5 & 5.40 & 5.63 & 2.49 & 3.32 & \\
2 & 0.4 & 15 & 37.5 & 5.43 & 5.60 & 2.50 & 3.33 & \\
3 & 0.4 & 15 & 37.5 & 5.44 & 5.64 & 2.48 & 3.31 & \\
Mean & & & & $5.42 \pm 0.02$ & $5.62 \pm 0.02$ & 2.49 & $3.32 \pm 0.01$ & $6.35 \pm 0.01$ \\
\hline
\end{tabular}

${ }^{a}$ Volume of concentrated SDS solution $(50 \mathrm{mM}) .{ }^{b}$ Volume of THP-T1 stock solution (1 mM) in concentrated SDS solution. ${ }^{c}$ Concentration of THP-T1 in initial SDS titrated solution: $c_{\mathrm{THP}}=\left(V_{\mathrm{THP}} \times 1 \mathrm{mM}\right) / 0.4 \mathrm{~mL} .{ }^{d}$ Volume of PBS dropped in titrated solution near titration end point. ${ }^{e}$ Volume of PBS dropped in titrated solution at titration end point. ${ }^{f}$ Concentration of THP-T1 in SDS titration-end-point solution. ${ }^{g} \mathrm{CMC}(\mathrm{mM})=c_{\mathrm{SDS}} \times V_{\mathrm{SDS}} /\left(V_{\mathrm{SDS}}+V_{\mathrm{PBS}}^{\prime}\right)=50 \times 0.4 /$ $\left(0.4+V_{\mathrm{PBS}}^{\prime}\right) .{ }^{h}$ Titrated $\mathrm{CMC}$ mean value \pm standard deviation with the approximate $c_{\mathrm{THP}}$ values by water. 
Table S15. Titrated CMC values of CTAB (10 mM) in PBS.

\begin{tabular}{|c|c|c|c|c|c|c|c|c|}
\hline Entry & $\begin{array}{l}V_{\mathrm{CTAB}}^{a} \\
/ \mathrm{mL}\end{array}$ & $\begin{array}{l}V_{\mathrm{THP}}^{b} \\
/ \mu \mathrm{L}\end{array}$ & $\begin{array}{l}c_{\mathrm{THP}}{ }^{c} \\
/ \mu \mathrm{M}\end{array}$ & $\begin{array}{l}V_{\mathrm{PBS}}^{d} \\
/ \mathrm{mL}\end{array}$ & $\begin{array}{l}V_{\mathrm{PBS}}^{\prime e} \\
/ \mathrm{mL}\end{array}$ & $\begin{array}{l}c_{\mathrm{THP}}^{\prime} \\
/ \mu \mathrm{M}\end{array}$ & $\begin{array}{l}\mathrm{CMC}^{g} \\
/ \mathrm{mM}\end{array}$ & $\begin{array}{l}\mathrm{CMC}^{h} \\
/ \mathrm{mM}\end{array}$ \\
\hline 1 & 0.4 & 17 & 42.5 & 6.30 & 6.50 & 2.47 & 0.58 & \\
\hline 2 & 0.4 & 17 & 42.5 & 6.29 & 6.48 & 2.47 & 0.58 & \\
\hline 3 & 0.4 & 17 & 42.5 & 6.30 & 6.47 & 2.47 & 0.58 & \\
\hline Mean & & & & $6.30 \pm 0.01$ & $6.48 \pm 0.02$ & 2.47 & $0.58 \pm 0.00$ & $0.80 \pm 0.01$ \\
\hline
\end{tabular}

${ }^{a}$ Volume of concentrated CTAB solution $(10 \mathrm{mM}) .{ }^{b}$ Volume of THP-T1 stock solution $(1 \mathrm{mM})$ in concentrated CTAB solution. ${ }^{c}$ Concentration of THP-T1 in initial CTAB titrated solution: $c_{\mathrm{THP}}=\left(V_{\mathrm{THP}} \times 1 \mathrm{mM}\right) / 0.4 \mathrm{~mL} .{ }^{d}$ Volume of PBS dropped in titrated solution near titration end point. ${ }^{e}$ Volume of PBS dropped in titrated solution at titration end point. ${ }^{f}$ Concentration of THP-T1 in CTAB titration-end-point solution. ${ }^{g} \mathrm{CMC}(\mathrm{mM})=c_{\mathrm{CTAB}} \times V_{\mathrm{CTAB}} /\left(V_{\mathrm{CTAB}}+V_{\mathrm{PBS}}^{\prime}\right)=$ $10 \times 0.4 /\left(0.4+V_{\mathrm{PBS}}^{\prime}\right) .{ }^{h}$ Titrated CMC mean value \pm standard deviation with the approximate $c_{\mathrm{THP}}$ values by water.

Table S16. Titrated CMC values of BS-12 (50 mM) in PBS.

\begin{tabular}{|c|c|c|c|c|c|c|c|c|}
\hline Entry & $\begin{array}{l}V_{\mathrm{BS}-12^{a}} \\
/ \mathrm{mL}\end{array}$ & $\begin{array}{l}V_{\mathrm{THP}}^{b} \\
/ \mu \mathrm{L}\end{array}$ & $\begin{array}{l}c_{\mathrm{THP}}{ }^{c} \\
/ \mu \mathrm{M}\end{array}$ & $\begin{array}{l}V_{\mathrm{PBS}}^{d} \\
/ \mathrm{mL}\end{array}$ & $\begin{array}{l}V_{\mathrm{PBS}}^{\prime}{ }^{e} \\
/ \mathrm{mL}\end{array}$ & $\begin{array}{l}c_{\mathrm{THP}}^{\prime} \\
/ \mu \mathrm{M}\end{array}$ & $\begin{array}{l}\mathrm{CMC}^{g} \\
/ \mathrm{mM}\end{array}$ & $\begin{array}{l}\mathrm{CMC}^{h} \\
/ \mathrm{mM}\end{array}$ \\
\hline 1 & 0.2 & 4 & 20 & 3.92 & 4.06 & 0.94 & 2.35 & \\
\hline 2 & 0.2 & 4 & 20 & 3.95 & 4.07 & 0.94 & 2.34 & \\
\hline 3 & 0.2 & 4 & 20 & 3.90 & 4.04 & 0.94 & 2.36 & \\
\hline Mean & & & & $3.92 \pm 0.03$ & $4.06 \pm 0.02$ & 0.94 & $2.35 \pm 0.01$ & $2.39 \pm 0.01$ \\
\hline
\end{tabular}

${ }^{a}$ Volume of concentrated BS-12 solution (50 mM). ${ }^{b}$ Volume of THP-T1 stock solution (1 mM) in concentrated BS-12 solution. ${ }^{c}$ Concentration of THP-T1 in initial BS-12 titrated solution: $c_{\mathrm{THP}}=\left(V_{\mathrm{THP}} \times 1 \mathrm{mM}\right) / 0.2 \mathrm{~mL} .{ }^{d}$ Volume of PBS dropped in titrated solution near titration end point. ${ }^{e}$ Volume of PBS dropped in titrated solution at titration end point. ${ }^{f}$ Concentration of THP-T1 in BS-12 titration-end-point solution. ${ }^{g} \mathrm{CMC}(\mathrm{mM})=c_{\mathrm{BS}-12} \times V_{\mathrm{BS}-12} /\left(V_{\mathrm{BS}-12}+V_{\mathrm{PBS}}^{\prime}\right)=50 \times 0.2$ $/\left(0.2+V_{\mathrm{PBS}}^{\prime}\right) .{ }^{h}$ Titrated CMC mean value \pm standard deviation with the approximate $c_{\mathrm{THP}}$ values by water. 
Table S17. Titrated CMC values of Triton X-100 (10 mM) in PBS.

\begin{tabular}{|c|c|c|c|c|c|c|c|c|}
\hline Entry & $\begin{array}{l}V_{\text {Triton X-100 }}^{a} \\
/ \mathrm{mL}\end{array}$ & $\begin{array}{l}V_{\mathrm{THP}}^{b} \\
/ \mu \mathrm{L}\end{array}$ & $\begin{array}{l}c_{\mathrm{THP}}{ }^{c} \\
/ \mu \mathrm{M}\end{array}$ & $\begin{array}{l}V_{\mathrm{PBS}}^{d} \\
/ \mathrm{mL}\end{array}$ & $\begin{array}{l}V_{\mathrm{PBS}}^{\prime}{ }^{e} \\
/ \mathrm{mL}\end{array}$ & $\begin{array}{l}c_{\mathrm{THP}}^{\prime} \\
/ \mu \mathrm{M}\end{array}$ & $\begin{array}{l}\mathrm{CMC}^{g} \\
/ \mathrm{mM}\end{array}$ & $\begin{array}{l}\mathrm{CMC}^{h} \\
/ \mathrm{mM}\end{array}$ \\
\hline 1 & 0.1 & 7.5 & 75 & 3.00 & 3.21 & 2.25 & 0.30 & \\
\hline 2 & 0.1 & 7.5 & 75 & 3.01 & 3.17 & 2.33 & 0.31 & \\
\hline 3 & 0.1 & 7.5 & 75 & 2.98 & 3.20 & 2.25 & 0.30 & \\
\hline Mean & & & & $3.00 \pm 0.02$ & $3.19 \pm 0.02$ & 2.25 & $0.30 \pm 0.01$ & 0.28 \\
\hline
\end{tabular}

${ }^{a}$ Volume of concentrated Triton X-100 solution (10 mM). ${ }^{b}$ Volume of THP-T1 stock solution $(1 \mathrm{mM})$ in concentrated Triton X-100 solution. ${ }^{c}$ Concentration of THP-T1 in initial Triton X-100 titrated solution: $c_{\mathrm{THP}}=\left(V_{\mathrm{THP}} \times 1 \mathrm{mM}\right) / 0.1$ mL. ${ }^{d}$ Volume of PBS dropped in titrated solution near titration end point. ${ }^{e}$ Volume of PBS dropped in titrated solution at titration end point. ${ }^{f}$ Concentration of THP-T1 in Triton X-100titration-end-point solution. ${ }^{g} \mathrm{CMC}(\mathrm{mM})=c_{\text {Triton X-100 }}$ $\times V_{\text {Triton X-100 }} /\left(V_{\text {Triton X-100 }}+V_{\mathrm{PBS}}^{\prime}\right)=10 \times 0.1 /\left(0.1+V_{\mathrm{PBS}}^{\prime}\right) .{ }^{h}$ Titrated CMC mean value with the approximate $c_{\mathrm{THP}}$ values by water.

Table S18. Titrated CMC values of DDBAC (50 mM) in PBS.

\begin{tabular}{lllllllll}
\hline Entry & $\begin{array}{l}V_{\mathrm{DDBAC}^{a}}{ }^{a} \\
/ \mathrm{mL}\end{array}$ & $\begin{array}{l}V_{\mathrm{THP}}{ }^{b} \\
/ \mu \mathrm{L}\end{array}$ & $\begin{array}{c}c_{\mathrm{THP}}{ }^{c} \\
/ \mu \mathrm{M}\end{array}$ & $\begin{array}{l}V_{\mathrm{PBS}}{ }^{d} \\
/ \mathrm{mL}\end{array}$ & $\begin{array}{l}V_{\mathrm{PBS}}^{\prime}{ }^{e} \\
/ \mathrm{mL}\end{array}$ & $\begin{array}{c}c^{\prime}{ }_{\mathrm{THP}}^{f} \\
/ \mu \mathrm{M}\end{array}$ & $\begin{array}{l}\mathrm{CMC}^{g} \\
/ \mathrm{mM}\end{array}$ & $\begin{array}{c}\mathrm{CMC}^{h} \\
/ \mathrm{mM}\end{array}$ \\
\hline 1 & 0.6 & 15 & 25 & 5.13 & 5.25 & 2.57 & 5.13 & \\
2 & 0.6 & 15 & 25 & 5.13 & 5.27 & 2.56 & 5.11 & \\
3 & 0.6 & 15 & 25 & 5.10 & 5.24 & 2.57 & 5.14 & \\
Mean & & & & $5.12 \pm 0.02$ & $5.25 \pm 0.02$ & 2.57 & $5.13 \pm 0.01$ & $8.36 \pm 0.04$ \\
\hline
\end{tabular}

${ }^{a}$ Volume of concentrated DDBAC solution $(50 \mathrm{mM}) .{ }^{b}$ Volume of THP-T1 stock solution $(1 \mathrm{mM})$ in concentrated DDBAC solution. ${ }^{c}$ Concentration of THP-T1 in initial DDBAC titrated solution: $c_{\mathrm{THP}}=\left(V_{\mathrm{THP}} \times 1 \mathrm{mM}\right) / 0.6 \mathrm{~mL}$. ${ }^{d}$ Volume of PBS dropped in titrated solution near titration end point. ${ }^{e}$ Volume of PBS dropped in titrated solution at titration end point. ${ }^{f}$ Concentration of THP-T1 in DDBAC titration-end-point solution. ${ }^{g} \mathrm{CMC}(\mathrm{mM})=c_{\mathrm{DDBAC}} \times V_{\mathrm{DDBAC}} /$ $\left(V_{\mathrm{DDBAC}}+V_{\mathrm{PBS}}^{\prime}\right)=50 \times 0.6 /\left(0.6+V_{\mathrm{PBS}}^{\prime}\right) .{ }^{h}$ Titrated CMC mean value \pm standard deviation with the approximate $c_{\mathrm{THP}}$ values by water. 
Table S19. Titrated CMC values of DTAC (50 mM) in PBS.

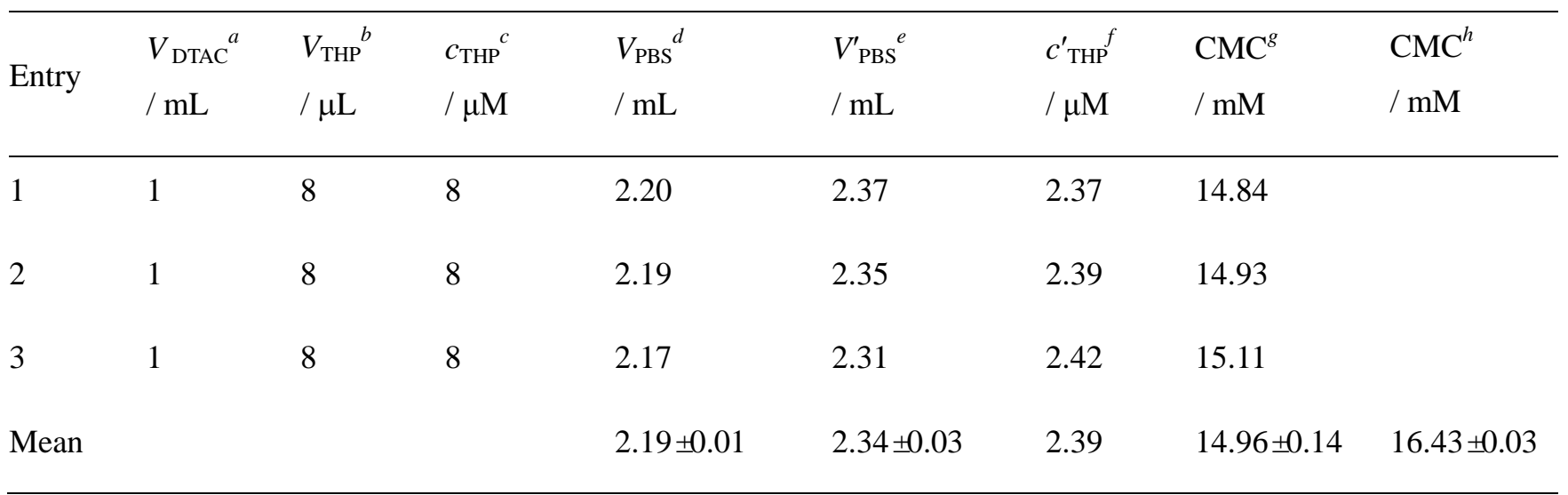

${ }^{a}$ Volume of concentrated DTAC solution $(50 \mathrm{mM}) .{ }^{b}$ Volume of THP-T1 stock solution $(1 \mathrm{mM})$ in concentrated DTAC solution. ${ }^{c}$ Concentration of THP-T1 in initial DTAC titrated solution: $c_{\mathrm{THP}}=\left(V_{\mathrm{THP}} \times 1 \mathrm{mM}\right) / 1 \mathrm{~mL} .{ }^{d}$ Volume of PBS dropped in titrated solution near titration end point. ${ }^{e}$ Volume of PBS dropped in titrated solution at titration end point. ${ }^{f}$ Concentration of THP-T1 in DTAC titration-end-point solution. ${ }^{g} \mathrm{CMC}(\mathrm{mM})=c_{\mathrm{DTAC}} \times V_{\mathrm{DTAC}}\left(V_{\mathrm{DTAC}}+V_{\mathrm{PBS}}^{\prime}\right)=50 \times 1$ $/\left(1+V_{\mathrm{PBS}}^{\prime}\right) .{ }^{h}$ Titrated $\mathrm{CMC}$ mean value \pm standard deviation with the approximate $c_{\mathrm{THP}}$ values by water. 
Determination of the CMC values of other surfactants using general $c^{\prime}{ }_{\text {THP }}$ at titration end point

Table S20. Titrated CMC values of SDSN with general $c_{\mathrm{s}}(50 \mathrm{mM})$ and $c_{\mathrm{THP}}^{\prime}(2.5 \mu \mathrm{M})\left(40{ }^{\circ} \mathrm{C}\right)$.

\begin{tabular}{|c|c|c|c|c|c|c|c|}
\hline Entry & $\begin{array}{l}V_{\mathrm{SDSN}}^{a} \\
/ \mathrm{mL}^{a}\end{array}$ & $\begin{array}{l}V_{\mathrm{THP}}^{b} \\
/ \mu \mathrm{L}\end{array}$ & $\begin{array}{l}c_{\mathrm{THP}}{ }^{c} \\
/ \mu \mathrm{M}\end{array}$ & $\begin{array}{l}V_{\mathrm{H} 2 \mathrm{O}}^{d} \\
/ \mathrm{mL}\end{array}$ & $\begin{array}{l}V_{\mathrm{H} 2 \mathrm{O}}^{\prime} \\
/ \mathrm{mL}\end{array}$ & $\begin{array}{l}c_{\mathrm{THP}}^{\prime} \\
/ \mu \mathrm{M}\end{array}$ & $\begin{array}{l}\mathrm{CMC}^{g} \\
/ \mathrm{mM}\end{array}$ \\
\hline 1 & 1 & 12.5 & 12.5 & 3.73 & 3.90 & 2.55 & 10.20 \\
\hline 2 & 1 & 12.5 & 12.5 & 3.70 & 3.89 & 2.56 & 10.22 \\
\hline 3 & 1 & 12.5 & 12.5 & 3.75 & 3.92 & 2.54 & 10.16 \\
\hline Mean & & & & $3.73 \pm 0.03$ & $3.90 \pm 0.03$ & 2.55 & $10.20 \pm 0.03$ \\
\hline
\end{tabular}

${ }^{a}$ Volume of concentrated SDSN solution $(50 \mathrm{mM}) .{ }^{b}$ Volume of THP-T1 stock solution $(1 \mathrm{mM})$ in concentrated SDSN solution. ${ }^{c}$ Concentration of THP-T1 in initial SDSN titrated solution: $c_{\mathrm{THP}}=\left(V_{\mathrm{THP}} \times 1 \mathrm{mM}\right) / 1 \mathrm{~mL}$. ${ }^{d}$ Volume of titrated water near titrating end point (near CMC). ${ }^{e}$ Volume of titrated water at titrating end point (at CMC). ${ }^{f} \mathrm{Concentration}$ of THP-T1 in SDSN titration-end-point solution. ${ }^{g} \mathrm{CMC}(\mathrm{mM})=c_{\mathrm{SDSN}} \times V_{\mathrm{SDSN}} /\left(V_{\mathrm{SDSN}}+V_{\mathrm{H} 2 \mathrm{O}}^{\prime}\right)=50 \times 1 /\left(1+V_{\mathrm{H} 2 \mathrm{O}}^{\prime}\right)$.

Table S21. Titrated CMC values of CTAC with general $c_{\mathrm{s}}(50 \mathrm{mM})$ and $c_{\text {THP }}^{\prime}(2.5 \mu \mathrm{M})$.

\begin{tabular}{|c|c|c|c|c|c|c|c|}
\hline Entry & $\begin{array}{l}V_{\text {CTAC }}^{a} \\
/ \mathrm{mL}^{a}\end{array}$ & $\begin{array}{l}V_{\mathrm{THP}}^{b} \\
/ \mu \mathrm{L}\end{array}$ & $\begin{array}{l}c_{\mathrm{THP}}{ }^{c} \\
/ \mu \mathrm{M}\end{array}$ & $\begin{array}{l}V_{\mathrm{H} 2 \mathrm{O}}^{d} \\
/ \mathrm{mL}\end{array}$ & $\begin{array}{l}V_{\mathrm{H} 2 \mathrm{O}}^{\prime}{ }^{e} \\
/ \mathrm{mL}\end{array}$ & $\begin{array}{l}c_{\mathrm{THP}}^{\prime} \\
/ \mu \mathrm{M}\end{array}$ & $\begin{array}{l}\mathrm{CMC}^{g} \\
/ \mathrm{mM}\end{array}$ \\
\hline 1 & 0.1 & 12.5 & 125 & 4.58 & 4.73 & 2.60 & 1.04 \\
\hline 2 & 0.1 & 12.5 & 125 & 4.62 & 4.77 & 2.58 & 1.03 \\
\hline 3 & 0.1 & 12.5 & 125 & 4.59 & 4.75 & 2.58 & 1.03 \\
\hline Mean & & & & $4.60 \pm 0.02$ & $4.75 \pm 0.02$ & 2.58 & $1.03 \pm 0.01$ \\
\hline
\end{tabular}

${ }^{a}$ Volume of concentrated CTAC solution $(50 \mathrm{mM}) .{ }^{b}$ Volume of THP-T1 stock solution $(1 \mathrm{mM})$ in concentrated CTAC solution. ${ }^{c}$ Concentration of THP-T1 in initial CTAC titrated solution: $c_{\mathrm{THP}}=\left(V_{\mathrm{THP}} \times 1 \mathrm{mM}\right) / 0.1 \mathrm{~mL} .{ }^{d}$ Volume of titrated water near titrating end point (near $\mathrm{CMC}$ ). ${ }^{e}$ Volume of titrated water at titrating end point (at $\mathrm{CMC}$ ). ${ }^{f}$ Concentration of THP-T1 in CTAC titration-end-point solution. ${ }^{g} \mathrm{CMC}(\mathrm{mM})=c_{\mathrm{CTAC}} \times V_{\mathrm{CTAC}} /\left(V_{\mathrm{CTAC}}+V_{\mathrm{H} 2 \mathrm{O}}^{\prime}\right)=$ $50 \times 0.1 /\left(0.1+V_{\mathrm{H} 2 \mathrm{O}}^{\prime}\right)$. 
Table S22. Titrated CMC values of BHS-12 with general $c_{\mathrm{s}}(50 \mathrm{mM})$ and $c_{\text {THP }}^{\prime}(1 \mu \mathrm{M})$.

\begin{tabular}{|c|c|c|c|c|c|c|c|}
\hline Entry & $V_{\text {CTAC }}{ }^{a}$ & $V_{\mathrm{THP}}^{b}$ & $c_{\mathrm{THP}}{ }^{c}$ & $V_{\mathrm{H} 2 \mathrm{O}}^{d}$ & $V_{\mathrm{H} 2 \mathrm{O}}^{\prime}{ }^{e}$ & $c_{\mathrm{THP}}^{\prime}$ & $\mathrm{CMC}^{g}$ \\
\hline & $/ \mathrm{mL}$ & $/ \mu \mathrm{L}$ & $/ \mu \mathrm{M}$ & $/ \mathrm{mL}$ & $/ \mathrm{mL}$ & $/ \mu \mathrm{M}$ & $/ \mathrm{mM}$ \\
\hline 1 & 0.1 & 4 & 40 & 3.90 & 4.05 & 0.96 & 1.20 \\
\hline 2 & 0.1 & 4 & 40 & 3.86 & 4.02 & 0.97 & 1.21 \\
\hline 3 & 0.1 & 4 & 40 & 3.85 & 4.00 & 0.98 & 1.22 \\
\hline Mean & & & & $3.87 \pm 0.03$ & $4.02 \pm 0.03$ & 0.97 & $1.21 \pm 0.01$ \\
\hline
\end{tabular}

${ }^{a}$ Volume of concentrated BHS-12 solution $(50 \mathrm{mM}) .{ }^{b}$ Volume of THP-T1 stock solution $(1 \mathrm{mM})$ in concentrated BHS12 solution. ${ }^{c}$ Concentration of THP-T1 in initial BHS-12 titrated solution: $c_{\mathrm{THP}}=\left(V_{\mathrm{THP}} \times 1 \mathrm{mM}\right) / 0.1 \mathrm{~mL} .{ }^{d} \mathrm{Volume}$ of titrated water near titrating end point (near $\mathrm{CMC}$ ). ${ }^{e}$ Volume of titrated water at titrating end point (at $\mathrm{CMC}$ ). ${ }^{f}$ Concentration of THP-T1 in BHS-12 titration-end-point solution. ${ }^{g} \mathrm{CMC}(\mathrm{mM})=c_{\mathrm{BHS}-12} \times V_{\mathrm{BHS}-12} /\left(V_{\mathrm{BHS}-12}+V_{\mathrm{H} 2 \mathrm{O}}^{\prime}\right)=$ $50 \times 0.1 /\left(0.1+V_{\mathrm{H} 2 \mathrm{O}}^{\prime}\right)$.

Table S23. Titrated CMC values of Triton X-114with general $c_{\mathrm{S}}(10 \mathrm{mM})$ and $c_{\mathrm{THP}}^{\prime}(2.5 \mu \mathrm{M})$.

\begin{tabular}{|c|c|c|c|c|c|c|c|}
\hline Entry & $\begin{array}{l}V_{\text {Triton X-114 }}{ }^{a} \\
/ \mathrm{mL}\end{array}$ & $\begin{array}{l}V_{\mathrm{THP}}^{b} \\
/ \mu \mathrm{L}\end{array}$ & $\begin{array}{l}c_{\mathrm{THP}}{ }^{c} \\
/ \mu \mathrm{M}\end{array}$ & $\begin{array}{l}V_{\mathrm{H} 2 \mathrm{O}}^{d} \\
/ \mathrm{mL}\end{array}$ & $\begin{array}{l}V_{\mathrm{H} 2 \mathrm{O}}^{e} \\
/ \mathrm{mL}\end{array}$ & $\begin{array}{l}c_{\mathrm{THP}}^{\prime} \\
/ \mu \mathrm{M}\end{array}$ & $\begin{array}{l}\mathrm{CMC}^{g} \\
/ \mathrm{mM}\end{array}$ \\
\hline 1 & 0.1 & 8.5 & 85 & 2.80 & 3.35 & 2.47 & 0.29 \\
\hline 2 & 0.1 & 8.5 & 85 & 2.71 & 3.30 & 2.47 & 0.29 \\
\hline 3 & 0.1 & 8.5 & 85 & 2.74 & 3.29 & 2.47 & 0.29 \\
\hline Mean & & & & $2.75 \pm 0.05$ & $3.31 \pm 0.03$ & 2.47 & $0.29 \pm 0.00$ \\
\hline
\end{tabular}

${ }^{a}$ Volume of concentrated Triton X-114 solution (10 mM). ${ }^{b}$ Volume of THP-T1 stock solution $(1 \mathrm{mM})$ in concentrated Triton X-114 solution. ${ }^{c}$ Concentration of THP-T1 in initial Triton X-114 titrated solution: $c_{\mathrm{THP}}=\left(V_{\mathrm{THP}} \times 1 \mathrm{mM}\right) / 0.1$ $\mathrm{mL} .{ }^{d}$ Volume of titrated water near titrating end point (near CMC). ${ }^{e}$ Volume of titrated water at titrating end point (at $\mathrm{CMC}) .{ }^{f}$ Concentration of THP-T1 in Triton X-114 titration-end-point solution. ${ }^{g} \mathrm{CMC}(\mathrm{mM})=c_{\text {Triton X-114 }} \times V_{\text {Triton X-114 }}$ $\left(V_{\text {Triton X-114 }}+V_{\mathrm{H} 2 \mathrm{O}}^{\prime}\right)=10 \times 0.1 /\left(0.1+V_{\mathrm{H} 2 \mathrm{O}}^{\prime}\right)$. 

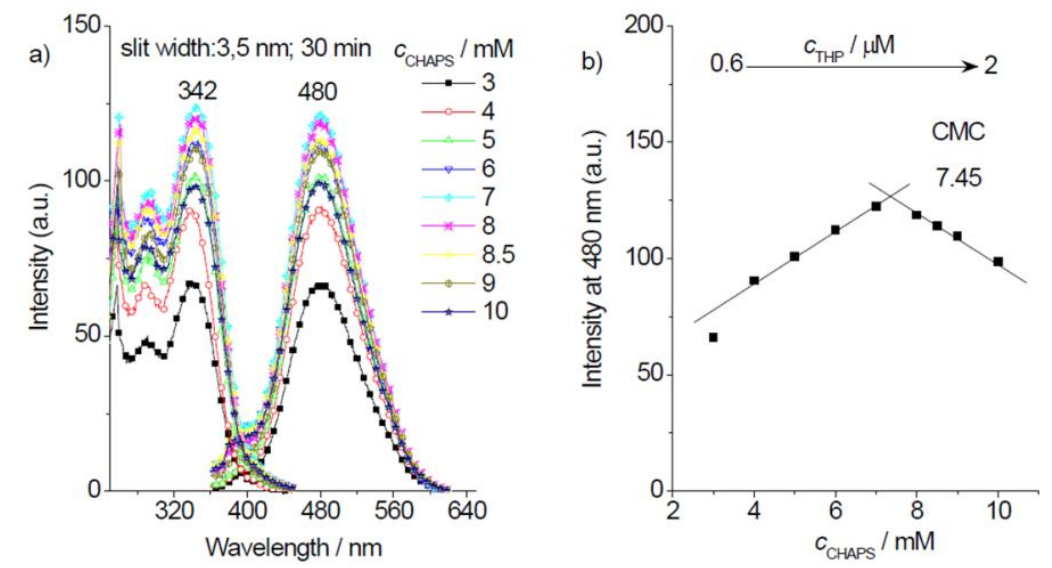

Figure S31. a) Excitation (left) and emission (right) spectra of THP-T1 in samples kept $30 \mathrm{~min}$. The concentration of CHAPS from 3 to $10 \mathrm{mM}$ and the concentration of THP-T1 from 0.6 to $2 \mu \mathrm{M}$. Emitted and excited at peaks marked in excitation and emission spectra, respectively. b) The relationship between the fluorescence intensity at emission peak of THP-T1 and the concentration of DDBAC in samples.

\section{Copie of ${ }^{1} \mathrm{H}$ spectra of THP-T1}

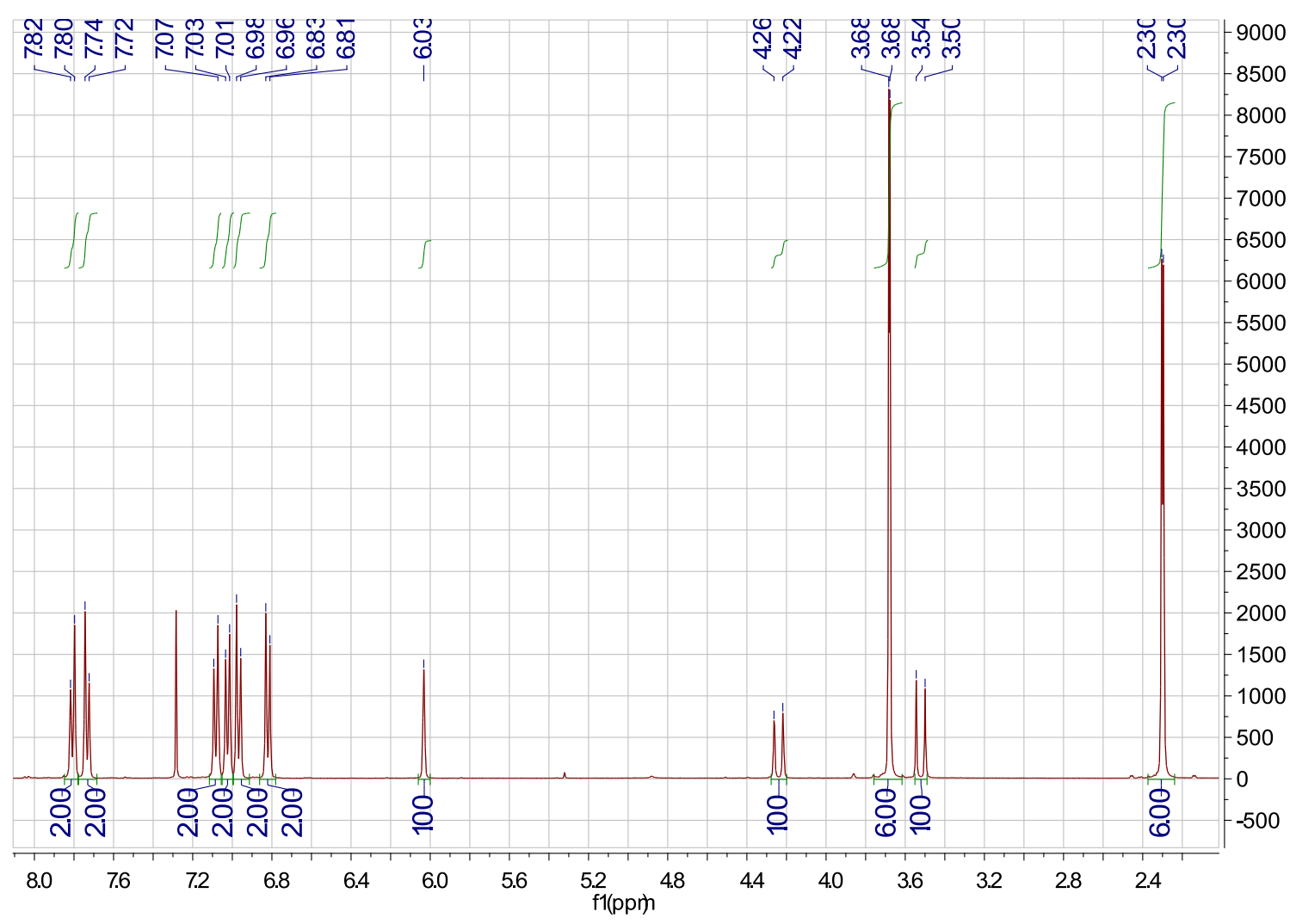

${ }^{1}$ H-NMR spectrum of THP-T1 ${ }^{[2]}$ 


\section{References}

[1] Q. Zhu, L. Huang, Z. Chen, S. Zheng, L. Lv, Z. Zhu, D. Cao, H. Jiang, S. Liu, Chem-Eur. J. 2013, 19, $1268-1280$.

[2] X. Cai, W. Yang, L. Huang, Q. Zhu, S. Liu, Sensor Actuat B-Chem 2015, 219, 251-260.

[3] Q. Zhu, L. Huang, J. Su, S. Liu, Chem. Commun. 2014, 50, 1107-1109.

[4] M. L. Corrin, W. D. Harkins, Journal of the American Chemical Society 1947, 69, 679-683.

[5] L. Cai, M. Gochin, K. Liu, Chemical communications 2011, 47, 5527-5529.

[6] P. Quagliotto, N. Barbero, C. Barolo, K. Costabello, L. Marchese, S. Coluccia, K. Kalyanasundaram, G. Viscardi, Dyes Pigments 2009, 82, 124-129.

[7] J. Xiao, F. Liu, V. M. Garamus, L. Almasy, U. A. Handge, R. Willumeit, B. Mu, A. Zou, Langmuir 2014, 30, $3363-3372$.

[8] Y. Chevalier, Y. Storet, S. Pourchet, L. P. Perchec, Langmuir : the ACS journal of surfaces and colloids 1991, 7, 848-853.

[9] M. Lavkush Bhaisare, S. Pandey, M. Shahnawaz Khan, A. Talib, H.-F. Wu, Talanta 2015, 132, 572-578.

[10] A. Chattopashyay, E. London, Analytical Biochemistry 1984, 139, 408-412.

[11] R. Sanan, R. K. Mahajan, Ind Eng Chem Res 2011, 50, 7319-7325.

[12] Gonza'lez-Pe'rez. A. , J. L. del Castillo., J. Czapkiewicz., J. R. Rodri'guez, J. Phys. Chem. B 2001, 105, $1720-1724$.

[13] A. Jusufi, A. Hynninen, P.,, M. e. a. Haataja, J. Phys. Chem. B 2009, 113, 6314-6320.

[14] J. Chlebicki, J. Wegrzynska, K. A. Wilk, J. Colloid Interface Sci. 2008, 323, 372-378. 